\title{
UNDERGRADUATE MUSIC STUDENTS' PERCEPTIONS OF LESSON AND REHEARSAL PLANNING
}

A Dissertation
presented to
the Faculty of the Graduate School
at the University of Missouri-Columbia
In Partial Fulfillment
of the Requirements for the Degree
Doctor of Philosophy
AARON T. WACKER
Dr. Brian Silvey, Dissertation Advisor

May, 2017 
The undersigned, appointed by the dean of the Graduate School, have examined the dissertation titled

UNDERGRADUATE MUSIC STUDENTS’ PERCEPTIONS OF LESSON AND

\section{REHEARSAL PLANNING}

presented by Aaron T. Wacker, a candidate for the degree of doctor of philosophy, and hereby certify that, in their opinion, it is worthy of acceptance.

Dr. Brian Silvey

Dr. Wendy Sims

Dr. Kathy Unrath

Dr. Erin Cooper 


\section{ACKNOWLEDGEMENTS}

I would like to express my deepest appreciation to my committee chair Dr. Brian Silvey, who has dedicated many hours to this project. He has provided countless time in helping me prepare for a career in academia and music education research. I could not have asked for a better mentor and advisor throughout my years at the University of Missouri.

Thanks to Dr. Wendy Sims, whose wisdom and support has helped me navigate through my doctoral degree. She has been a constant support for all aspects of my time at the University of Missouri.

I would also like to thank my committee members, Dr. Kathy Unrath and Dr. Erin Cooper, for their insightful comments and encouragement throughout this process.

My sincere thanks also go to Dr. Angelo Manzo, Dr. Marcia Spence, Dr. Iskander Akhmadullin, and Professor Edward Dolbashian, who have played an instrumental role in all musical aspects of my doctoral degree.

Finally, I would like to thank my family, friends, and my doctoral colleagues, especially Laura Kitchel, for their years of encouragement - graduate school is a long and arduous journey and I could not have accomplished this degree without their emotional and loving support. 


\section{Table of Contents}

ACKNOWLEDGEMENTS ......................................................................................... ii

LIST OF TABLES …................................................................................................................. vii

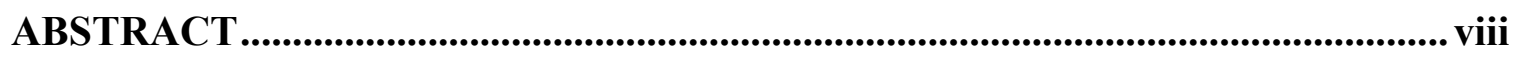

Chapter One ................................................................................................................................... 1

Introduction ........................................................................................................................................ 1

Background of the Problem................................................................................................... 2

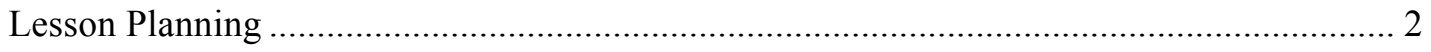

Pedagogical Content Knowledge ...................................................................................... 3

Content Knowledge and Pedagogical Content Knowledge ……………………………..... 3

Problem and Purpose ............................................................................................................................ 4

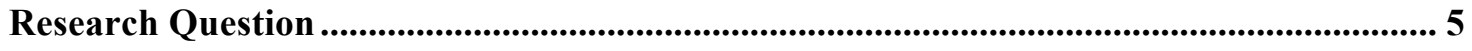

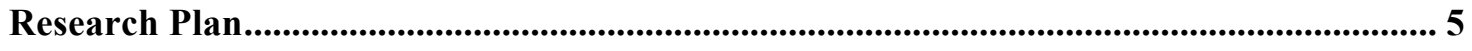

Importance of the Study ....................................................................................................... 7

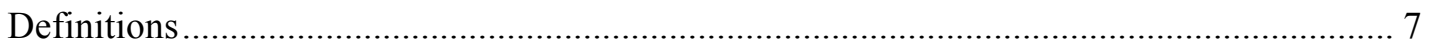

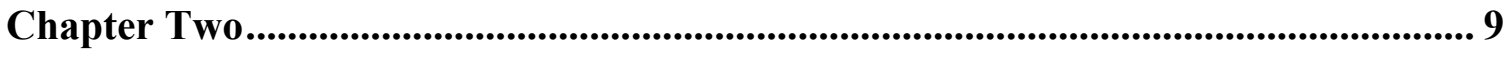

Knowledge of Teaching .......................................................................................................... 10

Content Knowledge ............................................................................................. 12

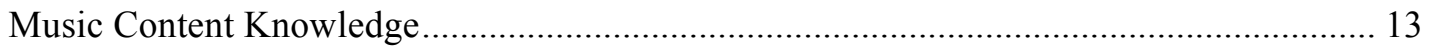

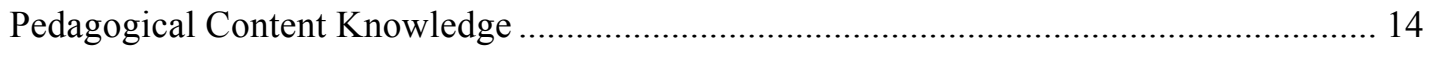

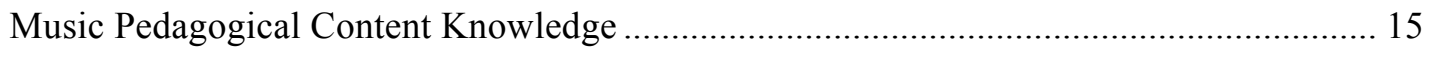

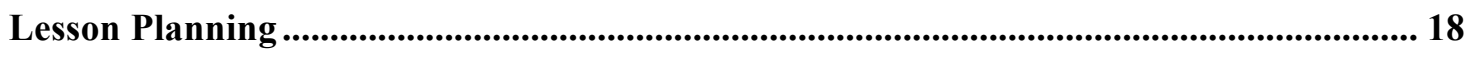

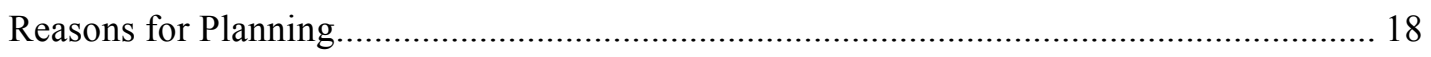

Types of Lesson Plans.......................................................................................... 19 
Experienced and Inexperienced Teachers’ Lesson Planning .......................................... 21

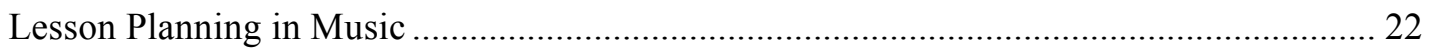

Applications and Implications.................................................................................................... 23

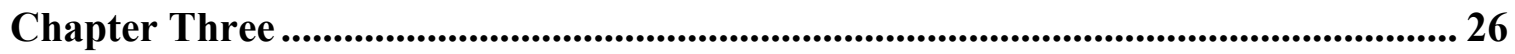

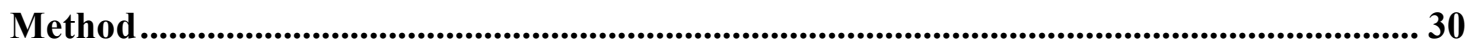

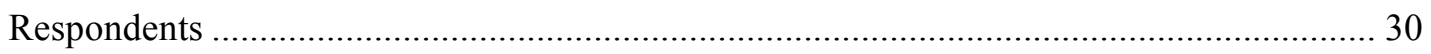

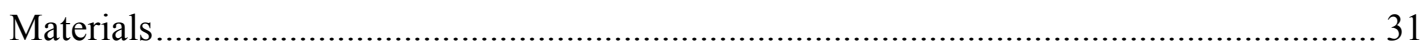

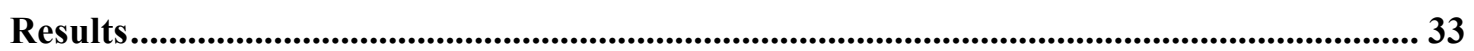

Section One: Lesson Planning in Undergraduate Coursework .......................................... 33

Section Two: Use of Lesson Planning in Undergraduate Coursework ................................ 33

Section Three: Beliefs About the Importance of Lesson Planning ....................................... 37

Section Four: How Prepared Do You Feel Using Lesson Plans? ....................................... 38

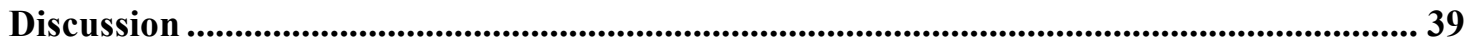

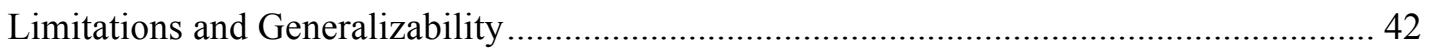

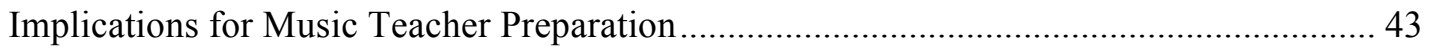

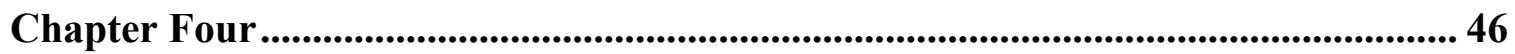

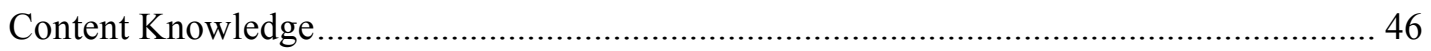

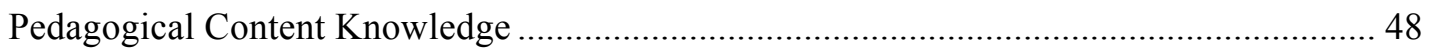

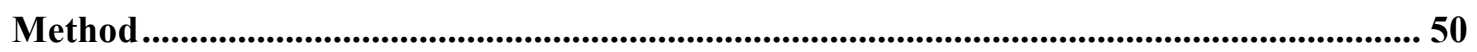

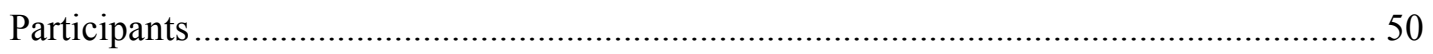

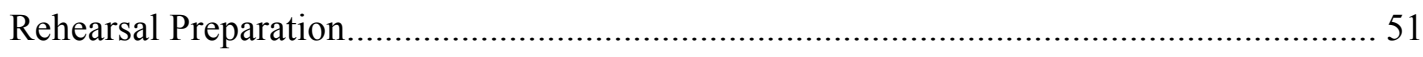

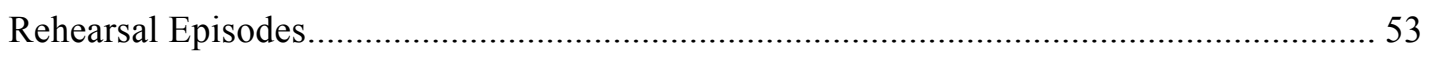

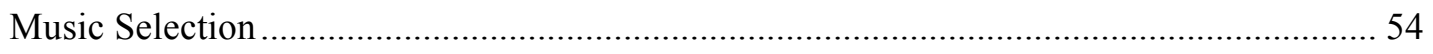

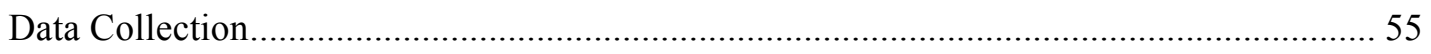

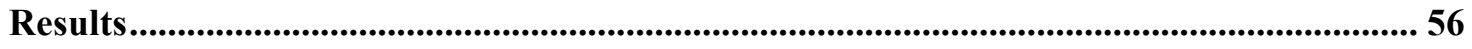




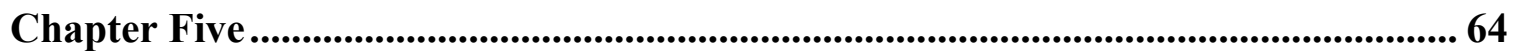

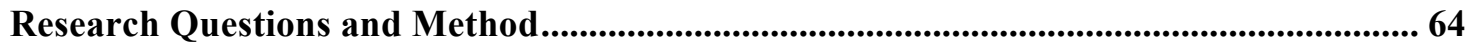

Major Findings ............................................................................................................................. 65

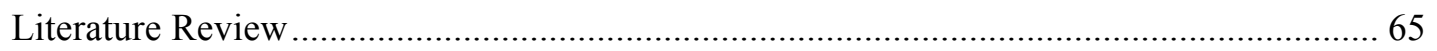

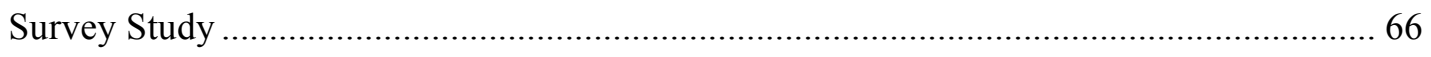

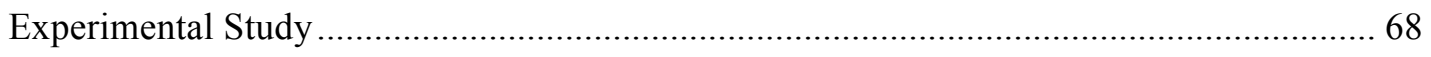

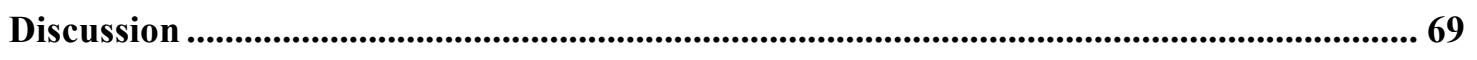

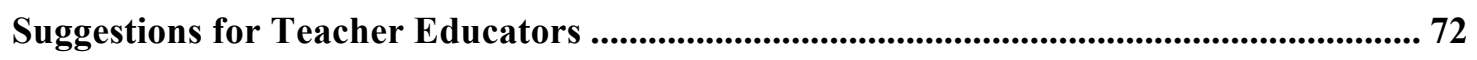

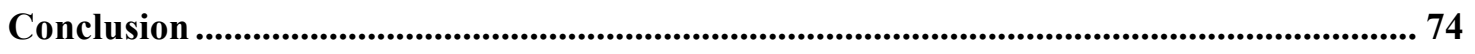

References........................................................................................................................................ 76

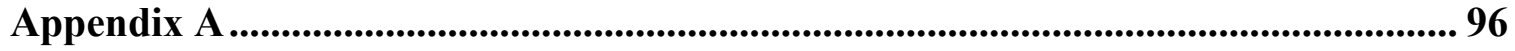

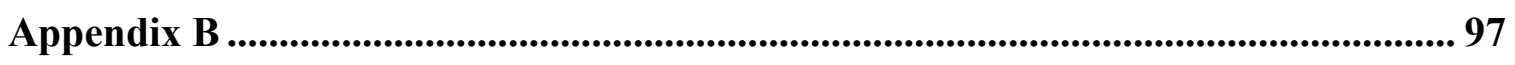

Appendix C ................................................................................................................... 98

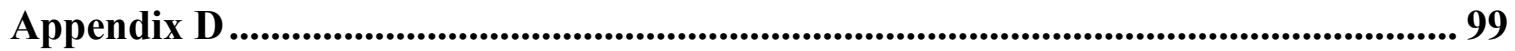

Appendix E .................................................................................................................... 108

Appendix F ............................................................................................................ 109

Appendix G........................................................................................................................... 110

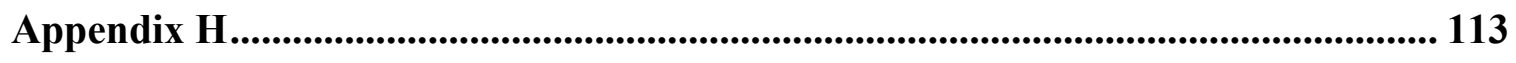

Appendix I ............................................................................................................. 116

Appendix J......................................................................................................................... 117 
Appendix K....................................................................................................................................... 120

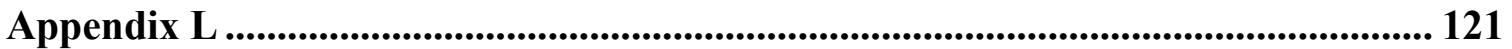

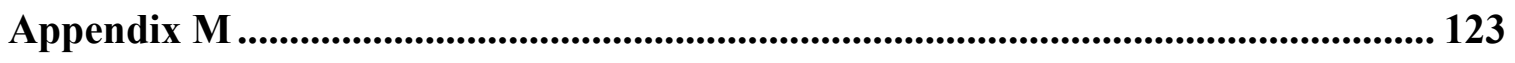

Appendix N

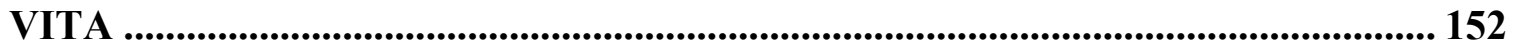




\section{LIST OF TABLES}

Table 1 Responses to Which Courses in General Education, Music Education, and Music Methods Respondents Were Taught How to Construct Lesson Plans ...................... 34

Table 2 Responses to Which Courses in General Education, Music Education, and Music Methods Respondents Used Lesson Plans ........................................................... 36

Table 3 Means (and Standard Deviations) of Numerical Rehearsal Evaluations ........... 57

Table 4 Categorization of Conductors' Comments for CK and PCK Conditions ............ 58 


\title{
UNDERGRADUATE MUSIC STUDENTS' PERCEPTION AND ABILITY TO \\ PREPARE FOR A LESSON
}

Aaron T. Wacker

Dr. Brian Silvey, Dissertation Supervisor

\begin{abstract}
This dissertation comprises three projects that were designed to investigate specific lesson planning practices and how music teacher educators might improve students' instructional preparation. The first investigation is a review of literature pertaining to lesson planning and teacher knowledge — specifically Pedagogical Content Knowledge (PCK) and Content Knowledge (CK). The second investigation is a survey study about preservice teachers' perceptions of where in their coursework lesson plans were taught and used, beliefs regarding the importance of planning, and how prepared they felt to use lesson planning in their classes. Respondents $(\mathrm{N}=107)$ indicated that they were taught lesson planning more often in music education courses than in general education or music method courses. The third investigation is an experimental study. Novice conductors $(\mathrm{N}=$ 20) were randomly divided into two equal groups ( $\mathrm{n}=10$ per group). I sought to determine whether novices who focused their rehearsal preparation using typical score study methodologies (CK) differed from those whose preparation involved both score study and specific rehearsal strategies (CK and PCK). I found no significant differences between the control and experimental groups' score study knowledge or rehearsal effectiveness ratings. Results from these three projects indicated that preservice teachers (a) found lesson planning to be important, (b) felt prepared to use lesson plans as part of
\end{abstract}


the instructional process, and (c) could use either preparation method to prepare for rehearsals. 


\section{Chapter One}

\section{Introduction}

Researchers have been investigating strategies to help novice teachers effectively prepare for their lessons over many years. In 1987, Lee Shulman suggested a set of knowledges that teachers should possess to be successful educators. Of these types of knowledge, content knowledge (CK) and pedagogical content knowledge (PCK) became the most dominant in educational research. Since that time, scholars in multiple fields have investigated the use of CK and PCK in their respective content areas (Ball, 1990; Ball, Sleep, Boerst, \& Bass, 2009; Forrester, 2015; Millican, 2013, 2016b; Magnusson, Krajcik, \& Borko, 1999; Rice, 2015). Many of the research findings from the aforementioned studies indicated that it may not be enough to have a strong understanding of content alone. A teacher may also need to possess a strong understanding of how to teach that specific content in order to be effective. Therefore, researchers have started to investigate what components of lesson preparation might help preservice teachers be more successful. Music education researchers have sought to understand how lesson planning (Brittin, 2005; Lane \& Talbert, 2015; Schmidt, 2005) and music score study (Lane, 2006; Silvey \& Montemayor, 2014; Silvey, Montemayor, \& Baumgartner, 2017) influenced music teacher preparation. My dissertation is designed to contribute to our understanding of best teaching practices for teacher educators who help prepare novice music teachers. 


\section{Background of the Problem}

\section{Lesson Planning}

Lesson planning has been defined as a "systematic development of instructional requirements, arrangement, conditions, and materials and activities, as well as testing and evaluation of teaching and learning” (Panasuk \& Todd, 2005, p. 215). However, the manner in which lesson plans are defined and constructed can often be less clear (Hill, Yinger, \& Robins, 1983; Jorgensen, 2002). Preservice music teachers often write more narrative or descriptive plans; nevertheless, they seem to find these types of planning to be unnecessary (Brittin, 2005; Schmidt, 2005).

There are often differences between how preservice and experienced teachers use lesson plans. Researchers have found that preservice teachers' understanding of how to write lesson plans is still in the formative stages of development because their plans tend to be simplistic and teacher-centered (Butler, 2001; Leinhardt, 1989). Similarly, there is evidence that novices were less efficient and effective when attempting to fix issues in their lessons that were not specifically found in their scripted plans (Borko, Livingston, \& Shavelson, 1990; Brittin, 2005; Schmidt, 2005). Contrary to novices' written lesson plans, expert teachers were more specific and used less words when writing out lesson plans, such as planning to work on specific errors rather than running the entire exercise (Brittin, 2005; Goolsby, 1999). There is also evidence that some expert teachers did not use a written plan when preparing for class (Borko, Livingston, \& Shavelson, 1990; Clark \& Peterson, 1984; Shorner-Johnson \& Moret, 2015; Stigle \& Hiebert, 1999). Despite some preservice teachers' desire to not use lesson plans (Schmidt, 2005), quality lesson 
planning has been shown to be related to teacher instructional quality (Dorovolomo, Phan, \& Maebuta, 2010; Lane, 2010).

\section{Pedagogical Content Knowledge}

The concept of teaching knowledge was introduced by Shulman (1986) in response to what he called a "missing paradigm" (p. 7) in teaching and teacher education. He labeled the unique connection between pedagogical knowledge and content as PCK. Since the introduction of PCK, scholars in different educational fields have agreed with Shulman's initial claim that PCK includes knowledge about what teachers need to know and how this type of knowledge applies to the practice of teaching (Ball, Hill, \& Bass, 2005; Ball, Thames, \& Phelps, 2008; Lee, Brown, Luft, \& Roehrig, 2007; Silverman \& Thompson, 2008). These investigations have helped researchers understand how PCK can be used to improve teaching in the classroom.

\section{Content Knowledge and Pedagogical Content Knowledge}

Once Shulman's concepts of teaching knowledge became a popular topic of investigation, many authors focused specifically on the importance of $\mathrm{CK}$, which can be defined as "items related to the factual knowledge of a specific discipline" (Millican, 2008, p. 68). There is evidence that possession of strong CK is an important criterion for demonstrating teacher quality (Kaplan \& Owings, 2002; Okpala \& Ellis, 2005). PCK, however, is rooted in the idea that teaching requires more than delivering content to students. Shulman (1987) defined it as "the category most likely to distinguish the understanding of the content specialist from that of the pedagogue" (p. 8). Within music, Ballantyne and Packer (2004) defined PCK as "knowledge of music teaching techniques, engaging students with music in a meaningful way, implementing the music curriculum 
effectively, assessing students' abilities in the various aspects of music, [and] explaining and demonstrating musical concepts" (p. 302). In other words, PCK is the idea of how to teach, whereas CK is what to teach.

Studies involving preservice music teachers' conducting skills and score knowledge have indicated that musical CK is important for preservice teachers' rehearsal preparation (Lane, 2006; Montemayor \& Moss, 2009). However, scholars have only recently started investigating what defines PCK in music education contexts (Emerich, 2015; Forrester, 2015; Millican, 2008, 2013, 2016a). For example, researchers have explored how band directors describe and use CK and PCK (Emerich, 2015; Forrester, 2015; Millican, 2013, 2016b), but few investigators have explored novice teachers' understanding and use of CK and PCK.

\section{Problem and Purpose}

Preparing to teach music courses requires time, effort, and knowledge to be successful. If preparing for a lesson is valuable, researchers and teacher educators must continue to find ways to help preservice teachers gain the necessary skills for learning how to do this. Scholars have studied the importance of using lesson plans and PCK in classrooms (Ballantyne \& Packer, 2004; Lane \& Talbert, 2015; Millican, 2016a; ShornerJohnson \& Moret, 2015). However, few investigators have studied preservice music teachers' perceptions of lesson planning. Despite extensive evidence of lesson planning and PCK being used in music education, no investigators have sought to understand how PCK could be used to improve lesson planning. Given the recent advances in our understanding of how CK and PCK function in undergraduate students' classwork, the 
purpose of this dissertation was to apply these theories to lesson preparation with preservice music teachers.

\section{Research Question}

This primary research question was used to guide this investigation: What are preservice teachers' perceptions of lesson planning, and can specific types of teacher knowledge (CK and PCK) improve their ability to plan and lead a rehearsal? I hoped to combine the new research in PCK with preservice teachers' perceptions of lesson planning in their college curriculum in order to better understand how we might improve their preparation.

\section{Research Plan}

To answer the research questions, I reviewed the existing bodies of literature related to CK, PCK, and lesson planning. By synthesizing this research, I identified the need for studies on students' perceptions of lesson planning and the use of CK and PCK in the planning process. Then, in two separate studies, I explored how this new understanding could be applied to preservice teacher education. Thus, this dissertation comprised three investigations designed to study how lesson preparation can be enhanced in undergraduate preservice teachers' degree programs.

The first investigation is a review of literature pertaining to lesson preparation and teacher knowledge. Current research on lesson planning, CK, and PCK in music focuses on how inservice and preservice teachers understand and use this knowledge in their classroom. Given the recent exploration of PCK and lesson planning in differing educational contexts, it seemed reasonable to investigate whether these types of knowledge and concepts may be combined to better equip preservice teachers when 
planning for their courses. This review of literature was designed to identify applications for preservice music teachers and teacher educators, as well as to suggest new areas of exploration related to this line of research.

The second investigation is a survey that was designed to determine preservice teachers' perceptions of lesson planning during their undergraduate curriculum. Although lesson planning in music has been investigated in the past (Brittin, 2005; Schmidt, 2005; Shorner-Johnson \& Moret, 2015), little is known about preservice music teachers' perceptions of planning in the undergraduate curriculum. A survey of current music education majors seems beneficial so that teacher educators can understand preservice music teachers' perceptions and beliefs about the importance of lesson planning, and how prepared they feel to use lesson plans in the future. This survey will be beneficial for teacher educators in understanding the beliefs of preservice music teachers and could hopefully lead to improved lesson planning instruction.

The third investigation is an experimental study involving novice instrumental conductors' rehearsal preparation. This study was needed to continue exploring the best practices for novice conductors to use when planning to lead a rehearsal. In addition to evaluations of the conductors' score knowledge and rehearsal effectiveness, a short questionnaire, similar to that used by Montemayor and Moss (2009), was given to the conductors to investigate their own perceptions of the rehearsal. Through this study, I sought to determine whether novices who focused their rehearsal preparation using typical score study methodologies (CK) differed from those whose preparation included specific rehearsal strategies (PCK). 
The final chapter of this dissertation provides a summary, a synthesis of findings, and implications for teaching and future research. Results will be connected in new ways to contribute to the understanding of the development of preservice music teachers' lesson preparation and to provide suggestions for teacher educators.

\section{Importance of the Study}

These investigations will contribute to the body of knowledge about how preservice teachers develop and prepare lessons. Specifically, they will build on our understanding of how different types of teaching knowledge can be applied to lesson preparation. I will also give suggestions about how PCK and CK can be used to improve lesson preparation effectiveness. Ideally, music teacher educators will use the results of these studies to more effectively prepare preservice music teachers.

\section{Definitions}

The following definitions were used in this study:

1. Content Knowledge (CK): Concepts related to factual knowledge of a discipline. In music education, this would include skills such as knowledge of performance on primary and secondary instruments, music theory, music history, instrument fingerings, and conducting mechanics.

2. Pedagogical Content Knowledge (PCK): "The blending of content and pedagogy into an understanding of how particular topics, problems, or issues are organized, represented, and adapted to the diverse interests and abilities of learners, and presented for instruction. PCK is the category most likely to distinguish the understanding of the content specialist from that of the pedagogue" (Shulman, 1987, p. 8). In music education, it has been described as "Knowledge of music teaching 
techniques, engaging students with music in a meaningful way, implementing the music curriculum effectively, assessing students' abilities in the various aspects of music, explaining and demonstrating musical concepts” (Ballantyne \& Packer, 204, p. 302).

3. Preservice Teacher: A student enrolled in a teacher education program at a college or university.

4. Teacher Educator: A person who instructs undergraduate education majors.

5. Lesson Planning: A "systematic development of instructional requirements, arrangement, conditions, and materials and activities, as well as testing and evaluation of teaching and learning” (Panasuk \& Todd, 2005, p. 215).

6. Rehearsal Planning: A systematic development of instructional requirements, materials and activities, and score study to lead an effective music rehearsal. For this dissertation, lesson and rehearsal planning will be used interchangeably. 


\section{Chapter Two}

\section{Lesson Preparation and Teacher Knowledge in Music Education: A Review of Literature}

There is disagreement regarding the best ways to teach preservice music teachers how to adequately prepare to teach their classes. Most conducting and rehearsal technique courses focus on score study, rehearsal strategies, and lesson planning, yet professional opinions differ regarding what specific skills should be learned by preservice music teachers in these settings (Ellis, 1994; Lane, 2006; Lane \& Talbert, 2015; Millican, 2013, 2016; Romines, 2003). Novice music teachers tend to have extensive experience as members of performing ensembles, but preparing to rehearse an ensemble may require pedagogical skills that are not learned by observing conductors during rehearsals. In the general educational literature on teacher preparation, there is evidence that knowledge of one's content may not be enough to adequately teach the subject (Shulman, 1986, 1987).

Although rehearsal preparation has been investigated extensively (Conway, 2002;

Lane, 2010; Lane \& Talbert, 2015; Millican, 2013; Montemayor, Silvey, Adams, \& Witt, 2016; Silvey \& Montemayor, 2014), there are often too many variables to study at one time; therefore, researchers have investigated individual techniques such as how lesson planning (Brittin, 2005; Lane \& Talbert, 2015; Schmidt, 2005), music score study (Lane, 2006, Silvey \& Montemayor, 2014; Silvey, Montemayor, \& Baumgartner, 2017), conducting skills (Forrester, 2015; Manfredo, 2008; Silvey, 2011a), and pedagogical content knowledge (Ballantyne \& Packer, 2004; Haston \& Leon-Guerrero, 2008; Millican, 2009, 2016a) influenced preservice music teachers' preparation. Given the exploration of lesson planning in general education settings, and music education 
specifically, a more well-rounded exploration of these topics is important to understand preservice music teacher preparation. Therefore, I will describe important issues in preservice teachers' development, including content knowledge and pedagogical content knowledge, and lesson planning, and explain possible applications to help better prepare instrumental music teachers.

\section{Knowledge of Teaching}

In the early-twentieth century, educational philosopher John Dewey noted the fundamental tensions that existed between theory and practice, specifically in the preparation of teachers (Dewey, 1904). Dewey argued that scholastic knowledge could sometimes become an external attachment to teaching, which needed to be acquired independently from the knowledge of the subject matter. In the 1980s, educational philosophers began to explore the connections between theory and implications of practice on student learning.

During this time, educational psychologist Lee Shulman began research about teacher knowledge and proposed a framework of how effective educators combine various skills and components of teaching. The concept of teacher knowledge was introduced as an answer to what he called a "missing paradigm" in teaching and teacher education (Shulman, 1986, p. 7). He categorized seven different types of knowledge for teachers to use in the classroom, namely (1) content knowledge (hereafter referred to as CK); (2) general pedagogical knowledge; (3) curriculum knowledge; (4) pedagogical content knowledge (hereafter referred to as PCK); (5) knowledge of learners and their characteristics; (6) knowledge of educational contexts; and (7) knowledge of educational ends, purposes, and values (Shulman, 1987, p. 8). Of those seven factors, CK and PCK 
were of special interest to scholars. Several researchers have used these frameworks in multiple content areas such as math (Ball, 1993; Hill, Schilling, Ball, 2004; Ball, Thames, \& Phelps, 2008; Silverman \& Thompson, 2008), science (Gess-Newsome \& Lederman, 2001; Magnusson, Krajcik, \& Borko, 1999; Van Driel, Verloop, \& de Vos, 1998), and music (Ballantyne \& Packer, 2004; Forrester, 2015; Millican, 2008, 2013, 2016a) to further understand teaching practices.

Despite the positive reception concerning the application of PCK in educational communities, Shulman's conceptualization has been criticized by those who have claimed that, within integrative models, PCK does not exist as a separate phenomenon, but rather that teaching requires integrating knowledge across different domains, such as subject matter, pedagogy, and context (Gess-Newsome, 1999). This line of thinking contrasts with Shulman's $(1986,1987)$ conceptualization, where PCK is treated as a unique type of knowledge that teachers rely on independently. Other scholars have doubted whether PCK can be theoretically or empirically distinguished from CK (Baumert, et al 2010; Bednarz \& Proulx, 2009; Saderholm, Ronau, \& Brown, 2010). Similarly, investigators have criticized how narrow the conceptualizations have been described, arguing for a broader concept of curriculum knowledge (Grossman, 1990). Finally, scholars have argued that components of PCK are different for individual teachers (Ball, Thames, \& Phelps, 2008; Bromme, 1995; Tirosh, Tsamir, Levenson, \& Taback, 2011; Van Driel \& Berry, 2012), which allows for interpretation in research and practice.

In an attempt to answer some of these criticisms, several scholars have refined Shulman's conceptualization of PCK (Ball, Hill, \& Bass, 2005; Hill, Schilling, \& Ball, 
2004). Members of Shulman's original research team expanded the definition to include four components of PCK: (1) knowledge of students' understanding, (2) knowledge of curriculum, (3) knowledge of instructional strategies, and (4) knowledge of purposes for teaching (Grossman, 1990; Marks, 1990). Since this expansion, several scholars in teacher education have studied how CK and PCK influenced teaching within specific content areas.

Within music education, researchers have begun to investigate PCK in preservice music education majors' development as teachers. Several investigators have suggested that preservice teacher preparation programs need to emphasize PCK that is related to music teaching, such as instrument knowledge, proper breathing skills, and posture (Ballantyne \& Packer, 2004; Forrester, 2015; Gohlke, 1994; Haston \& Leon-Guerrero, 2008; Millican, 2008, 2009, 2013). More specifically, scholars have investigated how PCK affects delivery of instruction (Millican, 2012; Raiber \& Teachout, 2014), application of technology in the classroom (Bauer, 2013; Mroziak \& Bowman, 2016a), jazz education (Venesile, 2011), and applied music teaching (Emerich, 2015; Villarreal, 2010).

\section{Content Knowledge}

CK is defined as a factual knowledge of a specific subject (Millican, 2008; Shulman, 1987) and has been further defined as concepts related to particular disciplines (Millican, 2008). Knowledge of content can include knowing formulas in mathematics,

phenomes in English, scientific methods, or music theory. Additionally, there is evidence that possession of strong $\mathrm{CK}$ is considered an important criterion for quality teaching (Kaplan \& Owings, 2002; Okpala \& Ellis, 2005). 
Researchers have indicated that $\mathrm{CK}$ is important and that teachers need to understand their content deeply in order to be successful (Hill, Schilling, \& Ball, 2004; Kennedy, 1998). Without appropriate levels of CK, teachers may struggle to help students learn necessary content (Ball \& McDiarmid, 1990; Snow, 1998). Hill, Ball, and Schilling (2008), who investigated mathematics education, broke down CK into three groups: common $\mathrm{CK}$, specialized $\mathrm{CK}$, and knowledge at the mathematical horizon. Common CK was described as the basic skills known by most adults, whereas specialized CK was described as knowledge of the content specifically needed for educators to teach (Ball, Thames, \& Phelps, 2008). Mathematical horizons indicate "awareness of how mathematical topics are related over the span of mathematics included in the curriculum" (Ball, Thames, \& Phelps, 2008, p. 403). In other words, teachers should not only know if the student is correct or incorrect, they should also know why the answer is wrong and how to fix the problem, which requires a deeper understanding of the content.

\section{Music Content Knowledge}

An application of $\mathrm{CK}$ in secondary music education includes the skills required for leading a rehearsal. These skills can include techniques such as beat pattern and gestural technique (Johnson \& Fredrickson, 1995; Mayne, 1992), conceptual knowledge of the musical score (Lane, 2006; Silvey, Fisher, \& Eubanks, 2015), error detection and correction (Green \& Gibson, 2004; Hunsberger \& Ernst, 1992; Labuta, 2010), instrumental fingerings and repair (Millican, 2008), and knowledge of secondary instruments (Millican, 2016b).

Researchers have sought to understand different components of CK in music education. Investigations regarding score study have helped uncover how experts and 
novices internalize music (Lane, 2006; Silvey, Springer, \& Eubanks, 2015; Silvey, Montemayor, \& Baumgartner, 2017) and how CK affects novices' rehearsals preparation skills (Silvey \& Montemayor, 2014). Overwhelmingly, these findings have indicated that, although score study may look different amongst conductors, score study is vital when preparing to lead a rehearsal.

Although music education research involving instrumental ensemble preparation has primarily addressed CK in music education research (Crowe, 1996; Lane, 2006; Montemayor \& Moss, 2009; Silvey, Montemayor, \& Baumgartner, 2017; Silvey \& Montemayor, 2014), possessing a high level of CK may not be the only skill necessary for music teachers to be successful (Millican, 2008). Villarreal (2010) found that applied music teachers believed they may benefit from more specific instruction on private lesson teaching during their education. Although CK is important to teaching, knowledge alone does not necessarily indicate that a teacher will be successful in conveying their knowledge to students (Loughran, Berry, \& Mulhall, 2012). Understanding how to teach the content may be just as important and meaningful as knowing the content.

\section{Pedagogical Content Knowledge}

PCK is rooted in the idea that teaching requires more than just delivering CK to students. Shulman (1987) indicated that PCK was "the category most likely to distinguish the understanding of the content specialist from that of the pedagogue" (p. 8).

Investigators have recently expanded components of Shulman's conceptualization of CK and PCK by discipline (Grossman, 1990; Kennedy, 2010; Kind, 2009; Magnusson, Krajcik, \& Borko, 1999; Millican, 2013). PCK includes three general areas of teacher knowledge: pedagogical knowledge, CK, and knowledge of context (Grossman, 1990). 
These have been mentioned as exerting a strong influence on teachers' knowledge bases in various research studies (Beijaard, Verloop, \& Vermunt, 2000; Kennedy, 2010; Lee, 2011). To help support the understanding of PCK, Kennedy (2010) addressed four contextual factors: (1) parameters of teachers' work, (2) students, (3) school incursions into classroom life, and (4) reform clutter, such as a shift from period to block scheduling or new school policies. These factors have helped researchers to further explain the function of PCK and its effect on individual content areas.

Since the initial investigation of teacher knowledge in the 1980s, researchersespecially in the fields of science and mathematics education — have explored specific components of PCK. Research findings have indicated that teachers should have knowledge of students' interests (Hill, Schilling, \& Ball, 2004; Ball, Thames, \& Phelps, 2008), common difficulties in understanding the content (Koehler \& Mishra, 2009; Tamir, 1988), specific strategies to teach concepts within a discipline (Magnusson, Krajcik, \& Borko, 1999; Rowan, Schilling, Ball, \& Miller, 2001), conveying instruction with appropriate sequencing (Hill, Ball, \& Schilling, 2008), typical errors made by students and frequent misunderstandings of the content (Hill, Ball, \& Schilling, 2008), and how to interpret student work and performances (Hill, Schilling, Ball, 2004; Hill, Ball, \& Schilling, 2008). These concepts have also been used in other content areas, including music education, and they have helped researchers to better understand the importance of PCK.

\section{Music Pedagogical Content Knowledge}

In music education, Ballantyne and Packer (2004) defined music PCK as "Knowledge of music teaching techniques, engaging students with music in a meaningful 
way, implementing the music curriculum effectively, assessing students' abilities in the various aspects of music, and explaining and demonstrating musical concepts" (p. 302). In other words, PCK is how to teach musical concepts, as compared with CK, the knowledge of the content itself. For example, if a teacher identifies that a clarinet player is not playing their tenuto markings long enough, this is CK. PCK is knowing how to teach the clarinet player where to put their tongue, how to use their air, and how long to play their note to get the proper tenuto articulation.

Music education researchers have investigated components of teaching related to PCK and how it is used during the implementation of music curricula (Millican, 2012; Raiber \& Teachout, 2014). Moreover, other rehearsal skills, including feedback (Goolsby, 1999; Sullivan, 1998), pacing (Price \& Byo, 2002; Worthy, 2005), and error detection and correction (DeCarbo, 1982; Forsythe \& Woods, 1983), have been explored to better understand preservice educators' preparation and its effects on teaching. Millican (2013) applied Shulman's PCK framework to explore the thought processes of expert beginning band teachers. Four expert band directors identified elements of PCK while viewing videotaped beginning band performances. The most common observed elements were (a) mental image/modeling, (b) understand the outcomes of the manipulation of variables to positively affect student performance, and (c) gather and interpret specific data to interpret student work, develop specific rules, procedures, and guidelines to help students master principles of performance. In a related study, Forrester (2015) interviewed four experienced school band conductors about their understanding of teaching knowledge in relation to conducting. She suggested that instrumental music 
teaching needs a specialized form of knowledge that integrates teaching and conducting, rather than teaching these concepts separately.

A recent aspect of PCK that has been explored by music scholars is technological pedagogy content knowledge (TPACK), which is described as involving the integration of "technology into the teaching and learning of music through the major ways that people engage with music — through creating (composing, improvising), performing (singing, playing instruments), and responding (listening to, analyzing, and evaluating)" (Mroziak \& Bowman, 2016b, p. 285). Reese, Bicheler, and Robinson (2015) investigated the use of $i P a d s$ in secondary general music classrooms. They found that there was tension among nine preservice music teachers and their beliefs about TPACK learning, and suggested that undergraduate students should observe experienced teachers using technology in the classroom. Bauer (2013) surveyed current music teachers on their curricular knowledge. These teachers cited their college experience as being an influential factor in the development of their CK and PCK; however, fewer respondents indicated that their undergraduate curriculum helped develop their TPACK. This area of PCK has just begun to be examined and additional research is needed to understand how preservice teachers learn to utilize technology in the music classroom.

PCK and TPACK appear to provide promising models for understanding the knowledge and skills that are needed to become an effective music teacher. Inservice teachers have agreed that PCK is important for teaching music courses (Millican, 2008, 2013) and that preservice teachers need help reinforcing PCK through experience, including observation and interaction with experienced teachers (Millican, 2008; Paul, 1998). These opportunities can be developed through field experience (Wolfgang, 1990), 
laboratory classes (Butler, 2001; Paul, 1998), and reflective teaching and planning activities (Barry, 1996). Once preservice teachers observe these skills being used successfully, they will better be able to use PCK and TPACK in their classroom. Additional studies investigating the most effective means of developing PCK and TPACK in preservice music teacher preparation are warranted.

\section{Lesson Planning}

In order to prepare for lessons, music teachers are expected to develop detailed plans that help students understand the subject matter. Although preparing for a class appears to be a different process for novice and experienced teachers (Brittin, 2005; Goolsby, 1999), it is commonly referred to as lesson planning. Examining how preservice music teachers prepare to lead a rehearsal or teach music classes can give insight into their thought processes and help prepare them to teach.

\section{Reasons for Planning}

Lesson planning can be considered a systematic development of instructional requirements, materials, and activities that are used to assess teaching and learning (Ferrell, 1992; Panasuk \& Todd, 2005; Skowron, 2001). Teachers report that they plan for many different reasons (Clark, 1988; Borko, Livingston, \& Shavelson, 1990). Researchers have also indicated that planning can be internally motivated (Borko, Livingston, \& Shavelson, 1990), can reduce anxiety and boost confidence (Borko, Livingston, \& Shavelson, 1990; Clark \& Yinger, 1979; John, 2006), and can help teachers to prepare for instruction and anticipate potential problems and how to circumvent them (Clark \& Yinger, 1979; Dorovolomo, Phan, \& Maebuta, 2010; John, 2006; McCutcheon, 1980). Nevertheless, the way lesson plans are defined and 
constructed in education courses can often be unclear (Hill, Yinger, \& Robins, 1983;

Jorgensen, 2002). Preservice music teachers frequently write plans that are long;

however, they tend to find planning as being unnecessary (Brittin, 2005; Schmidt, 2005).

However, some inservice teachers prefer to plan mentally without writing out their lesson plans and plan more sequential activities than preservice teachers (Clark \& Peterson, 1986; Goolsby, 1999).

\section{Types of Lesson Plans}

Lesson planning among teachers occurs in various forms; nonetheless, written lesson plans are the dominant approach used by teacher educators when preparing preservice teachers to plan for classroom instruction (Clark \& Peterson, 1986; Mutton, Hagger, \& Bum, 2011; Panasuk \& Todd, 2005; Shorner-Johnson \& Moret, 2015; Skowron, 2001). Since some expert teachers prepare without creating written lesson plans, some researchers have used "think-aloud" methodologies to capture how inservice teachers plan to teach their classes (McCutcheon, 1980; Sardo-Brown, 1988; Yinger, 1979, 1980; Zahorik, 1975). Through these investigations, researchers found that planning is often fragmented (Yinger, 1980), not always objective-driven (McCutcheon, 1980; Sardo-Brown, 1988; Zahorik, 1975), and that all planning may not be captured in written documents (Clark \& Peterson, 1986; McCutcheon, 1980; Sardo-Brown, 1988; Yinger, 1979).

Although educators disagree about how to use lessons plans, most inservice music teachers do agree that some type of planning is necessary (Bauer \& Berg, 2001; Fredrickson, Geringer, \& Pope, 2013; Teachout, 1997). Typically, practitioners suggest planning that is both objective-based and a means-end approach, such as a template that 
was created by Tyler (1950). This model describes planning as a four-step process:

specifying behavioral objectives, choosing and sequencing appropriate learning activities, organizing and sequencing the chosen activities, and selecting evaluation procedures. This has been a common form of lesson planning for over 60 years; however, it is not the only template that teachers use.

Even though Tyler's (1950) model has been popular with researchers and educators, another common lesson planning concept was designed in 1956, the Taxonomy of Education Objectives (Bloom, Engelhart, Furst, Hill, \& Krathwohl, 1956). This theory has six major categories in the cognitive domain: knowledge, comprehension, application, analysis, synthesis, and evaluation. These cognitive domains were later revised to remember, understand, apply, analyze, evaluate, and create (Krathwohl, 2002). The new Bloom's Taxonomy can be used to classify objectives, activities, and assessments, and provides a concise visual representation of lesson planning (Krathwohl, 2002) by helping teachers create multiple levels of plans based on students' needs.

Other commonly used lesson plans have been developed by researchers. Hunter (1982) suggested that lessons should contain eight elements to enhance learning: (1) anticipatory set, (2) objective and purpose, (3) input, (4) modeling, (5) checking for understanding, (6) guided practice, (7) independent practice, and (8) closure. She also advocated that these elements worked in the planning process no matter the teaching style, grade level, subject matter, or economic background of the student (Hunter, 1979). In this process, the teacher must have a clear understanding of the objectives they will use, and once the objectives are determined the teacher can follow the steps to complete the lesson plan. 
Yinger (1980) developed a three-stage repeated model to represent the instructional (weekly and daily) planning used often by teachers. During the problemfinding stage, the teacher considers content, goals, and their own knowledge and experience. During the second stage - the problem/solution and design stage - the teacher designs instructional activities by repeatedly cycling through a process of elaboration, investigation, and adaptation. In the final stage, implementation-finding-solutionevaluation, activities are rejected or modified and eventually incorporated into the teacher's instructional repertoire. Different, yet commonly used written approaches to lesson planning have also been explored.

Although previous investigators have focused primarily on written plans, veteran teachers often plan mentally through verbal discussion with colleagues, or mental dialogue with themselves (Brittin, 2005; Clark \& Peterson, 1986; McCutcheon, 1980; Morine-Dershimer, 1979). Research findings have indicated that written plans do not fully reflect teachers' mental dialogue, which can cover a wide range of planning concerns (McCutcheon, 1980; Morine-Dershimer, 1979; Hall \& Smith, 2006).

\section{Experienced and Inexperienced Teachers' Lesson Planning}

There are often differences between how preservice and experienced teachers use lesson plans. In general education settings, researchers have found that preservice teachers' understanding of effective teaching might be in the formative stages of development (Butler, 2001; Leinhardt, 1989). Likewise, there is evidence that novices are less efficient and effective when attempting to fix issues that were not specifically found in their scripted plans (Borko, Livingston, \& Shavelson, 1990; Brittin, 2005; Schmidt, 2005). Goolsby (1999) found that novice teachers spent more time in music rehearsals 
having the students play repertoire from the beginning to the end, whereas experts led more sequenced rehearsals. Other researchers have suggested that preservice teachers see the lesson planning process as a task that obstructs the teaching process (Harwood \& Wiggins, 2001; Schmidt, 2005). Contrary to novices' lesson plans—which used more words but were vague — expert teachers' plans were more specific and used less words (Brittin, 2005; Goolsby, 1999). Similarly, some researchers suggest that expert teachers should not use a written plan when preparing for class because teachers might plan spontaneously throughout the day without writing it down (Borko, Livingston, \& Shavelson, 1990; Clark \& Peterson, 1986; Shorner-Johnson \& Moret, 2015; Stigler \& Hiebert, 1999). Despite some preservice teachers' desire to not use lesson plans (Schmidt, 2005), quality lesson planning has been found to be related to teacher instructional quality (Dorovolomo, Phan, \& Maebuta, 2010; Lane, 2010). The pattern that emerges from the previously mentioned investigations shows that expert teachers' plans are more succinct than inexperienced preservice teachers' plans.

\section{Lesson Planning in Music}

There is a need for further research on lesson planning in music settings due to the variations in class types. For example, extant research findings have indicated that there may be differences between elementary and secondary music planning structures (Shorner-Johnson, 2015a; Shorner-Johnson, 2015b; Schmidt, 2005; Scott, 2011;

Standerfer, 2011). During interviews, music teacher educators claimed that lesson planning was problem/solution focused and suggested that a scripted sequential plan is not crucial to a successful lesson (Shorner-Johnson \& Moret, 2015). Less sequential planning is also explored in practitioner literature for both general and secondary classes 
(de Frece, 2010; Kearns, 2011; Scott, 2011). Because of these differences in approaches in elementary and secondary emphases, there is still a need to investigate lesson planning in music education courses further.

Researchers have also investigated how music preservice teachers plan for applied music lessons. Schmidt (2005) noticed a divide between conceptual understanding and practice in lesson planning. Her findings indicated that 10 preservice string teachers rarely engaged in written lesson planning and preferred to teach "on the fly" (p. 11), suggesting that more field experience may be beneficial toward understanding how lesson plans are implemented. It is still unclear to what degree learning about and incorporating written lesson plans may improve preservice students' teaching efficacy.

Novice teachers might have difficulties separating the way expert teachers plan from how they teach their classes because much of the planning might be completed outside of school. Preservice teachers often learn how to use lesson plans during field experiences (Clift \& Brady, 2005; Delorenzo, 1990; Millican, 2016a). However, planning during field experience can lead to disagreements between what students learn in college and how inservice teachers instruct their own students (Zeichner \& Tabachnick, 1981). Expert teachers generally write more concise lesson plans or plan mentally, whereas novice teachers write more extensively and plan with specific processes in mind (Brittin, 2005). Few preservice teachers have the opportunity to observe their instructors write lesson plans (Schmidt, 2005), which could lead to students' misunderstanding of the lesson planning process.

\section{Applications and Implications}

Preservice teachers are taught how to prepare for secondary rehearsals through a 
variety of score study and lesson planning techniques, but this does not necessarily account for all of their preparation. Research investigations about how to better prepare novice teachers to rehearse an ensemble have indicated that novices' teaching abilities are enhanced by both CK and PCK (Forrester, 2015; Millican, 2008, 2016b). In addition, preservice educators' use of lesson planning helps them better prepare for teaching (Gauthier \& McCrary, 1999). The development of these skills can help novice teachers be more successful in preparing to lead a musical ensemble. Although few researchers have investigated the use of CK and PCK in planning for lessons or rehearsals, these investigations have highlighted the important intersections among CK, PCK, and lesson planning.

Researchers might investigate how the development of PCK can be used in planning for rehearsals. Although expert teachers plan in diverse ways (e.g., written plans, discussion with colleagues, or mentally), it may be possible to include CK and PCK techniques into the planning process. Music teacher educators often include score study, rehearsal, and lesson planning techniques in their courses, which could help preservice teachers understand the connection between teacher knowledge, such as PCK, and lesson planning. For example, if a student has a poor tone quality, a teacher might be able to ascertain that the student is not using proper air support and plan to address this issue in future rehearsals. Another planning technique, however, might be to first have the student work on breathing exercises, followed by long tones, and then put the exercises into context with the part being played, using that instructional time to offer specific feedback to help maximize tone production. Novice teachers that plan for both CK and PCK might be able to instruct a more effective rehearsal. 
Although many aspects of teaching will improve with experience, it may be possible to instruct preservice teachers in certain planning methods to better prepare them to be successful sooner in their music careers. By using teacher knowledge that has been discussed in the research literature (see Ballantyne \& Packer, 2004; Millican, 2009; Shulman, 1986, 1987), novice teachers may be able to create more useful lesson plans that will lead to more successful teaching episodes. Given the amount of preparation that teachers give to their lessons, novice teachers may benefit from more deliberate $\mathrm{CK}$ and PCK instruction in their undergraduate music education preparation programs. Since preservice teachers may have difficulty teaching skills or concepts not found in their written plans (Schmidt, 2005), they might benefit from aspects of preparation skills (such as $\mathrm{CK}$ and PCK) during their teacher training program. 


\section{Chapter Three}

\section{An Examination of Music Education Majors' Perceptions of Lesson Planning}

Planning to teach a lesson is important for all teachers. Lesson planning can be summarized as a logical development of instructional requirements, materials, objectives, and activities that are used to assess teaching and learning (Ferrell, 1992; Panasuk \& Todd, 2005; Skowron, 2001). Nevertheless, the manner in which lesson plans are defined and constructed can often be unclear (Hill, Yinger, \& Robins, 1983; Jorgensen, 2002). Preservice teachers often write more scripted plans than experienced teachers; however, they seem to find planning to be unnecessary (Brittin, 2005; Schmidt, 2005). In contrast, experienced teachers prefer to plan mentally and plan more sequential activities than preservice teachers (Clark \& Peterson, 1984; Goolsby, 1999).

Although educators sometimes disagree about how to use lessons plans, most inservice teachers do agree that some type of planning is necessary (Bauer \& Berg, 2001; Fredrickson, Geringer, \& Pope, 2013; Teachout, 1997; Tsui, 2009). Other researchers have found that preservice teachers see the process as a chore that can obstruct the teaching process (Harwood \& Wiggins, 2001; Schmidt, 2005). Despite this evidence, many textbooks for preservice teachers include topics such as why a new teacher should write plans, components of an effective plan, templates for classroom use, and desired length of lesson plans (Abeles, Hoffer, \& Klotman, 1984; Colwell \& Hewitt, 2011; Kearns, 2011; Savage, 2014).

There are often differences between how preservice and experienced teachers use lesson plans. Veteran teachers often planned mentally or without traditional written plans, such as verbal discussion with colleagues (Clark \& Peterson, 1984). In general education 
settings, researchers have found that preservice teachers' understanding of how to write lesson plans is still in the formative stages of development because their plans seem to be unclear and teacher centered (Butler, 2001; Leinhardt, 1989). Likewise, there is evidence that novices are less efficient and effective when attempting to fix issues that were not specifically found in their scripted plans (Borko, Livingston, \& Shavelson, 1990; Brittin, 2005; Schmidt, 2005). Goolsby (1999) found that novice teachers spend more time in rehearsals playing repertoire from the beginning to the end, whereas experts had more sequenced rehearsals. Contrary to novices' lesson plans, expert teachers were more specific and used less words when writing out lesson plans (Brittin, 2005; Goolsby, 1999). Similarly, some researchers found that expert teachers do not use a written plan when preparing for class (Borko, Livingston, \& Shavelson, 1990; Clark \& Peterson, 1984; Shorner-Johnson \& Moret, 2015; Stigler \& Hiebert, 1999). Despite some preservice teachers' desire to not use lesson plans (Schmidt, 2005), quality lesson planning has been shown to be related to positive instructional quality (Dorovolomo, Phan, \& Maebuta, 2010; Lane, 2010).

It can be difficult to separate planning from teaching (Jorgensen, 2002). With preservice teachers, learning how to use lesson plans is often embedded within studies of pedagogical content knowledge and field experience (Clift \& Brady, 2005; Delorenzo, 1990; Millican, 2016a). However, planning during field experience can lead to dissonance between what students learn in school and how inservice teacher instruct their classes (Zeichner \& Tabachnick, 1981). This could be because expert teachers generally write more concise lesson plans or plan mentally, whereas novice teachers write with more words, explain more concepts, and plan with a target, but not a specific process 
(Brittin, 2005). Few preservice teachers have the opportunity to observe their instructor write lesson plans (Schmidt, 2005), which could lead to students' misunderstanding of the lesson planning process.

Although lesson planning among experienced teachers occurs in various forms, written lesson plans are the dominant approach to preparing lessons in preservice education at the university level (Clark \& Peterson, 1984; Lane \& Talbert, 2015; Mutton, Hagger, \& Bum, 2011; Panasuk \& Todd, 2005; Shorner-Johnson \& Moret, 2015; Skowron, 2001). Schmidt (2005) noticed a divide between conceptual understanding and practice in lesson planning. Her findings indicated that 10 preservice string teachers rarely engaged in written lesson planning and preferred to teach "on the fly" (p. 11), leading her to conclude that "early and extensive supervised field experiences may be even more crucial than the profession assumes them to be" (p. 19). It is still unclear to what degree learning about and incorporating written lesson plans may improve the teaching process for preservice music teachers.

Extant research findings indicate that there may be differences between elementary and secondary music planning structures (Shorner-Johnson, 2015a; ShornerJohnson, 2015b; Schmidt, 2005; Scott, 2011; Standerfer, 2011). For example, teacher educators claimed that secondary level rehearsal planning was problem/solution focused and suggested that a scripted sequential plan is not crucial (Shorner-Johnson \& Moret, 2015). Practitioners have agreed that lesson plans should focus on objectives and assessments (de Frece, 2010; Kearns, 2011; Scott, 2011). General music teacher educators may require a template that helps make teaching more meaningful and 
documents teacher thought processes (Shorner-Johnson, 2015b). Due to the differences in approaches, there is still a need to investigate lesson planning in music education courses.

Music education practitioners have written articles on how to construct lesson plans at both the elementary and secondary levels (Boshkoff, 1991; Branscome, 2014; de Frece, 2010; Scott, 2011). However, far less is known about how lesson plans are taught and used by undergraduate music education majors in teacher preparation programs. Researchers have explored the effects of lesson plan training on novices' pacing and sequencing during instruction (Lane, 2010; Maclin, 1993), how preservice music educators write lesson plans (Lane \& Talbert, 2015; Schmidt, 2005), and how novices' and experts' lesson planning differed (Brittin, 2005). Although researchers have recently investigated how music educators teach lesson planning in music education courses such as secondary ensemble and elementary music (Shorner-Johnson, 2015a; ShornerJohnson, 2015b; Shorner-Johnson \& Moret, 2015), no investigators have explored music majors' perceptions of lesson planning processes during their time spent in university curricula. Due to the lack of research concerning the training and use of lesson planning in multiple courses, an investigation into the current perceptions of music education majors would be beneficial for teacher educators to better understand preservice teachers' lesson planning knowledge.

The purpose of this study was to provide researchers and teacher educators with information about music education majors' perceptions of lesson planning in the university curricula. I surveyed respondents regarding (a) in which classes they were taught to construct lesson plans, (b) in which classes they were asked to use lesson plans, (c) their beliefs about the importance of lesson planning, and (d) how prepared they felt 
to use lesson plans while student teaching, and during their first year of teaching. As Jorgensen (2002) stated, it is important to examine the relationship between beliefs and curriculum as curriculum is often informed as much by beliefs as it is by objective reasoning.

\section{Method}

\section{Respondents}

Students enrolled in colleges and universities accredited by the National Association for Schools of Music (NASM) were chosen as participants because of the institutions' similarities in teaching standards, learning goals, and curricula. Participants were limited to Missouri and its contiguous states (Arkansas, Illinois, Iowa, Kansas, Kentucky, Nebraska, Oklahoma, and Tennessee). Using the NASM online database (https://nasm.arts-accredit.org/directory-lists/accredited-institutions/), I searched for degree-granting accredited institutions that were (a) listed as public or private and (b) located in each of the nine states representing the aforementioned Midwest region (NASM, 2015). Only institutions offering undergraduate degrees in music education were included $(N=126)$. Search results indicated the name of the institution, contact information for the department chair, and the internet address for each accredited school of music. Music education coordinators' e-mail addresses were retrieved from either the institution's website or via e-mail from the school/department of music chair.

The target population was junior- and senior-level music education majors in the Midwest region of the United States. This group was chosen because they had completed most of their educational coursework and could represent how lesson plans were taught and used at the bachelor's level. I sent recruitment messages to the music education 
coordinators via e-mail. (See Appendix A for a copy of the email.) Acting as "gatekeepers," faculty members forwarded a recruitment message with a hyperlink to the survey to music education majors at their institution. A request was added to the e-mail that the "gatekeepers" respond if they were willing to forward the recruitment letter. One week later, an additional request went out to participating professors asking them to provide the number of students to whom they forwarded the information. Data collection remained open for three weeks, at which time I sent a follow-up e-mail to the coordinators asking them to send another request to their students indicating that the survey remained open for an additional week. (See Appendix B for this e-mail.)

From the total number of music education coordinators contacted $(N=126), 43$ (34.1\%) responded and agreed to forward the online survey to approximately 465 students. A total of 114 surveys were completed. Seven responses were removed due to being outside the desired population, leaving 107 usable surveys, yielding a $23.01 \%$ response rate. Respondents included junior $(n=29,27.1 \%)$ and senior $(n=78,72.9 \%)$ music education majors from accredited NASM institutions in the Midwest region. Male $(n=44,41.1 \%)$ and female $(n=63,58.9 \%)$ students were represented. Instrumental education majors, $57.9 \%(n=62)$, vocal education majors, $26.2 \%(n=28)$, dual certification $14.9 \%(n=16)$ students, and an elementary music education major $(n=1$; $0.9 \%)$ were represented.

\section{Materials}

An IRB-approved (see Appendix C) survey was created using Qualtrics, an online survey tool. I designed the survey by adopting and incorporating reports of teachers' lesson planning practices and strategies that were found in research studies and 
pedagogical literature (Branscome, 2014; de Frece, 2010; Kearns, 2011; ShornerJohnson, 2015a, 2015b; Shorner-Johnson \& Moret, 2015). The four-section survey was designed to gather information about music education majors' perceptions of (a) the classes in which the respondents were taught to construct lesson plans, (b) classes in which respondents were asked to use lesson plans, (c) beliefs about the importance of lesson planning, and (d) how prepared respondents felt using lesson plans. Each section of the survey featured yes/no, multiple choice, Likert-type scale, and/or open-ended response questions. At the start of the survey, respondents provided demographic information (e.g., gender, location, year in school, age, major emphasis, and public or private institution). The courses were defined as music education (courses on specific instruction on teaching technique in music education), music method (technique courses designed to instruct preservice teachers on basic understanding of instruments and voice), and general education (courses on general education techniques and laws).

To help with the validity of the survey, five music education faculty members first piloted the survey so that I could determine the appropriateness, content, clarity, and approximate length of time to complete the survey. These experts (who were not involved in the administration of the survey) gave feedback that helped to establish the content validity of the survey instrument. Feedback from the pilot survey indicated that I should (a) add additional demographic information, (b) make answers to questions more general in sections 1 and 2, (c) use different vocabulary for ease of reading in section 3, (d) add a few additional questions in section 3, and (e) clarify perception questions in section 4. (See Appendix D for the complete survey.) 


\section{Results}

\section{Section One: Lesson Planning in Undergraduate Coursework}

Respondents were asked to identify in which specific general education, music education, and music method courses instructors taught them how to construct a lesson plan. The most selected course in general education was "special education" $(n=33$, $30.8 \%)$. "General music K-5" ( $n=74,69.2 \%)$ was the most frequently chosen response in music education courses, and "advanced conducting" ( $n=36,33.6 \%)$ was selected the most for music method courses. (See Table 1 for a complete list and percentage of courses.) A greater number of respondents responded that they were taught how to construct lesson plans in music education courses than in general education or music method courses.

\section{Section Two: Use of Lesson Planning in Undergraduate Coursework}

In the second section, participants were asked in which courses did they use lesson plans. In general education courses, "elementary methods field experience" $(n=$ $39,36.4 \%)$ was selected the most often. "General music K-5" $(n=71,66.4 \%)$ was the most frequently chosen answer for courses in music education. Similar to section one, "advanced conducting" ( $n=33,30.8 \%)$ was selected most often for music method courses (see Table 2). When comparing respondents' selections for the first three questions in each section, the frequency of selection was similar. General education courses were selected less, with "special education" $(n=33)$, being selected the most often in the first section, and "elementary field experience" $(n=39)$ being selected more often in the second section. For the next two questions in both sections 1 (taught) and 2 (used), "general music K-5" was selected the most frequently ( $n=74$ and $n=71$, 
Table 1

Responses to Courses in Which General Education, Music Education, and Music Methods Respondents Were Taught How to Construct Lesson Plans

\begin{tabular}{|c|c|c|c|c|c|c|c|c|}
\hline General Education & $N$ & $\%$ & Music Education & $N$ & $\%$ & Music Methods & $N$ & $\%$ \\
\hline Special Education & 33 & $\begin{array}{l}30.8 \\
\%\end{array}$ & General Music K-5 & 74 & $\begin{array}{l}69.2 \\
\%\end{array}$ & Advanced Conducting & 36 & $33.6 \%$ \\
\hline Middle School/High School Methods & 31 & $\begin{array}{l}29.0 \\
\%\end{array}$ & Secondary Teaching Music & 57 & $\begin{array}{l}53.3 \\
\%\end{array}$ & I did not use lesson plans & 27 & $25.2 \%$ \\
\hline $\begin{array}{l}\text { Middle School/High School Field } \\
\text { Experience }\end{array}$ & 30 & $\begin{array}{l}28.0 \\
\%\end{array}$ & $\begin{array}{l}\text { Instrumental Material and } \\
\text { Methods }\end{array}$ & 53 & $\begin{array}{l}49.5 \\
\%\end{array}$ & Basic Conducting & 25 & $23.4 \%$ \\
\hline Elementary Field Experience & 29 & $\begin{array}{l}27.1 \\
\%\end{array}$ & $\begin{array}{l}\text { Introduction to Music } \\
\text { Education }\end{array}$ & 52 & $\begin{array}{l}48.6 \\
\%\end{array}$ & Rehearsal Clinic & 24 & $22.4 \%$ \\
\hline Elementary Methods & 29 & $\begin{array}{l}27.1 \\
\%\end{array}$ & General Music 6-12 & 42 & $\begin{array}{l}39.3 \\
\%\end{array}$ & Woodwinds Methods & 21 & $19.6 \%$ \\
\hline I was not taught & 25 & $\begin{array}{l}23.4 \\
\%\end{array}$ & Vocal Material and Methods & 37 & $\begin{array}{l}34.6 \\
\%\end{array}$ & Brass Methods & 19 & $17.8 \%$ \\
\hline Foundation of Education & 24 & $\begin{array}{l}22.4 \\
\%\end{array}$ & I did not use lesson plans & 5 & $\begin{array}{l}46.7 \\
\%\end{array}$ & Percussion Methods & 13 & $12.1 \%$ \\
\hline $\begin{array}{l}\text { Reading and Writing in the Content } \\
\text { Area }\end{array}$ & 22 & $\begin{array}{l}20.6 \\
\%\end{array}$ & Other & 5 & $4.7 \%$ & String Methods & 12 & $11.2 \%$ \\
\hline Education Psychology & 16 & $\begin{array}{l}15.0 \\
\%\end{array}$ & & & & String Technique & 10 & $9.3 \%$ \\
\hline Other & 4 & $3.7 \%$ & & & & $\begin{array}{l}\text { Marching Band } \\
\text { Techniques }\end{array}$ & 9 & $8.4 \%$ \\
\hline \multirow[t]{2}{*}{$\begin{array}{l}\text { 1 eaching English to speakers of } \\
\text { Other Languages }\end{array}$} & 2 & $1.9 \%$ & & & & Other & 7 & $6.5 \%$ \\
\hline & & & & & & Jazz Methods & 4 & $3.7 \%$ \\
\hline Total & 245 & & & 325 & & & 207 & \\
\hline
\end{tabular}

Note: Participants were able to select multiple answers. 
respectively), and "advanced conducting" was chosen the most often ( $n=36$ and $n=33$, respectively). Similar to section 1, which asked in which classes were students taught how to construct lesson plans, more respondents indicated that they used lesson plans in music education courses than general education or music method courses (see Table 2).

Question 4 asked, "To what extent do your instructors address specific lesson planning in your courses?" Twenty answers were provided and participants were asked to choose if they used the procedure "not at all," "very little," "somewhat," or "a lot." Seventy respondents selected "a lot" (66.0\%) for "Evaluation/assessments," followed by "objectives" ( $n=66,62.9 \%)$, "rehearsal techniques" $(n=60,56.6 \%)$, "score study" $(n=$ 59, 55.7\%), and "lesson sequencing/procedures" ( $n=59,55.7 \%)$.

For question 5, respondents were asked "In these courses, were you asked to write using a specific style/template?" Ninety-four (87.6\%) students responded to this question with "yes," whereas 13 (12.5\%) answered "no." The respondents who answered "yes" were then asked this follow-up question: "To what extent were you asked to write in the following specific style/template?” Ten options were given. The most commonly-used template was "detailed lesson plans," with 63 respondents indicating that they used these "a lot" (67.0\%). The next most used template was "course specific lesson plans" with the most students selecting "a lot" $(n=35,37.2 \%)$. 
Table 2

Responses to Courses in Which General Education, Music Education, and Music Methods Respondents Used Lesson Plans.

\begin{tabular}{|c|c|c|c|c|c|c|c|c|}
\hline General Education & $N$ & $\%$ & Music Education & $N$ & $\%$ & Music Methods & $N$ & $\%$ \\
\hline Elementary Field Experience & 39 & $36.4 \%$ & General Music K-5 & 71 & $66.4 \%$ & $\begin{array}{l}\text { Advanced } \\
\text { Conducting }\end{array}$ & 33 & $30.8 \%$ \\
\hline $\begin{array}{l}\text { Middle School/High School Field } \\
\text { Experience }\end{array}$ & 37 & $34.6 \%$ & $\begin{array}{l}\text { Secondary Teaching } \\
\text { Music }\end{array}$ & 53 & $49.5 \%$ & $\begin{array}{l}\text { I did not use lesson } \\
\text { plans }\end{array}$ & 26 & $24.3 \%$ \\
\hline I did not use lesson plans & 25 & $23.4 \%$ & $\begin{array}{l}\text { Instrumental Material } \\
\text { and Methods }\end{array}$ & 50 & $46.7 \%$ & Rehearsal Clinic & 22 & $20.6 \%$ \\
\hline Elementary Methods & 21 & $19.6 \%$ & $\begin{array}{l}\text { Introduction to Music } \\
\text { Education }\end{array}$ & 45 & $42.1 \%$ & Basic Conducting & 20 & $18.7 \%$ \\
\hline Special Education Methods & 20 & $18.7 \%$ & General Music 6-12 & 43 & $40.2 \%$ & $\begin{array}{l}\text { Woodwinds } \\
\text { Methods }\end{array}$ & 20 & $18.7 \%$ \\
\hline Foundation of Education & 20 & $18.7 \%$ & $\begin{array}{l}\text { Vocal Material and } \\
\text { Methods }\end{array}$ & 37 & $34.6 \%$ & Brass Methods & 17 & $15.9 \%$ \\
\hline Middle School/High School Methods & 19 & $17.8 \%$ & $\begin{array}{l}\text { I did not use lesson } \\
\text { plans }\end{array}$ & 7 & $6.5 \%$ & Strings Methods & 15 & $14.0 \%$ \\
\hline $\begin{array}{l}\text { Reading and Writing in the Content } \\
\text { Area }\end{array}$ & 16 & $15.0 \%$ & Other & 5 & $4.7 \%$ & String Techniques & 13 & $12.1 \%$ \\
\hline Education Psychology & 9 & $8.4 \%$ & & & & Percussion Methods & 8 & $7.5 \%$ \\
\hline Other & 6 & $5.6 \%$ & & & & Other & 6 & $5.6 \%$ \\
\hline \multirow[t]{2}{*}{$\begin{array}{l}\text { Teaching English to Speakers of Other } \\
\text { Languages }\end{array}$} & 2 & $1.9 \%$ & & & & $\begin{array}{l}\text { Marching Band } \\
\text { Techniques }\end{array}$ & 4 & $3.7 \%$ \\
\hline & & & & & & Jazz Methods & 4 & $3.7 \%$ \\
\hline Total & 214 & & & 311 & & & 188 & \\
\hline
\end{tabular}

Note: Participants were able to select multiple answers. 
When asked, "To what extent were you taught the following rehearsal strategies in your education courses?," respondents indicated that "modeling" was the most frequently used strategy (“a lot," $n=75,70.6 \%$ ). The second most selected strategy was "appropriate feedback" $(n=68,64.2 \%)$. The least used strategy reported was "use of technology" $(n=30,28.6 \%)$.

\section{Section Three: Beliefs About the Importance of Lesson Planning}

For the first question, participants were given eight choices and asked to "Please rank the following reasons to use lesson plans from most important to least important." Respondents positioned all eight responses from most important (1) to least important (8) by using their mouse to drag the choices into the boxes provided. The highest ranked response was "prepare for ensemble rehearsal" $(n=45,43.3 \%)$. This was followed by "document mental planning process" ( $n=25,24.0 \%)$, "making teaching more purposeful" ( $n=13,12.5 \%)$, "anticipate problems" $(n=8,7.7 \%)$, and "develop transitional flow" ( $n=4,3.8 \%)$. "Organize necessary resources," "develop instructional pacing," and "used during teaching as a paper copy" were selected three times each $(2.9 \%)$.

Question 2 asked, "When creating lesson plans, how many verbal statements do you believe should be written out?" Fifty-two responded that "some" should be written out (48.6\%), whereas 29 (27.1\%) selected "a few," 17 (15.9\%) chose "most," five (4.7\%) selected "all," and four (3.7\%) chose "none." Question 3 asked, "When creating lesson plans, how many procedural steps do you believe should be written out?" The most chosen response was "most" ( $n=51,47.7 \%)$. Finally, participants were asked, "On average, how many hours per week should you spend working on lesson plans?" 
Respondents' answers ranged from 0 to 20 hours, with an average of 6.76 hours $(S D=$ 4.25) spent in lesson planning per week.

\section{Section Four: How Prepared Do You Feel Using Lesson Plans?}

For the first statement, "I am prepared to use lesson plans when I teach in public school," forty-eight (44.6\%) "strongly agreed," followed closely by "agree" $(n=46$, 43.0\%). "Disagree" $(n=10,9.3 \%)$ was third, and fourth was "strongly disagree" $(n=3$, 28\%). In response to the second statement, "The use of lesson plans is important for secondary courses," 55 respondents (51.4\%) marked "strongly agree," 45 (42.0\%) marked "agree," six (5.6\%) marked "disagree," and one respondent (0.9\%) marked "strongly disagree." Seventy-five respondents (70\%) marked "strongly agree" to the third statement, "The use of lesson plans is important for elementary courses," while 31 (29\%) marked "agree," and one (0.9\%) marked "disagree."

When asked, "How often do you believe secondary music teachers should create lesson plans for rehearsal?" (Question 4), the majority of respondents chose "weekly" ( $n$ $=48,45.3 \%)$. Followed, in order, by "daily" ( $n=35,33 \%)$, and "unit" $(n=23,21.7 \%)$. When responding to question 5, "How often do you believe elementary teachers should create lesson plans?" participants ranked "daily" as the most selected $(n=58,54.2 \%)$. A distant second was "weekly" $(n=34,31.8 \%)$, followed "by unit" $(n=15,14.0 \%)$.

For Question 6, "Which of the following is the most important aspect of rehearsal preparation for middle school/high school music teaching?", most participants selected a combination of score study and lesson planning as the most important $(n=85,79.4 \%)$. Although selected less often than a "combination of both," "score study" did have more responses than "lesson planning" ( $n=18,16.8 \% ; n=4,3.7 \%$, respectively). When 
asked, "Do you plan on using written lesson plans during your student teaching semester?" (Question 7), 104 (97.2\%) selected "yes" and three (2.8\%) selected "no."

\section{Discussion}

The purpose of this study was to provide researchers and teacher educators with information about music education majors' perceptions of lesson planning in the university curricula. Although much has been reported about teacher educators' perceptions of lesson planning recently — primarily through interviews and surveys (Shorner-Johnson, 2015a, 2015b; Shorner-Johnson \& Moret, 2015)—-there is little information about preservice teachers' perceptions. Through the administration of this survey, I gathered respondents' thoughts about their lesson planning instruction during their undergraduate coursework and their beliefs about the use of lesson planning at the elementary and secondary levels.

When I asked the respondents about their opinion of the purpose of lesson planning (i.e., rank why lesson plans are needed from most important to least), I modeled my questions after those found in a study by Shorner-Johnson (2015a, 2015b), who surveyed music teacher educators. The results of the present study indicated that respondents most frequently chose that the reason to use lesson plans was to prepare for ensemble rehearsals. This differs from results found by Shorner-Johnson (2015a) who reported that secondary music teacher educators selected "making teaching more purposeful" and whose respondents in another study indicated that elementary music teachers should use paper copies for reference during teaching (2015b). While "making teaching more purposeful" was marked as the third most selected response in this study, music education majors selected "using lesson plans as a paper copy" the least. It is 
interesting that professors and students appear to perceive why lesson plans are used differently. I speculate that undergraduate music education students' lack of teaching experience may be the cause of this disagreement. Inservice teachers and music education professors may have different values when planning their courses. Future researchers could interview preservice and expert teachers on these aforementioned disparities to see why there are differences in perception of lesson planning.

I also surveyed preservice music teachers about the courses in which professors required the use of lesson plans. Results indicated that respondents were taught about and used lesson planning more frequently in music education classes than in either music method or general education courses. Respondents were taught lesson planning and used plans most frequently in general music $\mathrm{K}-5$. This may be because elementary teacher educators recommend using paper copies of lesson plans during teaching, whereas secondary teacher educators reported thinking of planning as a way to make teaching more meaningful (Shorner-Johnson \& Moret, 2015). Perhaps the perception is that a template for the planning process in secondary ensemble courses is not needed in addition to score study because a preconceived aural image of the music does not need to be written down. University music education faculty members might consider being more explicit in their explanations of lesson plans as they relate to ensemble rehearsals so preservice music teachers have a clearer understanding of why lesson plans are used for rehearsals.

Fewer respondents reported that music method course instructors taught or asked the students to use lesson plans than in music education courses. Of these courses, advanced conducting was selected the most frequently for both learning lesson plans 
(30.8\%) and requiring written plans (33.6\%). This is not surprising as advanced conducting course instructors often require preservice teachers to prepare to conduct or rehearse an ensemble.

The respondents in this study indicated that they anticipate using lesson plans during their student teaching internship and first year of teaching. They also believe that elementary music teachers should plan daily, whereas secondary music teachers should plan weekly, with no respondent selecting the option "do not plan." This appears to contradict a previous report by Schmidt (2005) who suggested that preservice teachers perceived lesson planning to be unnecessary. This could be due to the students in the present study being surveyed about lesson planning, instead of being asked to produce lesson plans for an experimental teaching scenario, as was the case in his study. Future researchers might investigate the use of lesson planning during student teaching placements and the first year of teaching to see if similar results are found in where and how lesson plans are taught in the university curricula.

Consonant with previous literature (Shorner-Johnson, 2015a, 2015b; ShornerJohnson \& Moret, 2015), respondents ( $n=94,87.6 \%$ ) indicated they were asked to write lesson plans using specific templates in their music education classes. The most frequently selected lesson template used was “detailed lesson planning," followed by “course specific plans," and "state specific" plans. Shorner-Johnson and Moret (2015) found that music teacher educators adopted detailed templates from general education courses and used those in their own music courses. This seems contrary to advice from practitioners who have suggested that lesson planning should be more of a process of thinking through the lesson rather than using a specific written template (Branscome, 
2014; Thomson, 2005). Teacher educators may teach specific plans, such as detailed planning, out of the convenience of standardized grading practice, or they may also teach how to use lesson plans that have worked best for them in their own classes.

Respondents indicated that "evaluation and assessments" were the most frequently addressed component of lesson plans, followed by "objectives," "rehearsal techniques," "score study," and "lesson sequencing/procedures." Shorner-Johnson (2015a, 2015b) found similar results with "objectives" being selected as the most frequently used component of lesson planning. These findings should be viewed positively, as it seems that teacher educators and preservice teachers agree on what components of lesson planning are being taught in undergraduate music education courses. The focus seems to be on objectives, with an emphasis on the why of lesson planning rather than the how. Future researchers might investigate what specific planning components inservice teachers use and find important to compare those with preservice teachers and teacher educators' perceptions.

\section{Limitations and Generalizability}

One limitation of this study was how the survey was distributed to potential respondents (i.e., music education coordinators who chose to forward the survey to their students). This could help explain the low response rate (23.01\%). Still, I attempted to maximize the responses by (a) designing the survey to be completed in 10 minutes or less, (b) reminding faculty members to forward the survey link to their students, and (c) leaving the survey open for an additional week. While the gatekeepers were asked to respond with the number of music education students to whom they forwarded the survey request, some coordinators responded with only approximate numbers. Another 
limitation is that juniors were surveyed along with senior music education students. This was done in an attempt to increase the number of responses. Juniors, however, may not have taken some of their required education or method courses and therefore may not have had enough information to fully answer all the questions. Due to this, it was difficult to ascertain the response rate for each school. Since the numbers of respondents in each state was unequal, these findings may not be indicative of the entire Midwestern region. Caution is warranted regarding the generalizability of the results from this study.

\section{Implications for Music Teacher Preparation}

Based on my findings, I propose a few recommendations for teacher educators. The results of this study indicated that music education majors perceived that they learned how to lesson plan in music education courses more so than in general education or music method courses. Because music education specialists often have had experience teaching public school music classes, as well as teaching undergraduate music education courses, these instructors might not adequately address concepts specific to secondary and elementary music teaching. Further guidance in teaching how to plan for common method courses could help improve the instruction of lesson planning.

When comparing of this investigation with previous lesson planning surveys (Shorner-Johnson, 2015a, 2015b), the results seem similar for many responses (e.g. questions what specific templates are used, what components of lesson plans are taught, and students' beliefs). These are positive results because preservice teachers are indicating that objectives are the most commonly used component of lesson plans, suggesting that plans should be about why the lesson is needed, not necessarily how the procedures will be taught. Many inservice teachers agree that some kind of lesson 
planning is needed (Bauer \& Berg, 2001; Fredrickson, Geringer, \& Pope, 2013;

Teachout, 1997; Tsui, 2009), and it seems that music teacher educators do use lesson planning templates in their courses. They seem to be based, however, on the teachers' own beliefs about lesson planning (Shorner-Johnson \& Moret, 2015) and perhaps not what will function best with individual students. With the implementation of state and national educational teacher assessment programs, such as the edTPA, it may be worthwhile for teacher educators to standardize the lesson plans they use to most closely resemble these newly-mandated national and state templates. What inservice teachers learn by using lesson these types of plans and how do they implement those strategies in plans warranted future investigation.

Because nearly all respondents said they would use lesson planning during their student teaching internship and first year of teaching (97.2\%), I suggest that undergraduate music teacher educators should consider requiring their students to provide evidence of planning during each of their classes, similar to the recommendation made by Silvey, Springer, and Eubanks (2016) about incorporating evidence of score study in undergraduate conducting and rehearsal technique courses. Although many respondents indicated they will use lesson plans in the future, fewer indicated that lesson planning was taught, or even used, in many of their courses. Since it is becoming clearer that objective-based plans are being taught in undergraduate courses, music teacher educators might need to go further than teaching the procedures of lesson planning, and help improve preservice teachers' understanding of why a lesson is being taught. Continued research related to the perception of lesson planning with preservice, inservice, and teacher educators will hopefully provide insights that may help music teacher educators 
better develop novice teachers' skills that allow them to be successful in their course preparation. 


\section{Chapter Four}

\section{Effects of Knowledge Type on Perceptions of Novices' Rehearsal Effectiveness: An}

\section{Exploratory Study}

The concept of teacher knowledge types was introduced by Shulman (1986) as an answer to the perceived lack of focus on subject matter, or what he and his colleagues called a 'missing paradigm' (p.6) in teaching and teacher education research. He labeled the unique method in which teachers work within their content area as pedagogical content knowledge (PCK). Since the introduction of Shulman's understandings of teaching, scholars in different educational fields have furthered Shulman's initial conception and claim that PCK includes knowledge about what teachers need to know and how that applies to the practice of teaching (Ball, 2000; Ball, Hill, \& Bass, 2005; Ball, Thames, \& Phelps, 2008; Lee, Brown, Luft, \& Roerhig, 2007; Silverman \& Thompson, 2008).

\section{Content Knowledge}

Once Shulman's concept of teacher knowledge became a popular topic of investigation in education, many scholars focused specifically on the importance of content knowledge (CK). CK can be defined as items related to factual knowledge of a specific discipline (Millican, 2008; Shulman, 1987). There is evidence that possession of strong CK is considered an important criterion for teacher quality (Kaplan \& Owings, 2002; Okpala \& Ellis, 2005).

Research findings have indicated that $\mathrm{CK}$ is important and that teachers need to understand their content deeply to be successful (Ball, Hill, \& Bass, 2005; Kennedy, 1998). Without appropriate CK, teachers may struggle to help students learn in their area 
(Ball \& McDiarmid, 1990; Snow, 1998). Hill, Ball, \& Schilling (2008) categorized CK into three groups: common $\mathrm{CK}$, specialized $\mathrm{CK}$, and knowledge at the mathematical horizon. Common CK was described as the basic skills known by most adults, whereas specialized CK was described as knowledge of the content specifically needed for educators to teach (Ball, Thames, \& Phelps, 2008). In other words, teachers should not only know if the student is correct or incorrect, they should know how and why the student made an error. This, of course, requires more in-depth knowledge of the content.

Although CK is important to teaching, knowledge alone does not necessarily indicate that a teacher will be successful in conveying their knowledge to students (Loughran, Berry, \& Mulhall, 2012). Phelps and Schilling (2004) developed a measurement tool to test $\mathrm{CK}$ in reading. Their findings suggested that phonemes, that is, the distinct sound that distinguish one word from another, are not enough to guarantee success in learning how to read or spell, and posited that teaching reading includes multiple dimensions. Similarly, it seems reasonable to suggest that while a good music performer might also be able to help their students perform at a high level, this also may not be the case due to their inability to teach performing to their students.

CK necessary for leading an ensemble could be described as the technical skills required for conducting or those needed to study a musical score. These include kinesthetic skills (e.g., beat pattern, gestural technique), conceptual knowledge of the musical score (e.g., identification of melody, countermelody, accompaniment, and bass line), and error detection and correction (Forrester, 2015; Green \& Gibson, 2004; Hunsberger \& Ernst, 1992; Labuta, 2010). Nevertheless, strong CK may not be enough 
for music teachers to be successful, and should be combined with expertise in developing teaching procedures and strategies for the classroom, commonly known as PCK.

\section{Pedagogical Content Knowledge}

$\mathrm{PCK}$ is rooted in the idea that teaching requires more than delivering $\mathrm{CK}$ to students. Shulman (1987) defined PCK as “... the category most likely to distinguish the understanding of the content specialist from that of the pedagogue" (p. 8). Ballantyne and Packer (2004) defined music PCK as "Knowledge of music teaching techniques, engaging students with music in a meaningful way, implementing the music curriculum effectively, assessing students' abilities in the various aspects of music, explaining and demonstrating musical concepts" (p. 302). PCK is the idea of how to teach, whereas CK is the what to teach. That is, if you know a trumpet player is playing an A flat instead of a written A natural, that is CK. However, if the teacher understands that students are more likely to play the seventh scale degree incorrectly in a B-flat major scale, and that information helps the student understand how a major scale works, that is PCK.

Researchers have recently expanded components of Shulman's initial conceptualization of CK and PCK by discipline. Some researchers have examined PCK in science (Kind, 2009; Magnusson, Krajcik, \& Borko, 1999; Loughran, Berry, \& Mulhall, 2012), math (Ball, 1993; Borko \& Livingston, 1989; Depaepe, Verschaffel, \& Kelchtermans, 2013), and music (Haston \& Leon-Guerrero, 2008; Millican, 2013, 2016a, 2016b). Three general areas of teacher knowledge have been identified, which include pedagogical knowledge, content knowledge, and knowledge of context (Grossman, 1990). These three areas are combined into PCK and are mentioned as having a strong influence on teachers' knowledge bases in various research studies (Beijaard, Verloop, \& 
Vermunt, 2000; Kennedy, 2010; Lee, 2011). The aforementioned factors have helped researchers to better explain the function of PCK.

Since the initial investigation of PCK in the late 1980s, researchers-especially in science and mathematics education — have explored specific components of PCK. Several research findings have indicated that teachers should have knowledge of student interests (Hill, Schilling, \& Ball, 2004; Ball, Thames, \& Phelps, 2008), common difficulties in the content (Tamir, 1988; Koehler \& Mishra, 2009), specific strategies to teach concepts within a discipline (Magnusson, Krajcik, \& Borko, 1999; Rowan, Schilling, Ball, Miller, Atkins-Burnett, \& Camburn, 2001), appropriate sequencing of instruction (Hill, Ball, \& Schilling, 2008), typical student error and misunderstandings of content (Hill, Ball, \& Schilling, 2008), and how teachers interpret student work and performances (Ball, Bass, Hill, \& Schilling, 2005; Hill, Ball, \& Schilling, 2008). These concepts in specific disciplines have helped researchers better understand the importance of PCK in teacher education.

Music education researchers have investigated the importance of PCK and its impact on teacher delivery (Millican, 2012; Raiber \& Teachout, 2014). Millican (2013) applied Shulman's PCK framework to explore beginning band directors' thought processes. Four experienced band directors identified elements of PCK while viewing videotaped performances of beginning band students. The most commonly observed elements by these band directors were (a) mental image/modeling, (b) understanding the outcomes of the manipulation of variables to positively effect student performance, (c) gather and interpret specific data to interpret student work, develop specific rules, procedures, and guidelines to help students master principles of performance, and (d) 
make specific rules, procedures, and guidelines. Similarly, Forrester (2015) interviewed four experienced band directors and suggested that instrumental music teaching demands a specialized form of knowledge that integrates teaching and conducting, rather than the teaching of these two concepts independently.

Research findings involving preservice music teachers' conducting and score knowledge have indicated that musical CK is important for preservice teachers' rehearsal preparation (Lane, 2006; Montemayor \& Moss, 2009; Silvey, Montemayor, \& Baumgartner, 2017). However, few studies of PCK exist in music perhaps because scholars have only recently investigated what defines CK in music education (Emerich, 2015; Millican, 2013, 2016b). Although researchers have explored teacher knowledge of experienced band directors through qualitative studies (Emerich, 2015; Forrester, 2015), no investigators have explored novice teachers' understanding and use of CK and PCK during rehearsal preparation.

Therefore, the purpose of this study was to compare the effects of CK (music score knowledge) versus PCK (lesson planning) on novices' rehearsal effectiveness and knowledge of the score. I explored whether novices' rehearsals would be judged differently based upon two different methods of preparation. How would novices who focused their rehearsal preparation using typical score study methodologies (CK) differ from those whose preparation also included specific rehearsal strategies (PCK)?

\section{Method}

\section{Participants}

Conductors. Twenty instrumental music majors (10 freshmen and 10 sophomores) at a large Midwestern university served as participants for this study. I 
solicited participants through announcements in band and orchestra rehearsals, visits to undergraduate music courses, and e-mail correspondence (see Appendix F for conductor recruitment script). I sought volunteers who had not taken score study or conducting, rehearsal technique, or advanced music education courses. To ensure that participants felt capable leading an ensemble, volunteers were asked to report confidence in their ability to perform basic conducting patterns as prerequisite for participation. I confirmed this with each participant as part of the IRB recruitment procedures (Copies of the consent form can be found in Appendix G).

Performers. Additional participants included musicians $(N=40)$ who performed in a band that the study participants conducted. A full list of consent forms can be found in Appendix H. I gathered volunteers by visiting ensemble rehearsals and through individual solicitations (See Appendix I for ensemble recruitment script). The band was composed of undergraduate $(n=13)$ and graduate $(n=7)$ music majors, as well as nonmusic majors $(n=20)$, all who played either primary or secondary instruments. The instrumentation of the ensemble was complete, with mostly one performer per part. (The conducting participants did not play in the ensemble.)

Expert Evaluators. Graduate students enrolled in a large Midwestern university $(N=3)$ also participated in this study and served as rehearsal evaluators. (See Appendix $\mathbf{J}$ for a copy of the consent form.) Their average years of teaching experience was 15.33 $(S D=2.08)$. Each judge was asked to report his or her degree classification (master, $n=$ 1; doctorate, $n=2$ ) and emphasis area (conducting, $n=1$; music education, $n=2$ ).

\section{Rehearsal Preparation}

Participants $(N=20)$ were randomly divided into two groups of ten. Each group 
received a separate 2-hour rehearsal preparation instructional period one week prior to the rehearsal. For both groups, the first half hour of each lesson was dedicated to learning about basic conducting techniques, while the next half hour was dedicated to basic score study, as none of the conducting participants in this study had previous conducting or score study experience. The final hour was dedicated to the independent variables, either intensive score study practice (CK) or rehearsal techniques (PCK). The first hour of activities was organized in the same chronological order. The remaining hour was instruction specific to either of the two individual experimental groups (see Appendix L for the lesson plan).

I labeled the first experimental group the content knowledge (CK) group because the rehearsal preparation procedures used were focused exclusively on score study and the development of an aural image of the music, often considered the most important prerequisite for leading an ensemble rehearsal (Battisti \& Garofalo, 1993; Green \& Gibson, 2004; Labuta, 2010). The first 30 minutes of the session was focused on basic conducting techniques and was followed by 30 minutes of score orientation and discussion about score marking. During the final hour of their session, the CK group participants studied the score in the following manner: (a) identified important music lines, such as the melody; (b) marked specific music material in their scores, such as meter changes, dynamics, and unfamiliar terms; (c) listened several times to a professional recording of their excerpt while following the score and/or practicing conducting gestures; (d) repeatedly sang individual melodic lines; and (e) engaged in silent score study. These methods were adopted from previous research investigations and expert conductors' score study suggestions (Battisti \& Garofalo, 1993; Hunsberger, 
1988; Montemayor \& Moss, 2009; Silvey \& Montemayor, 2014). At the end of the session, participants were reminded to prepare for their rehearsal by using the same strategies they had been shown during the preparation session. Each participant was required to show me their score three days prior to their rehearsal so that I could ensure they had marked and studied the score as previously discussed.

The participants in the second group, which I labeled the pedagogical content knowledge (PCK) group, completed the same preparation tasks during the first hour as did the CK group participants. During the last hour of the session, I led discussion and practice on the following: (a) modeling — singing how you want the part to go; (b) instructional sequencing; (c) feedback delivery; and (d) contextualizing the rehearsal. During the training, participants watched video examples of expert conductors who demonstrated the previously-mentioned rehearsal techniques. After each video, participants practiced, in small groups, by writing or using each strategy with a piece of

music that was comparable to their assigned excerpt. PCK group participants were asked to write four specific rehearsal strategies for their rehearsal and to continue prepare individually by studying the score and determining how to incorporate their written comments into their rehearsal. Each participant was required to show me their written rehearsal strategies three days prior to their rehearsal.

\section{Rehearsal Episodes}

As in previous research studies involving novices' rehearsals, a 5-minute rehearsal time was used (Lane, 2010; Lane \& Talbert, 2013). Five-minute rehearsal times were chosen as to allow all the participants' rehearsals to occur on a single day. Furthermore, shorter rehearsal episodes seemed less overwhelming for novices who are 
preparing to conduct their first rehearsal. Lessons were scheduled at 7-minute intervals and participants were not in the room during other conductors' rehearsals. Before the rehearsals began, I instructed the ensemble members to avoid talking, using electronic devices, or engaging in any off-task behavior so that participants could focus on their rehearsals without distraction. The ensemble was also told to follow and respond to the participants conducting and instruction precisely. After 10 participants had completed their rehearsals, a short 10-minute break was given to members of the ensemble.

I monitored the start and stop times of each rehearsal using a digital stopwatch on an Apple iPad. Each rehearsal began with a verbal cue to the participants that indicated the start time (i.e., "You may start now"). After three minutes had elapsed, I provided a nonverbal cue indicating that two minutes remained (2 fingers held in the air). Another cue was given with one-minute remaining (1 finger held in the air). Participants were stopped with a verbal cue at the end of the five-minute rehearsal (i.e., "Your time is up").

\section{Music Selection}

Pieces were selected from Volumes 1-6 of the Teaching Music Through Performance in Band series (Miles, 1997-2007) and represented high-quality, standard band repertoire. The ten chosen pieces were listed at a grade 2 (of 6) difficulty level, appropriate for a typical middle school band. Ten contrasting excerpts were chosen to provide variety and to decrease the opportunity for the ensemble to improve with multiple performances. Within each piece, I identified approximately one minute of music for participants to study and rehearse. Similar to procedures used in prior studies (Montemayor \& Moss, 2009; Silvey \& Montemayor, 2014), excerpts began and ended at logical points in the music and consisted of full ensemble playing. The randomly 
assigned music selections used in this study were: (1) As Torrents in Summer arranged by Albert O. Davis, (2) Flourish for Wind Band by Ralph Vaughn Williams, (3) Down Country Lane by Aaron Copland, (4) Llwyn Onn by Brian Hogg, (5) Mini-Suite, Movement One by Morton Gould, (6) Polly Oliver by Thomas Root, (7) Rites of Tamburo by Robert W. Smith, (8) Sonatina for Band by Frank Erickson, (9) They Led My Lord Away arranged by Fred J. Allen, and (10) When the Stars Began to Fall arranged by Fred J. Allen. (See Appendix K for measure numbers.)

\section{Data Collection}

Three different sets of data were collected in this study: (a) ensemble members' evaluations of the conductors, (b) conductors' self-evaluations, and (c) experts' evaluations of the conductors. During the time between each 5-minute rehearsal, ensemble members were asked to rate the conductor's score knowledge and the conductor's rehearsal effectiveness using a Likert-type scale anchored by 1 (low) and 10 (high). (See Appendix M for Likert-type forms.) The ensemble members were blind to participants' assigned experimental condition. Secondly, the conductors completed selfevaluations immediately following their own rehearsal. Conductors were asked to rate themselves using the same Likert-type scale as the ensemble members. Similar to procedures used by Montemayor and Moss (2009), the conductors were asked three freeresponse questions regarding (a) how prepared they felt to lead the rehearsal, (b) what they believed were their strongest aspects of their teaching, and (c) what were the weakest aspects of their teaching.

A Kodak EIS digital video recorder was used to record each rehearsal. All rehearsal episodes (a total of 100 minutes) were randomly arranged on three DVDs in 
three different orders to help control for possible order effects. I provided a separate DVD to three graduate students who were enrolled in music education or conducting programs. Similar to the ensemble members, the three graduate students were unaware of any experimental assignments. Using the same Likert-type scale as the ensemble and conductors, these experts were asked to evaluate each conductor's score knowledge and rehearsal effectiveness.

\section{Results}

I calculated the means and standard deviations of the novice conductors' two numerical evaluations of themselves, namely score knowledge and rehearsal effectiveness. All conductor self-evaluation scores were slightly higher for the PCK group (score knowledge, $M=8.3, S D=1.059$; rehearsal effectiveness, $M=6.7, S D=$ 2.002) than for the CK group (score knowledge, $M=6.9, S D=1.853$; rehearsal effectiveness, $M=6.3, S D=1.947)$. Due to the small number of conductors in each group $(n=10)$, I used a Mann-Whitney $U$ test to analyze differences between the PCK and CK groups. No significant differences between experimental conditions were found in the conductors' evaluations of their own rehearsal effectiveness, $U=48.5, p=.908, r$ $=.03$, or score knowledge, $U=27.0, p=.073, r=.06$.

I also calculated the means and standard deviations of the ensemble members' two numerical evaluations of the conductors' score knowledge and rehearsal effectiveness. All evaluation scores that were assigned by the ensemble members were slightly higher for the PCK group than the CK group. The highest score was the evaluation of score knowledge in the PCK group, $M=6.93(S D=1.002)$, and the lowest evaluation score was for the CK group's rehearsal effectiveness, $M=5.83(S D=1.002)$. 
I conducted separate one-way analyses of variance tests (ANOVA) for the ensemble members' evaluations of conductors' score knowledge and rehearsal effectiveness. No

Table 3

Means (and Standard Deviations) of Numerical Rehearsal Evaluations

\begin{tabular}{lc}
\hline Evaluations & Rehearsal \\
\hline Conductor self-evaluation of Rehearsal Effectiveness & $8.3(1.059)$ \\
CK Group & $6.7(2.002)$ \\
PCK Group & $6.9(1.853)$ \\
Conductor self-evaluation of Score Knowledge & $6.3(1.947)$ \\
CK Group & \\
PCK Group & \\
Ensemble member evaluation of Conductor Rehearsal & $5.8(6.295)$ \\
Effectiveness & $6.3(1.441)$ \\
CK Group & \\
PCK Group & $6.43(1.032)$ \\
Ensemble member evaluation of Conductor Score & $6.93(1.002)$ \\
Knowledge & \\
CK Group & $3.23(1.01)$ \\
PCK Group & $3.87(1.67)$ \\
Expert evaluation of Conductor Rehearsal Effectiveness & \\
CK Group & $4.33(1.23)$ \\
PCK Group & $4.97(1.76)$ \\
Expert evaluation of Conductor Score Knowledge & \\
CK Group &
\end{tabular}

Note: All ratings are on a 10-point scale from 1 (low) to 10 (high).

significant differences between experimental conditions were found for the ensemble members' evaluation of conductor score knowledge, $F(1,18)=1.220, p=.284, \eta^{2}=.06$ or rehearsal effectiveness, $F(1,18)=.717, p=.408, \eta^{2}=.04$.

Following each rehearsal, conductors were asked to answer three free-response questions: (1) How prepared did you feel to lead the rehearsal? Why?; (2) What were the strongest aspects of your rehearsal? Why?; and (3) What were the weakest aspects of your rehearsal? Why? To analyze these comments, I adopted coding procedures in my 
categorization of participants' written comments similar to those used in prior investigations (Price \& Mann, 2011; Silvey 2011; Silvey \& Fisher, 2015). Coded comments $(N=76)$ were organized by category (preparation, conducting knowledge, or rehearsal technique), group (CK and $\mathrm{PCK}$ ), and direction (positive or negative). Two reliability observers coded and categorized the free-response data to identify categories. Any disagreements regarding the data were resolved through discussion until consensus was achieved (Denzin \& Lincoln, 2005). This resulted in two preparation, two conducting knowledge, and five rehearsal technique subcategories. All responses appear in Table 4. See Appendix N for all comments written by the conductors.

\section{Table 4}

Categorization of Conductors' Comments for CK and PCK Conditions

\begin{tabular}{lcccccc}
\hline & \multicolumn{5}{c}{ CK Group } & \multicolumn{3}{c}{ PCK Group } \\
\cline { 2 - 7 } Category & Pos & Neg & $\Sigma \%$ & Pos & Neg & $\Sigma \%$ \\
\hline Preparation & 6 & 1 & 18.9 & 10 & 3 & 33.3 \\
Felt Prepared & 0 & 8 & 21.6 & 0 & 7 & 17.9 \\
Nervous & & & & & & \\
Conducting Knowledge & & & & & & \\
Conducting & 3 & 2 & 13.5 & 1 & 3 & 10.3 \\
Score Study & 4 & 0 & 10.8 & 4 & 0 & 10.3 \\
& & & & & & \\
Rehearsal Technique & & & & & & \\
Eye Contact & 1 & 2 & 8.1 & 0 & 1 & 2.6 \\
Sequencing/pacing & 1 & 0 & 2.7 & 3 & 0 & 7.7 \\
Comfort with Rehearsing & 0 & 5 & 13.5 & 0 & 0 & 0.0 \\
Modeling & 1 & 0 & 2.7 & 2 & 1 & 7.7 \\
Feedback/Clarity of instruction & 0 & 3 & 8.1 & 3 & 1 & 10.3 \\
$\Sigma$ & 16 & 21 & & 23 & 16 & \\
$\Sigma \%$ & 43.2 & 56.6 & 100 & 59.0 & 41.0 & 100 \\
\hline
\end{tabular}

Note: Pos $=$ positive; Neg $=$ negative 
Participants in the CK group commented more negatively (56.6\%) than positively (43.2\%) to the three questions asked, whereas the PCK group wrote more positive (59.0\%) than negative (41.0\%) comments. The most frequent negative comments that appeared in both the CK and PCK groups were in reference to how nervous they were (21.6\% and $17.9 \%$, respectively). Members of the CK group most often commented on their conducting (13.5\%). The PCK group said they felt more prepared for their rehearsal than the CK group (33.3\% versus $18.9 \%$, respectively).

Most of the participants (16 out of 20) responded that they felt prepared to lead their rehearsal. Examples of these comments included "I felt prepared because I read through the score a lot and listened to different bands play it" and "I was very prepared, because I was at the point musically where I could feel the music go by, and not just watch it." Nevertheless, many students also wrote that nerves got in their way. One example included, "I felt relatively prepared for the rehearsal, and then you walk in and see 40 eyes looking back at you, and it all goes down the drain..."

Several participants in the CK group reported that they felt prepared during their score preparation, but not when they began rehearsing the ensemble. One conductor wrote "Generally, I felt underprepared. While I know a lot about the score and had listened to the piece, I was unsure of how to lead a rehearsal. I wasn't sure what to focus on, how to speak, etc" (emphasis by the participant). Another wrote that "I didn't feel very prepared because I knew how to find the key components of the score, but I wasn't sure how to get the point across." Unlike some members of the CK group, the PCK group wrote more positive remarks about their rehearsal techniques. For example, "I think I was able to model well and have them play exactly what I wanted," "I feel like I was doing 
sequencing okay, separating the melody from the bass line and checking that balance," and "I was pretty specific on what I wanted. I kept the rehearsal going so we get more done."

To determine whether the rehearsal would be evaluated differently based upon the conductors' preparation method, I asked three graduate students to evaluate the score knowledge and rehearsal effectiveness of the 20 conductors' videotaped rehearsals on a 10-point Likert-type rating scale anchored by low (1) and high (10). Reliability, as calculated by the average measure intraclass correlation coefficient, was acceptable at .79 (Cohen, 1988). As with the conductors' self-evaluations, I used a Mann-Whitney $U$ test to compare results for both the score knowledge and rehearsal effectiveness variables. There were no significant differences between experimental conditions found in the conductors' evaluations of their own rehearsal effectiveness, $U=360.0, p=.178, r=.25$ or score knowledge, $U=258.5, p=.171, r=.25$.

\section{Discussion}

The purpose of this study was to compare the effects of CK (score knowledge) versus PCK (written rehearsal techniques) on novices' rehearsal effectiveness and score knowledge. No significant differences were found for any of the three dependent measures, including participants' self-evaluation, ensemble members' evaluations, or experts' evaluation of conductors' score knowledge or rehearsal effectiveness.

The nature of conductors' written comments regarding their rehearsal preparedness and teaching effectiveness were slightly different for each method of preparation. For example, participants in the PCK group tended to be more positive about their rehearsal, whereas the CK group were more negative. That participants felt more 
positively about using a combination of rehearsal techniques and score study, rather than score study alone, may suggest a combination of score study and rehearsal techniques should be taught to preservice teachers simultaneously. Even with a short amount of time to prepare, many of the participants indicated they felt prepared to rehearse the ensemble. As expected, members of the CK group more often cited they felt prepared with score study, while more PCK participants indicated they felt prepared to rehearse the ensemble. Nevertheless, each group mentioned that being nervous affected their ability to led a rehearsal. Future researchers might consider using more experienced students for a study such as this so that nerves would not get in the way. Introducing PCK (e.g., rehearsal techniques, lesson planning) and CK (e.g., score study, conducting gestures) in university courses could help improve preservice teachers' ability to rehearse more effectively. As Silvey and Montemayor (2014) suggested, perhaps teacher educators should develop novice teachers' overall rehearsal and conducting skills in a "holistic manner" (p. 172).

Participants were freshman and sophomore instrumental music majors who conducted a brief rehearsal, a methodology similar to previous studies in this area (Montemayor, Silvey, Adams, \& Witt, 2016; Lane, 2010; Lane \& Talbert, 2013). Even though the participants in this study were novices, I chose not to provide specific feedback on their preparation activities after the experimental treatments. Although I believe that each participant was capable of rehearsing the group, it is likely that more experience with conducting or rehearsal technique courses would have helped students understand and prepare better for these rehearsals. Additionally, novice teachers may require more individualized guidance in preparing for the difficult task of rehearsing a group of advanced musicians. Future researchers might consider studies that involve 
multiple rehearsals and consider providing some feedback to the participants prior to each rehearsal, similar to other investigations (Lane, 2010; Lane \& Talbert, 2013).

Conductors' written responses suggested that nerves affected their conducting. If the participants had led multiple rehearsals, perhaps they would have been less nervous rehearsing, possibly leading to higher evaluation scores. Considering that secondary music teacher educators often cite a lack of podium time as negatively affecting undergraduate conducting skill development (Romines, 2003), professors might try to design courses that give their students more frequent conducting opportunities with both CK and PCK components. This could include partnerships with local schools where students are required to score study and have planned rehearsal techniques in advance, or more opportunities to learn about conducting, score study, and rehearsal strategies and the application of these techniques in music courses.

This study should be considered an exploratory investigation for several reasons. First, it included a small convenience sample of undergraduate music majors. Most participants were freshman and sophomores that I had taught in class or knew personally. Second, the single rehearsal seemed to hinder the conductors' confidence level, as selfreported in their short answer responses. Perhaps with more frequent or longer rehearsals, a clearer understanding of the effects of these experimental groups could be understood. However, these findings may help researchers who are interested in how different preparation methods influence novice music teachers. Future researchers might consider studies that include a greater number of participants from multiple institutions.

There is much evidence that $\mathrm{CK}$ and PCK development helps expand preservice music teachers' ability to lead a rehearsal (Ballantyne \& Packer, 2004; Emerich, 2015; 
Millican, 2018); however, more pedagogues should consider using Shulman's (1987) PCK and CK frameworks to further understand how to help preservice music teachers prepare for rehearsals. PCK is a relatively new field of study in music education, and many aspects of how musical CK is taught are still not fully understood. Although Millican (2013, 2016a) investigated how expert and preservice teachers described PCK, little is still known about how these descriptions of teaching music are used in novices' rehearsal preparation. The results of this study indicated that there was no perceived difference between conductors who used CK or PCK preparation. Perhaps novice teachers do understand PCK skills but lack the guidance on how to effectively convey their ideas during a rehearsal. It may also be difficult to separate these two components when instructing preservice teachers. Furthermore, it might be more beneficial to teach all parts together, rather than any one part individually. In other words, it may be unrealistic to separate lesson planning and score study. While there are many variables that affect preservice teachers' rehearsal skills, the continued exploration of PCK, and how it relates to novice teachers' skill development, might help increase preservice teachers' rehearsal efficacy. 


\section{Chapter Five}

\section{Summary and Conclusions}

Although music education researchers have found that some type of lesson planning is necessary for effective instruction (Bauer \& Berg, 2001; Fredrickson, Geringer, \& Pope, 2013; Teachout, 1997; Tsui, 2009), there is still disagreement about which preparation techniques assist teachers in being most successful. Why are some teachers more skillful in teaching their classes? Why are some detailed lesson plans less successfully implemented? Why are some planning procedures more successful than other? What are the best ways to teach preservice music teachers how to adequately prepare for an ensemble rehearsal? The planning process is complex and one that involves many factors, such as written lesson plans, sequencing, and connecting previous knowledge to new knowledge.

\section{Research Questions and Method}

The purpose of this dissertation was to better understand how preservice teachers' preparation influenced their perceptions about lesson planning practices in music teaching contexts and their ability to lead ensemble rehearsals. The following primary research question was used to guide this investigation: What are preservice teachers' perceptions of lesson planning and can specific teacher knowledge (either Content Knowledge, CK, or Pedagogical Content Knowledge, PCK) improve their ability to teach a class? I then divided this question to create two separate research studies. In the first study, I sent a survey requesting preservice music teachers to answer the following: “(a) in which classes they were taught to construct lesson plans, (b) in which classes they were asked to use lesson plans, (c) beliefs about the importance of lesson planning, and 
(d) how prepared they felt to use lesson plans while student teaching and during their first year of teaching." For the second study, posed this question: Would novices' rehearsals be judged differently based upon two different methods of preparation (PCK, and CK)? To answer the primary and individual investigation research questions, I completed a comprehensive review of literature (Chapter Two), a survey on undergraduate music education majors' perceptions of lesson planning (Chapter Three), and an experimental study involving undergraduate instrumental conductors' rehearsal preparation and subsequent rehearsal effectiveness (Chapter Four). The following section highlights major findings from each of the investigations.

\section{Major Findings}

\section{Literature Review}

Although rehearsal preparation strategies have been the topic of investigations (Conway, 2002; Lane, 2010; Lane \& Talbert, 2015; Millican, 2013; Montemayor, Silvey, Adams, \& Witt, 2016; Silvey \& Montemayor, 2014), there are still many components of lesson planning, such as the use of PCK and CK in lesson planning instruction and how preservice teacher prepare to instruct a course, that have not been explored with developing preservice teachers. More specifically, researchers have investigated how lesson planning (Brittin, 2005; Lane \& Talbert, 2015; Schmidt, 2005), score study (Lane, 2006, Silvey \& Montemayor, 2014; Silvey, Montemayor, \& Baumgartner, 2017), conducting instruction (Forrester, 2015; Manfredo, 2008; Silvey, 2011b), and pedagogical content knowledge (Ballantyne \& Packer, 2004; Haston \& Leon-Guerrero, 2008; Millican, 2009, 2016a) have influenced preservice music teacher preparation. Given the number of researchers that have explored lesson preparation in both general 
education and music education contexts, in the review of literature I described important issues in preservice teachers' development including knowledge of teaching, music content knowledge, pedagogical content knowledge, and lesson planning, as well as offered possible applications to help better prepare instrumental music teachers.

Although many aspects of teaching may improve with experience, it seems possible to equip preservice teachers with lesson planning methods to help them be more successful during their undergraduate courses. Teachers may be able to create more meaningful lesson plans by using the concept of teacher knowledge. These concepts could include CK, general pedagogical knowledge, curriculum knowledge, PCK, knowledge of students and their characteristics, and knowledge of educational contexts (see Ballantyne \& Packer, 2004; Millican, 2008; Shulman, 1986, 1987). Considering the amount of time that many teachers spend in planning, novice teachers may benefit from more explicit $\mathrm{CK}$ and PCK instruction in their undergraduate music education preparation programs. If preservice teachers are better able to implement the preparation skills that they have learned as undergraduates, then it is possible that they will have more success executing lessons plans.

\section{Survey Study}

To investigate preservice music teachers' beliefs about lesson planning, I surveyed junior and senior music education majors in the Midwestern region of the United States. Respondents $(N=107)$ were from NASM accredited colleges and universities from Missouri and its contiguous states that were (a) listed as public or private and (b) offered a bachelor of music education degree (NASM, 2015). I sent recruitment messages to each music education coordinator at the institutions in the 
aforementioned states. These professors acted as "gatekeepers" and forwarded the recruitment message (with a hyperlink to the IRB-approved survey) to prospective participants at their school. From the total number of music education coordinators contacted $(N=126), 43(34.1 \%)$ agreed to forward the online survey to approximately 465 students. A total of 107 completed surveys met my requirements, yielding a 23.01\% response rate.

The respondents in this study indicated that they anticipated using lesson plans during their student teaching internship and first year of teaching. The majority of respondents also believed that elementary music teachers should plan daily, whereas secondary music teachers should plan weekly, with no respondent selecting the option "do not plan." This finding, however, could be due to the participants in the present study being surveyed about lesson planning instead of being asked to write their own lesson plans similar to previous studies (Brittin, 2005; Schmidt, 2005). I asked the respondents about their opinions of why lesson plans are used (that is, ranking why lesson plans are needed from most important to least important). Results indicated that respondents most frequently chose to use lesson plans when preparing for ensemble rehearsals, indicating that respondents think that preparing to lead a rehearsal is important.

I also surveyed respondents about which courses, undergraduate music education, general education, and music method courses, required the use of lesson plans. Results indicated that respondents were taught and used lesson planning more frequently in music education classes than in either music method or general education courses. Fewer respondents reported that music method course instructors taught or asked them to use lesson plans when compared to music education instructors. Consonant with previous 
literature (Shorner-Johnson, 2015a, 2015b; Shorner-Johnson \& Moret, 2015), respondents $(n=94)$ indicated they were asked to write lesson plans using specific templates in their music education classes. Respondents indicated that "evaluation and assessments" were the most frequently addressed component of lesson plans, followed by “objectives," "rehearsal techniques," "score study," and "lesson sequencing/procedures." Shorner-Johnson (2015a, 2015b) found similar results with "objectives" being selected as the most frequently used component of lesson planning in his survey of music teacher educators who prepared preservice teachers to use lesson plans.

\section{Experimental Study}

I investigated the effect of CK and PCK on novices' rehearsal preparation. Two comparable groups of freshman and sophomore instrumental music majors participated in this experiment. Each group completed a two-hour intensive rehearsal preparation class. During the first hour, each group was taught identical basic conducting and score study preparation procedures. The CK group then had an additional hour of score study practice, while the PCK group was taught how to devise and implement several rehearsal techniques in an ensemble setting. Participants prepared independently for a five-minute rehearsal for an additional week after the two-hour training session. No significant differences were found for any of the three dependent measures, including ensemble members', expert evaluators', and participants' self-evaluation of score knowledge or rehearsal effectiveness.

After their rehearsals, each conductor was asked to answer the following three questions: (1) How prepared did you feel to lead the rehearsal? Why?; (2) What were the strongest aspects of your rehearsal? Why?; and (3) What were the weakest aspects of 
your rehearsal? Why? To analyze these comments descriptively, I adopted coding procedures similar to those used in prior investigations (Price \& Mann, 2011; Silvey 2011; Silvey \& Fisher, 2015). Conductors' written comments regarding their preparedness and teaching effectiveness were slightly different for each method of preparation, with $\mathrm{CK}$ conductors writing more negative comments, whereas PCK conductors wrote more positive comments.

\section{Discussion}

The investigations in this dissertation were conducted to better understand undergraduate music majors' perceptions of lesson and rehearsal planning. Through the three investigations, I sought to answer my primary research question in multiple ways (i.e., a comprehensive literature review, a survey to preservice teachers, and an experimental study on rehearsal preparation methods). Preservice teachers seem to find planning necessary when preparing for teaching. However, no significant differences were found between CK and PCK preparation methods.

A sub-question that I sought to answer was in which courses were preservice teachers taught preservice teachers how to plan and which courses asked them to use those plans? I asked respondents about which music education, music method, and general education courses required the use of lesson plans. Results from my studies indicated that respondents were taught and used lesson planning more frequently in music education classes than either music method or general education courses. Perhaps those who are involved in the planning process in secondary ensemble courses believe there is not a need for a specific template, but rather the focus needs to be on score study or creating an aural image of the music that is to be conducted. This claim seems to have 
merit, as there were no significant differences between conductors in either the CK (score study) or PCK (rehearsal techniques) groups in Chapter Four, perhaps indicating that a combination of both techniques could be beneficial in developing undergraduates' rehearsal techniques.

In line with previously cited investigations (Shorner-Johnson, 2015a, 2015b; Shorner-Johnson \& Moret, 2015), respondents $(n=94)$ indicated they were asked to write lesson plans using specific templates in their music education classes. The mostfrequently selected lesson template used was “detailed lesson planning," followed by "course specific plans," and "state specific" plans. No specific preparation method, however, yielded better results for either rehearsal effectiveness or score study ratings, similar to the results found by Silvey and Montemayor (2014). Even though a detailed lesson plan seems to be the preferred preparation method used by music teacher educators, it is not clear what components of these plans are the most helpful. Additional research is needed in this area to further understand how the details of a lesson plan may influence novices' rehearsal effectiveness.

Most respondents selected that they thought a combination of score study and lesson planning was important for preparing for secondary ensemble rehearsals $(79.4 \%)$. This is interesting because most of the conductors' written comments also indicated that they felt prepared to rehearse the ensemble, regardless of preparation method. The fact that undergraduate music majors recognized the importance of rehearsal preparation seems encouraging. Researchers should consider experiments using CK and PCK preparation strategies in order to see how these may influence novice conductors' perception of the planning process for secondary ensemble rehearsals. A more general 
approach to teaching lesson planning where students are given multiple opportunities to use both CK and PCK methods seems to be important.

Music teacher educators can use findings from each of these studies to further understand instructional strategies that novice teachers use and possibly better prepare them to instruct the courses they will eventually teach. Researchers should consider replicating these studies with greater number of participants, with multiple institutions, and for a longer period of time. For example, in the rehearsal skills investigation, researchers might expand to include multiple institutions as well as several rehearsals, similar to Montemayor, Silvey, Adams, and Witt (2016). The survey investigation could be expanded to include a larger geographical area as to involve more undergraduate music education majors throughout the United States. By better understanding the various ways music teachers prepare to teach, teacher educators could structure their undergraduate courses to involve more modeling of explicit preparation processes, such as score study, rehearsal techniques, and lesson planning.

Respondents' perceptions seem to be contrary to previous research that suggests preservice teachers tend to find planning unnecessary (Brittin, 2005; Schmidt, 2005). Nearly all the novice conductors in who participated in the experiment commented that they felt prepared to rehearse after attending either of the two experimental preparation sessions, and most of the preservice music teachers surveyed indicated they felt prepared to use lesson plans when they enter the first year of teaching ("strongly agreed" $44.6 \%$; "agree" $43 \%$ ). I view these as positive results because it seems that preservice teachers are receiving adequate lesson and rehearsal planning instruction by music teacher educators. 
It is important to recognize several limitations of these investigations. First, I recognize that separating $\mathrm{CK}$ and PCK methods may not be possible in a teaching setting. Perhaps, these two components should not be separated in teacher educator programs, and should be taught in a more inclusive approach. Even so, future researchers might investigate if any differences exist between a CK, PCK, or a combination of both preparation methods. Secondly, the participants in the experiment were freshman and sophomore music majors with little conducting experience. Perhaps more experienced conductors would yield different results. Junior participants were included in survey study, who may not have taken enough education courses to accurately respond to each question. Lastly, the low response rate of $23.01 \%$ in the survey, along with the small number of participants in the experiment, warrant caution regarding the generalizability of the results found in this dissertation.

\section{Suggestions for Teacher Educators}

Expert teachers agree that preparing to teach lessons is important (Bauer \& Berg, 2001; Fredrickson, Geringer, \& Pope, 2013; Teachout, 1997). In the present investigations, novice conductors in both CK and PCK groups commented that they felt prepared to lead a rehearsal (Chapter Four), and junior and senior music education majors recorded that planning and score study were equally important (Chapter Three). Similar to previous research findings, responses to the survey (Chapter Three) indicated that students were taught to use specific templates in the courses, that specific components of lesson plans were also taught, and students believed that lesson planning was important (Shorner-Johnson \& Moret, 2015). Likewise, conductors (Chapter Four) responded that they felt more prepared when they were taught specific rehearsal preparation strategies. 
Components of PCK (e.g., rehearsal techniques planning) and CK (e.g., score study, conducting mechanics) in undergraduate courses such as rehearsal techniques might improve preservice teachers' knowledge of preparing to teach a music class. Perhaps as Silvey and Montemayor (2014) suggested, teacher educators should develop novice teachers' overall rehearsal and conducting skills in a more "holistic manner" by including multiple ways to prepare a lesson (p. 172). Combining PKC and CK in teacher preparation courses might help music teachers better prepare for the difficult task of teaching music.

Although a large number of respondents indicated they will use lesson plans in the future, fewer indicated that lesson planning was taught, or even used, in some of their education courses. Since these results indicated that objective-based plans are being taught in undergraduate education coursework, music teacher educators should perhaps go farther than teaching the procedures of lesson planning, and help improve preservice teachers' understanding of why a lesson is being taught by showing them how to think through specific aspects of the procedures. I suggest that undergraduate music teacher educators consider requiring their students to provide evidence of planning during their courses, similar to the recommendation made by Silvey, Springer, and Eubanks (2016) about incorporating evidence of score study in undergraduate conducting and rehearsal technique courses. Additionally, it is reasonable to believe that novices may require more individualized guidance in preparing to teach music courses. Future researchers might consider expanding this study to include multiple rehearsals, with limited feedback before each rehearsal like previous investigations (Lane, 2010; Lane \& Talbert, 2013). A greater number of participants (e.g., all junior and senior music education majors who are 
members of NAfME or more conductors in each group) also warrants future investigations.

Since music teacher educators often indicate that limited undergraduate teaching experiences negatively affect undergraduates' instructional skills (Ballantyne, 2006;

Romines, 2003; Silvey, 2011b), music teacher educators should try to design courses that give their students more frequent teaching opportunities, utilizing objective-based lesson planning involving both CK and PCK components. This could include partnerships with local schools where students are required to score study and have planned rehearsal techniques in advance of their teaching, instructing after school music classes, conducting or coaching small chamber ensembles, or being given more opportunities to learn about lesson planning, score study, and rehearsal strategies and the application of these techniques in their undergraduate music courses.

\section{Conclusion}

This dissertation was designed to investigate how preservice music teachers perceive lesson and rehearsal planning. Based on the data collected, undergraduate music education majors seem to perceive lesson planning as important. Furthermore, instrumental music education majors who participated in either of the two different planning processes commented they felt prepared to teach their rehearsal. Although there were no significant differences between the experimental groups in the study reported in Chapter Four, it is encouraging to see that most conductors felt positive about their preparation process and the rehearsal itself. Further research to clarify what specific components, such as CK, PCK, and lesson development, best help preservice teachers conduct a rehearsal seems warranted to find if there are any significant differences 
preservice music teachers in their preparation procedures. The majority of lesson preparation investigations - similar to the ones completed in this dissertation-focus on preservice teachers and teacher educators (e.g, Lane \& Talbert, 2013; Schmidt, 2005, Shorner-Johnson \& Moret, 2015; Silvey \& Montemayor, 2014). Perhaps expanding these investigations to include the perceptions of inservice teachers could help fill the gap in the research on teaching preparation. The findings of this study indicated that when preservice teachers are exposed to certain activities (such as both CK and PCK) they might have a better chance of success in instructing their music courses because they have multiple opportunities to practice these skills. 


\section{References}

Abeles, H. F., Hoffer, C. R., \& Klotman, R. H. (1994). Foundations of music education. New York, NY: Schirmer.

Austin, J. R. (2006). The teaching of secondary instruments a survey of instrumental music teacher educators. Journal of Music Teacher Education, 16(1), 55-65. doi:10.1177/10570837060160010107

Ball, D. L. (1990). The mathematical understandings that prospective teachers bring to teacher education. The Elementary School Journal, 90(4), 449-466. doi:10.1086/461626

Ball, D. L. (1993). With an eye on the mathematical horizon: Dilemmas of teaching elementary school mathematics. The Elementary School Journal, 93(4), 373397. doi:10.1086/461730

Ball, D. L. (2000). Bridging practices intertwining content and pedagogy in teaching and learning to teach. Journal of Teacher Education, 51(3), 241-247. doi:10.1177/0022487100051003013

Ball, D. L., \& McDiarmid, G. W. (1990). The subject matter preparation of teachers. In W. R. Houston (Ed.), Handbook of research on teacher education (pp. 437449). New York, NY: Macmillan.

Ball, D. L., Bass, H., Hill, H., \& Schilling, S. (2005). Developing measures of mathematical knowledge for teaching. In Teachers Development Group Leadership Seminar. Portland, OR: Teachers Development Group

Ball, D. L., Hill, H. C., \& Bass, H. (2005). Knowing mathematics for teaching. American Educator, 29(3), 14-17, 20-22, 43-46. 
Ball, D. L., Sleep, L., Boerst, T. A., \& Bass, H. (2009). Combining the development of practice and the practice of development in teacher education. The Elementary School Journal, 109(5), 458-474. doi:10.1086/596996

Ball, D. L., Thames, M. H., \& Phelps, G. (2008). Content knowledge for teaching what makes it special? Journal of Teacher Education, 59(5), 389-407. doi:10.1177/0022487108324554

Ballantyne, J. (2006). Reconceptualising preservice teacher education courses for music teachers: The importance of pedagogical content knowledge and skills and professional knowledge and skills. Research Studies in Music Education, 26(1), 37-50. doi:10.1177/1321103X060260010101

Ballantyne, J., \& Packer, J. (2004). Effectiveness of preservice music teacher education programs: Perceptions of early-career music teachers. Music Education Research, 6(3), 299-312. doi:10.1080/1461380042000281749.

Barry, N. H. (1996). Promoting reflective practice in an elementary music methods course. Journal of Music Teacher Education, 5(2), 6-13. doi:10.1177/105708379600500203

Battisti, F., \& Garofalo, R. J. (1993). Suggestions for marking the score. In F. Fennel \& H. Begian (Eds), Conductors Anthology (Vol. 2, pp. 279-282). Northfield, IL: Instrumentalist Co.

Bauer, W. I. (2013). The acquisition of musical technological pedagogical and content knowledge. Journal of Music Teacher Education, 22(2), 51-64. doi:10.1177/1057083712457881 
Bauer, W. I., \& Berg, M. H. (2001). Influences on instrumental music teaching. Bulletin of the Council for Research in Music Education, 150, 53-66.

Baumert, J., Kunter, M., Blum, W., Brunner, M., Voss, T., Jordan, A., ... Tsai, Y. M. (2010). Teachers' mathematical knowledge, cognitive activation in the classroom, and student progress. American Educational Research Journal, 47(1), 133-180. doi:10.3102/0002831209345157

Bednarz, N., \& Proulx, J. (2009). Knowing and using mathematics in teaching: conceptual and epistemological clarifications. For the Learning of Mathematics, $29(3), 11-17$.

Beijaard, D., Verloop, N., \& Vermunt, J. D. (2000). Teachers' perceptions of professional identity: An exploratory study from a personal knowledge perspective. Teaching and Teacher Education, 16(7), 749-764.

doi:10.1016/S0742-051X(00)00023-8

Bloom, B. S., Engelhart, M. D., Furst, F. J., Hill, W. H., \& Krathwohl, D. R. (1956). Taxonomy of educational objectives: Book 1: Cognitive domain. New York: David McKay Company.

Borko, H., \& Livingston, C. (1989). Cognition and improvisation: Differences in mathematics instruction by expert and novice teachers. American Educational Research Journal, 26(4), 473-498. doi:10.3102/00028312026004473

Borko, H., Livingston, C., \& Shavelson, R. J. (1990). Teachers' thinking about instruction. Remedial and Special Education, 11(6), 40-49. doi:10.1177/0027432114553016 
Boshkoff, R. (1991). Lesson planning the Kodály way. Music Educators Journal, 78(2), 30-34. doi:10.2307/3398257

Branscome, E. E. (2014). Concert programming and performing as a model for lesson planning and teaching. Music Educators Journal, 101(2), 71-75. doi: $10.1177 / 0027432114553016$

Brittin, R. V. (2005). Preservice and experienced teachers' lesson plans for beginning instrumentalists. Journal of Research in Music Education, 53, 26-39. doi:10.1177/002242940505300103

Bromme, R. (1995). What exactly is pedagogical content knowledge? Critical remarks regarding a fruitful research program. In S. Hopmann (Ed), Didaktik And/or Curriculum: An International Dialogue. (pp. 205-216). New York, NY: P. Lang

Butler, A. (2001). Preservice music teachers' conceptions of teaching effectiveness, microteaching experiences, and teaching performance. Journal of Research in Music Education, 49, 258-272. doi:10.2307/3345711

Clark, C. M. (1988). Asking the right questions about teacher preparation: Contributions of research on teacher thinking. Educational Researcher, 17(2), 5-12. doi:10.3102/0013189X017002005

Clark, C. M., \& Peterson, P. L. (1984). Teachers' thought processes. Occasional Paper No. 72 . Retrieved from http://eric.ed.gov/?id=ED251449

Clark, C. M., \& Yinger, R. J. (1979). Three studies of teacher planning. Research Series No. 55. Retrieved from http://eric.ed.gov/?id=ED175855 
Clift, R. T., \& Brady, P. (2005). Research on methods courses and field experiences. In M. Cochran-Smith \& K. M. Zeihner (Eds), Studying Teacher Education: The Report of the AERA Panel on Research and Teacher Education (pp. 309-424). Washington D.C: AERA Teams with L. Erlbaum.

Cohen, J. (1988). Statistical Power Analysis for the Behavioral Sciences. 2nd ed. Hillsdale, NJ: L. Erlbaum.

Colwell, R. J., \& Hewitt, M. P. (2011). The teaching of instrumental music (4th ed.). Boston, MA: Prentice Hall.

Conway, C. (2002). Perceptions of beginning teachers, their mentors, and administrators regarding preservice music teacher preparation. Journal of Research in Music Education, 50, 20-36. doi:10.2307/3345690

Crowe, D. R. (1996). Effects of score study style on beginning conductors' errordetection abilities. Journal of Research in Music Education, 44, 160-171. doi: $10.2307 / 3345668$

de Frece, R. (2010). Planning for success: Optimizing your teaching. General Music Today, 24(1), 32-40. doi:10.1177/1048371310368485

DeCarbo, N. J. (1982). The effects of conducting experience and programmed materials on error-detection scores of college conducting students. Journal of Research in Music Education, 30, 187-200. doi:10.2307/3345085

DeLorenzo, L. C. (1990). Early field experiences in the community. Music Educators Journal, 77(3), 51-53. doi:10.2307/3397840

Denzin, N. K., \& Lincoln, Y. S. (2005). The Sage handbook of qualitative research. Thousand Oaks, CA: Sage. 
Depaepe, F., Verschaffel, L., \& Kelchtermans, G. (2013). Pedagogical content knowledge: A systematic review of the way in which the concept has pervaded mathematics educational research. Teaching and Teacher Education, 34, 12-25. doi:10.1016/j.tate.2013.03.001

Dewey, J. (1904). The educational situation. Chicago, IL: University of Chicago Press.

Dorovolomo, J., Phan, H. P., \& Maebuta, J. (2010). Quality lesson planning and quality delivery: Do they relate? The International Journal of Learning, 17(3), 447456.

Ellis, B. L. (1994). Selected band conductors' preparation to conduct selected band compositions (Doctoral Dissertation). Retrieved from ProQuest Dissertations Publishing. (UMI No. 9503182)

Emerich, D. J. (2015). Evidence of pedagogical content knowledge among high school band directors and university applied music teachers in the context of student self-evaluation (Unpublished master's thesis). University of Alabama, Tuscaloosa, Alabama

Ferrell, B. G. (1992). Lesson plan analysis as a program evaluation tool. Gifted Child Quarterly, 36(1), 23-26. doi:10.1177/001698629203600106

Forrester, S. H. (2015). Music teacher knowledge: An examination of the intersections between instrumental music teaching and conducting (Doctoral dissertation). Retrieved from ProQuest Dissertations Publishing. (UMI No. 3731290).

Forsythe, J. L., \& Woods, J. R. (1983). The effects of conducting on the error detection ability of undergraduate and graduate instrumental conductors. Contributions to Music Education, (10), 27-32. 
Fredrickson, W. E., Geringer, J. M., \& Pope, D. A. (2013). Attitudes of string teachers and performers toward preparation for and teaching of private lessons. Journal of Research in Music Education, 61, 217-232. doi:10.1177/0022429413485245

Gauthier, D., \& McCrary, J. (1999). Music courses for elementary education majors: An investigation of course content and purpose. Journal of Research in Music Education, 47, 124-134. doi:10.2307/3345718

Gess-Newsome, J. (1999). Pedagogical content knowledge: An introduction and orientation. In J. Gess-Newsome \& N. G. Lederman (Eds), Examining pedagogical content knowledge (pp. 3-17). Berlin, Germany: Springer.

Gohlke, L. J. (1994). The music methods class: Acquisition of pedagogical content knowledge by preservice music teachers. (Doctoral dissertation). ProQuest Dissertations Publishing. (UMI No. 9504621)

Goolsby, T. W. (1999). A comparison of expert and novice music teachers' preparing identical band compositions: An operational replication. Journal of Research in Music Education, 47, 174-187. doi:10.2307/3345722

Green, E. A. H., \& Gibson, M. (2004). The modern conductor (7th ed.). Upper Saddle River, NJ: Prentice Hall.

Grossman, P. (1990). The making of a teacher: Teacher knowledge and teacher education. New York, NY: Teachers College Press.

Hall, T. J., \& Smith, M. A. (2006). Teacher planning, instruction and reflection: What we know about teacher cognitive processes. Quest, 58(4), 424-442. doi:10.1080/00336297.2006.10491892 
Harwood, E., \& Wiggins, J. (2001). Composing a lesson: Examining our metaphors. The Mountain Lake Reader, 1(2), 32-41.

Haston, W., \& Leon-Guerrero, A. (2008). Sources of pedagogical content knowledge reports by preservice instrumental music teachers. Journal of Music Teacher Education, 17(2), 48-59. doi:10.1177/1057083708317644

Hill, H. C., Ball, D. L., \& Schilling, S. G. (2008). Unpacking pedagogical content knowledge: Conceptualizing and measuring teachers' topic-specific knowledge of students. Journal for Research in Mathematics Education, 39(4), 372-400.

Hill, H. C., Schilling, S. G., \& Ball, D. L. (2004). Developing measures of teachers' mathematics knowledge for teaching. The Elementary School Journal, 105(1), 11-30. doi:10.1086/428763

Hill, J., Yinger, R., \& Robins, D. (1983). Instructional planning in a laboratory preschool. Elementary School Journal, 83(3), 182-193. doi:10.1086/461308

Hunsberger, D. (1988). Score study and preparation. In F. Fennel \& H. Begian (Eds), Conductors Anthology (Vol. 2, pp. 282-295). Northfield, IL: Instrumentalist Co.

Hunsberger, D., \& Ernst, R. (1992). The art of conducting (2 ${ }^{\text {nd }}$ ed.). New York, NY: McGraw Hill, Inc.

Hunter, M. (1979). Teaching is decision making. Educational Leadership, 37(1), 62-67.

Hunter, M. C. (1982). Mastery teaching. Thousand Oaks, CA: Corwin Press.

John, P. D. (2006). Lesson planning and the student teacher: Re-thinking the dominant model. Journal of Curriculum Studies, 38(4), 483-498. doi:10.1080/00220270500363620. 
Johnson, C. M., \& Fredrickson, W. E. (1995). The effect of aural commentary, written comments, and behavioral self-assessment on conductor intensity. Journal of Band Research, 30(2), 27.

Jorgensen, E. R. (2002). The aims of music education: A preliminary excursion. Journal of Aesthetic Education, 36(1), 31-49. doi:10.2307/3333624

Kaplan, L. S., \& Owings, O., W. A. (2002). Teacher quality, teaching quality, and school improvement. Bloomington, IN: Phi Delta Kappa International Press.

Kearns, R. E. (2011). Quick reference for band directors. Lanham, MD: Rowman \& Littlefield.

Kennedy, M. M. (1998). Education reform and subject matter knowledge. Journal of Research in Science Teaching, 35(3), 249-263. doi:10.1002/(SICI)1098$2736(199803) 35$

Kennedy, M. M. (2010). Attribution error and the quest for teacher quality. Educational Research, 39(8), 591-598. doi:10.3102/0013189X10390804

Kind, V. (2009). Pedagogical content knowledge in science education: Potential and perspectives for progress. Studies in Science Education, 45(2), 169-204. doi:10.1080/03057260903142285

Koehler, M., \& Mishra, P. (2009). What is technological pedagogical content knowledge (TPACK)? Contemporary Issues in Technology and Teacher Education, 9(1), 60-70.

Krathwohl, D. R. (2002). A revision of Bloom's taxonomy: An overview. Theory into Practice, 41(4), 212-218. 
Labuta, J. A. (2010). Basic conducting techniques (6th ed.). Englewood Cliffs, NJ: Prentice-Hall.

Lane, J. S. (2006). Undergraduate instrumental music education majors' approach to score study in various musical contexts. Journal of Research in Music Education, 54, 215-230. doi:10.1177/002242940605400305

Lane, J. S. (2010). An analysis of relationships between lesson planning training and rehearsal pacing of undergraduate instrumental music education majors in practice teaching settings. Journal of Band Research, 46(1), 52-63.

Lane, J. S., \& Talbert, M. D. (2015). Examining lesson plan use among instrumental music education majors during practice teaching. Journal of Music Teacher Education, 24(3), 83-96. doi:10.1177/1057083713514979

Lee, E., Brown, M. N., Luft, J. A., \& Roehrig, G. H. (2007). Assessing beginning secondary science teachers' PCK: Pilot year results. School Science and Mathematics, 107(2), 52-60. doi:10.1111/j.1949-8594.2007.tb17768.x

Lee, Y. (2011). Enhancing pedagogical content knowledge in a collaborative schoolbased professional development program for inquiry-based science teaching. Asia-Pacific Forum on Science Learning and Teaching, 12(2), 1-29.

Leinhardt, G. (1989). Math lessons: A contrast of novice and expert competence. Journal for Research in Mathematics Education, 20(1), 52-75. doi: $10.2307 / 749098$

Loughran, J., Berry, A., \& Mulhall, P. (2012). Understanding and developing science teachers' pedagogical content knowledge (2nd ed.). Boston, MA: Sense Publishers. 
Maclin, J. P. (1993). The effect of task analysis on sequential patterns of music instruction. Journal of Research in Music Education, 41, 48-56. doi: $10.2307 / 3345479$

Magnusson, S., Krajcik, J., \& Borko, H. (1999). Nature, sources, and development of pedagogical content knowledge for science teaching. In J. Gess-Newsome \& N. G. Lederman (Eds.), Examining pedagogical content knowledge (pp. 95-132). Berlin, Germany: Springer.

Manfredo, J. (2008). Factors influencing curricular content for undergraduate instrumental conducting courses. Bulletin of the Council for Research in Music Education, 43-57.

Marks, R. (1990). Pedagogical content knowledge: From a mathematical case to a modified conception. Journal of Teacher Education, 41(3), 3-11. doi:10.1177/002248719004100302

Mayne, R. G. (1992). An investigation of the use of facial expression in conjunction with musical conducting gestures and their interpretation by instrumental performers (Doctoral Dissertation). ProQuest Dissertations Publishing. (UMI No. 9238229)

McCutcheon, G. (1980). How do elementary school teachers plan? The nature of planning and influences on it. The Elementary School Journal, 81(1), 4-23. doi:10.1086/461201

Miles, R. (Ed.). (1997-2007). Teaching music through performance in band (Vols. 16). Chicago, IL: GIA. 
Millican, J. S. (2008). A new framework for music education knowledge and skill. Journal of Music Teacher Education, 18(1), 67-78. doi:10.1177/1057083708323146

Millican, J. S. (2009). Band and orchestra teachers' rankings of general pedagogical knowledge and skill. Journal of Music Teacher Education, 19(1), 68-79. doi:10.1177/1057083709344045

Millican, J. S. (2012). Starting out right: Beginning band pedagogy. Lanham, MD, Scarecrow Press.

Millican, J. S. (2013). Describing instrumental music teachers' thinking implications for understanding pedagogical content knowledge. Update: Applications of Research in Music Education, 31(2), 45-53. doi:10.1177/8755123312473761

Millican, J. S. (2016a). Describing preservice instrumental music educators' pedagogical content knowledge. Update: Applications of Research in Music Education, 34(2), 61-68. doi:10.1177/8755123314552664

Millican, J. S. (2016b). Examining pedagogical content knowledge of an expert band director teaching lips slurs. Journal of Music Teacher Education, Advance Online, 1-14. doi:10.1177/1057083716629610

Mishra, P., \& Koehler, M. (2006). Technological pedagogical content knowledge: A framework for teacher knowledge. The Teachers College Record, 108(6), 10171054. doi:10.1111/j.1467-9620.2006.00684.x

Montemayor, M., \& Moss, E. A. (2009). Effects of recorded models on novice teachers' rehearsal verbalizations, evaluations, and conducting. Journal of Research in Music Education, 57, 236-251. doi:10.1177/0022429409343183 
Montemayor, M., Silvey, B. A., Adams, A. L., \& Witt, K. L. (2016). Effects of internal and external focus of attention during novices' instructional preparation on subsequent rehearsal behaviors. Journal of Research in Music Education, 63, 455-468. doi:10.1177/0022429415612201

Morine-Dershimer, G. (1979). Teacher plan and classroom reality: The south bay study, part IV. Research Series No. 60. Retrieved from http://eric.ed.gov/?id=ED191796

Mroziak, J., \& Bowman, J. (2016a). Educating the educators. In M. C. Herring, M. J. Koehler, \& P. Mishra (Eds.), Handbook of Technological Pedagogical Content Knowledge (TPACK) for Educators (203). New York, NY: Routledge.

Mroziak, J., \& Bowman, J. (2016b). Music TPACK in higher education. In M. C. Herring, M. J. Koehler, \& P. Mishra (Eds.), Handbook of Technological Pedagogical Content Knowledge (TPACK) for Educators (285-308). New York, NY: Routledge.

Mutton, T., Hagger, H., \& Bum, K. (2011). Learning to plan, planning to learn: The developing expertise of beginning teachers. Teachers and Teaching: Theory and Practice, 17(4), 399-416. doi:10.1080/13540602.2011.580516

NASM. (2015). State accredited institutions. Reston, VA: NASM. Retrieved from http://nasm.arts-accredit.org/index.jsp?page=List_Accredited_Members

Okpala, C. O., \& Ellis, R. (2005). The perceptions of college students on teacher quality: A focus on teacher qualifications. Education, 126(2), 374-383.

Panasuk, R. M., \& Todd, J. (2005). Effectiveness of lesson planning: Factor analysis. Journal of Instructional Psychology, 32(3), 215-232. 
Paul, S. J. (1998). The effects of peer teaching experiences on the professional teacher role development of undergraduate instrumental music education majors. Bulletin of the Council for Research in Music Education, (137), 73-92.

Phelps, G., \& Schilling, S. (2004). Developing measures of content knowledge for teaching reading. The Elementary School Journal, 105(1), 31-48. doi:10.1086/428764

Price, H. E., \& Byo, J. L. (2002). Rehearsing and conducting. In R. Parncutt \& G. E. McPherson (Eds.), The science and psychology of music performance: Creative strategies for teaching and learning (pp. 335-351). New York, NY: Oxford University Press.

Price, H. E., \& Mann, A. M. (2011). The effect of conductors on ensemble evaluations. Bulletin of the Council for Research in Music Education, (189), 57-72. doi:10.5406/bulcouresmusedu.189.0057

Raiber, M., \& Teachout, D. (2014). From music student to teacher. New York, NY: Routledge.

Reese, J. A., Bicheler, R., \& Robinson, C. (2016). Field experiences using iPads impact of experience on preservice teachers' beliefs. Journal of Music Teacher Education, 26(1), 96-11. doi:10.1177/1057083715616441

Rice, A. M. (2015). Shaping pedagogical content knowledge for experienced agriculture teachers in the plan sciences: A grounded theory (Unpublished doctoral dissertation). University of Missouri, Columbia, MO

Romines, F. D. (2003). A survey of undergraduate instrumental conducting curricula. Journal of Band Research, 38(2), 80-90. 
Rowan, B., Schilling, S. G., Ball, D. L., Miller, R., Atkins-Burnett, S., \& Camburn, E. (2001). Measuring teachers' pedagogical content knowledge in surveys: An exploratory study. Presented at the Ann Arbor: Consortium for Policy Research in Education, University of Pennsylvania.

Saderholm, J., Ronau, R., Brown, E. T., \& Collins, G. (2010). Validation of the diagnostic teacher assessment of mathematics and science (DTAMS) instrument. School Science and Mathematics, 110(4), 180-192. doi:10.1111/j.1949-8594.2010.00021.x

Sardo-Brown, D. (1988). Twelve middle-school teachers' planning. The Elementary School Journal, 89(1). 69-87. doi:10.1086/461563

Savage, J. (2014). Lesson Planning: Key concepts and skills for teachers. New York, NY: Routledge.

Schmidt, M. (2005). Preservice string teachers' lesson planning processes: An exploratory study. Journal of Research in Music Education, 53, 6-25. doi:10.1177/002242940505300102

Scott, S. J. (2011). Constructivist perspectives for developing and implementing lesson plans in general music. General Music Today, 25(2), 24-30. doi:10.1177/1048371311398285

Shorner-Johnson, K. (2015a). Rehearsal planning in secondary music method courses: Teacher educator perspectives. Poster Session presented at the Symposium on Music Teacher Education. University of North Carolina at Greensboro, Greensboro, NC. 
Shorner-Johnson, K. (2015b). Teacher educators' beliefs about general/elementary music lesson planning. Poster Session presented at the Symposium on Music Teacher Education. University of North Carolina at Greensboro, Greensboro, NC.

Shorner-Johnson, K., \& Moret, L. (2015). Curricular planning in music education. In M. R. Campbell and L. K. Thompson Analyzing influences: Research on decision making and the music education curriculum (pp. 21-44). Charlotte, North Carolina: Information Age Publishing.

Shulman, L. S. (1986). Those who understand: Knowledge growth in teaching. Educational Researcher, 15(2), 4-14. doi:10.3102/0013189X015002004

Shulman, L. S. (1987). Knowledge and teaching: Foundations of the new reform. Harvard Educational Review, 57(1), 1-23. doi:10.17763/haer.57.1.j463w79r56455411

Silverman, J., \& Thompson, P. W. (2008). Toward a framework for the development of mathematical knowledge for teaching. Journal of Mathematics Teacher Education, 11, 499-511. doi:10.1007/s10857-008-9089-5

Silvey, B. A. (2011a). Effects of score study on novices' conducting and rehearsing: A preliminary investigation. Bulletin of the Council for Research in Music Education, (187), 33-48.

Silvey, B. A. (2011b). Undergraduate music majors' perceptions of instrumental conducting curricula. Journal of Music Teacher Education, 21(1), 27-38. doi:10.1177/1057083710387521 
Silvey, B. A., \& Fisher, R. A. (2015). Effects of conducting plane on band and choral musicians' perceptions of conductor and ensemble expressivity. Journal of Research in Music Education, 63, 369-383. doi:10.1177/0022429415597888

Silvey, B. A., \& Montemayor, M. (2014). Effects of internal and external focus of attention on novices' rehearsal evaluations. Journal of Research in Music Education, 62, 161-174. doi:10.1177/0022429414530434

Silvey, B. A., Montemayor, M., \& Baumgartner, C. M. (2017). An observational study of score study practices among undergraduate instrumental music education majors. Journal of Research in Music Education, 65, 52-71. doi: $10.1177 / 0022429416688700$

Silvey, B. A., Springer, D. G., \& Eubanks, S. C. (2016). An examination of university conducting faculty members' score study attitudes and practices. Journal of Music Teacher Education, 26(1), 82-95. doi:10.1177/1057083715616442

Skowron, J. (2001). Powerful lesson planning models. Arlington Heights, IL: Skylight Publishing. Retrieved from http://files.hbe.com.au/samplepages/CO7491.pdf

Snow, S. L. (1998). Rehearsing in the choral context: A qualitative examination of undergraduate conductor/teacher planning processes and relationships to emergent pedagogical knowledge evidenced in teaching (Doctoral dissertation). ProQuest Dissertations Publishing. (UMI No. 9922376)

Standerfer, S. L. (2011). Differentiation in the music classroom. Music Educators Journal, 97(4), 43-48. doi:10.1177/0027432111404078 
Stigler, J. W., \& Hiebert, J. (1999). Understanding and Improving. In J. Barbara \& D Phillips (Eds), Comparing Standards Internationally: Research and Practice in Mathematics and beyond, (pp. 119). Oxford, UK: Symposium Books Ltd

Sullivan, J. M. (1998). Syllabic articulation instruction for woodwinds and its effect on articulation accuracy and ensemble precision. (Unpublished doctoral dissertation). University of Iowa, Iowa City.

Tamir, P. (1988). Subject matter and related pedagogical knowledge in teacher education. Teaching and Teacher Education, 4(2), 99-110. doi:10.1016/0742051X(88)90011-X

Teachout, D. J. (1997). Preservice and experienced teachers' opinions of skills and behaviors important to successful music teaching. Journal of Research in Music Education, 45, 41-50. doi:10.2307/3345464

Thomson, K. W. (2005, October). Focusing on a process - Not a template. School Band and Orchestra Magazine.

Tirosh, D., Tsamir, P., Levenson, E., \& Tabach, M. (2011). From preschool teachers' professional development to children's knowledge: Comparing sets. Journal of Mathematics Teacher Education, 14(2), 113-131. doi:10.1007/s10857-011$9172-1$

Tsui, A. B. (2009). Distinctive qualities of expert teachers. Teachers and Teaching: Theory and Practice, 15(4), 421-439. doi:10.1080/13540600903057179

Tyler, R. W. (1950). Basic principles of curriculum and instruction: Syllabus for Education. Chicago: Syllabus Division. Chicago, IL: University of Chicago Press. 
van Driel, J. H., \& Berry, A. (2012). Teacher professional development focusing on pedagogical content knowledge. Educational Researcher, 41(1), 26-28. doi:10.3102/0013189X11431010

van Driel, J. H., Verloop, N., \& de Vos, W. (1998). Developing science teachers' pedagogical content knowledge. Journal of Research in Science Teaching, 35(6), 673-695. doi:10.1002/(SICI)1098-2736(199808)35:6<673::AIDTEA5 $>3.0 . \mathrm{CO} ; 2-\mathrm{J}$

Venesile, C. J. (2011). The acquisition of pedagogical content knowledge by vocal jazz educators. (Doctoral Dissertation). ProQuest Dissertations Publishing. (UMI No. 3446481)

Villarreal, E. K. (2010). Private lesson teachers' attitudes towards private teaching and preservice education: a replication and extension (Unpublished Master's thesis). Texas Tech University, Lubbock, TX.

Wolfgang, R. E. (1990). Early field experience in music education: A study of teacher role socialization. (Doctoral dissertation). ProQuest Dissertations Publishing. (UMI No. 9117573)

Worthy, M. D. (2005). The effects of self-evaluation on the timing of teacher and student behaviors in lab rehearsals. Journal of Music Teacher Education, 15(1), 8-15. doi:10.1177/10570837050150010103

Yinger, R. J. (1979). Routines in teacher planning. Theory into Practice, 18(3), 163169. doi:10.1080/00405847909542827

Yinger, R. J. (1980). A study of teacher planning. The Elementary School Journal, 80(3), 107-127. doi:10.1086/461181 
Zahorik, J. A. (1975). Teachers' planning models. Educational Leadership, 33(2), 1349.

Zeichner, K. M., \& Tabachnick, B. R. (1981). Are the effects of university teacher education "washed out" by school experience? Journal of Teacher Education, 32(3), 7-11. doi:10.1177/002248718103200302 


\section{Appendix A}

Dr./Professor $\{$ Last Name $\}$ :

My name is Aaron Wacker and I'm a PhD candidate at the University of Missouri. As part of my dissertation, I am conducting a survey on music education majors' perceptions of lesson and rehearsal planning.

In order to reach as many students as possible, I am asking for your assistance in forwarding a recruitment message to all junior and senior music education majors (vocal or instrumental) at your institution.

If you have any questions, please do not hesitate to contact me at xxxxxxx@xxxxxxx.edu or Dr. Brian Silvey at xxxxxxx@xxxxxxx.edu.

If you are willing to send this out to your students, please reply to this email.

Thank you for your assistance,

Aaron T. Wacker

Ladies and Gentlemen:

You are being asked to participate in a research study. In this study, you will complete a survey about your lesson planning preparation. The survey contains questions about your use of lesson plan templates, other forms of curricular planning, and beliefs about lesson/rehearsal planning. The survey will take approximately 10 minutes to complete. Participation in the survey is voluntary. If you have any questions about the study and your potential involvement, please email Aaron T. Wacker at xxxxxxx@xxxxxxx.edu.

Link to the survey:

https://missouri.qualtrics.com/SE/?SID $=\mathrm{SV}$ 74otcbP301fitxP 


\section{Appendix B}

Dr./Professor $\{$ Last Name $\}$ :

This email serves as a reminder about a survey that is detailed below.

My name is Aaron Wacker and I'm a PhD candidate at the University of Missouri. As part of my dissertation, I am conducting a survey on music education majors' perceptions of lesson and rehearsal planning.

In order to reach as many students as possible, I am asking for your assistance in forwarding a recruitment message to all junior and senior music education majors (vocal or instrumental) at your institution.

If you have any questions, please do not hesitate to contact me at xxxxxxx@xxxxxxx.edu or Dr. Brian Silvey at xxxxxxx@xxxxxxx.edu.

If you are willing to forward this survey to your students, please reply to this email with the number of students you will be forwarding this survey to.

Thank you for your assistance,

Aaron T. Wacker

Ladies and Gentlemen:

You are being asked to participate in a research study. In this study, you will complete a survey about your lesson planning preparation. The survey contains questions about your use of lesson plan templates, other forms of curricular planning, and beliefs about lesson/rehearsal planning. The survey will take approximately 10 minutes to complete. The survey will be open for one week. Participation in the survey is voluntary. If you have any questions about the study and your potential involvement, please email Aaron T. Wacker at xxxxxxx@xxxxxxx.edu.

Link to the survey:

https://missouri.qualtrics.com/SE/?SID=SV 74otcbP301fitxP 


\section{Appendix C}

\section{Institutional Review Board University of Missouri-Columbia}

Principal Investigator: Aaron Timothy Wacker Department: School of Music

Your Exempt Application to project entitled An Examination of Senior Music Education Majors' Perception of Lesson Planning Training, Practice, and Efficacy was reviewed and approved by the MU Institutional Review Board according to terms and conditions described below:

$\begin{array}{ll}\text { IRB Project Number } & 2003956 \\ \text { IRB Review Number } & 209318\end{array}$

Initial Application Approval Date October 19, 2015

IRB Expiration Date October 19, 2016

Level of Review Exempt

Project Status Active - Open to Enrollment

Exempt Categories $\quad 45$ CFR 46.101b(2)

Risk Level Minimal Risk

The principal investigator (PI) is responsible for all aspects and conduct of this study. The PI must comply with the following conditions of the approval:

1. No subjects may be involved in any study procedure prior to the IRB approval date or after the expiration date.

2. All unanticipated problems, adverse events, and deviations must be reported to the IRB within 5 days.

3. All changes must be IRB approved prior to implementation unless they are intended to reduce immediate risk.

4. All recruitment materials and methods must be approved by the IRB prior to being used.

5. The Annual Exempt Form must be submitted to the IRB for review and approval at least 30 days prior to the project expiration date. If the study is complete, the Completion/Withdrawal Form may be submitted in lieu of the Annual Exempt Form

6. Maintain all research records for a period of seven years from the project completion date.

7. Utilize all approved research documents located within the attached files section of eCompliance. These documents are highlighted green.

If you have any questions, please contact the IRB at 573-882-3181 or irb@missouri.edu.

Thank you,

MU Institutional Review Board 


\section{Appendix D}

An Examination of Music Education Majors' Perceptions of Lesson Planning

Purpose of this research project: To understand music education majors' beliefs about the use of lesson/rehearsal plans and planning templates in their courses.

Survey Procedure: The survey contains questions about your use of lesson plan templates, other forms of curricular planning, and beliefs about lesson/rehearsal planning. The survey will take approximately 10 minutes to complete. This survey is voluntary to complete.

Risks, Benefits, and Compensation: This study poses minimal risks to participants. The study will benefit an increased understanding of preservice lesson and rehearsal planning. Understandings gained will be used to inform the professional field of practice. You will not be compensated for your participation in this study.

Confidentiality: You will not be required to disclose your identity to complete this survey. No identifying information will be collected during this survey. Only the primary researcher (Aaron T. Wacker) will have access to data and statements gained from this survey.

Investigator: If you have any questions concerning the research project, you may contact Aaron T. Wacker (xxxxxxx@xxxxxxx.edu). Should you have any questions about your participants' rights involved in this research you may contact the University of Missouri Institutional Review Board at xxxxxxx@xxxxxxx.edu.

If you agree to participate, please click the "next" button to enter the survey.

\section{DEMOGRAPHIC INFORMATION}

What is your year in school?

O Junior

Senior

O Other

What is your age?

What is your Gender?

O Male

O Female

O Other 
What is your emphasis?

Instrumental Music Education

O Vocal Music Education

Dual Certification

O Elementary/General Music Education

In which state is your institution located?
O Arkansas
O Illinois
O Iowa
O Kansas
O Kentucky
O Missouri
O Nebraska
O Oklahoma
O Tennessee

Is your university Public or Private?

O Public

O Private

\section{SECTION 1: LESSON PLANNING IN UNDERGRADUATE COURSEWORK.}

1. In which general education courses were you taught how to construct lesson/rehearsal plans? (Check all that apply.)

$\square$ Special Education

- Middle School/High School Field Experience

$\square$ Middle School/High School Methods

Elementary Methods/Field Experience

Elementary Methods

Teaching English to Speakers of Other Languages (TESOL)

$\square$ Reading and Writing in the Content Area

Educational Psychology

F Foundation of Education

Other, please specify

I I was not taught how to design lesson/rehearsal plans in general education courses

2. In which music education courses were you taught how to construct lesson/rehearsal plans? (Check all that apply.)

Introduction to Music Education

General Music Methods 6-12

- General Music Kindergarten-5

- Middle School/High School Music Teaching Methods

$\square$ Instrumental Material and Methods

$\square$ Vocal Material and Methods

$\square$ Other, please specify

I was not taught how to design lesson/rehearsal plans in music education courses 
3. In which music method courses were you taught how to construct lesson/rehearsal plans? (Check all that apply.)

- Basic Conducting

$\square$ Advanced Conducting

$\square$ Rehearsal Clinic

- Percussion Methods

Strings Methods

Guitar Methods

$\square$ Woodwinds Methods

$\square$ Brass Methods

- String Techniques

Marching Band Techniques

- Jazz Methods

$\square$ Other, please specify

I was not taught how to design lesson/rehearsal plans in music method courses

\section{SECTION 2: USE OF LESSON PLANNING IN UNDERGRADUATE COURSE WORK.}

1. In which general education courses were you asked to USE lesson/rehearsal plans? (Check all that apply.)

- Special Education Methods

Middle School/High School Field Experience

- Middle School/High School methods

Elementary Methods/field experience

$\square$ Elementary methods

Teaching English to Speakers of Other Languages (TESOL)

$\square$ Reading and Writing in the Content Area

Education Psychology

$\square$ Foundation of Education

I did not use lesson/rehearsal plans in general education courses

$\square$ Other, please specify

2. In which music education courses were you asked to use lesson/rehearsal plans? (Check all that apply.)

Introduction to Music Education

G General Music Methods 6-12

General Music Kindergarten-5

- Middle School/High School Teaching Music

Instrumental Material and Methods

- Vocal Material and Methods

I did not use lesson plan/rehearsal plans in my music education courses

Other, please specify 
3. In which music method courses were you asked to use lesson/rehearsal plans? (Check all that apply.)

B Basic Conducting

$\square$ Advanced Conducting

- Rehearsal Clinic

口 Percussion Methods

a Strings Methods

Guitar Methods

Woodwinds Methods

Brass Methods

String Techniques

$\square$ Marching Band Techniques

a Jazz Methods

$\square$ Other, please specify

口 I Did Not Use Lesson/Rehearsal Plans 
4. To what extent do your instructors address specific lesson planning in your courses?

\begin{tabular}{|c|c|c|c|c|}
\hline & Not At All & Very Little & Somewhat & A Lot \\
\hline Objectives (1) & O & O & O & O \\
\hline Unit Development (2) & O & O & O & O \\
\hline Materials (3) & 0 & O & O & O \\
\hline $\begin{array}{l}\text { Lesson Development } \\
\text { (4) }\end{array}$ & O & 0 & 0 & 0 \\
\hline Closures (5) & O & O & O & 0 \\
\hline $\begin{array}{c}\text { Evaluation/Assessments } \\
\text { (6) }\end{array}$ & $\mathrm{O}$ & 0 & $\mathrm{O}$ & 0 \\
\hline Objective Summary (7) & O & O & O & O \\
\hline $\begin{array}{l}\text { Having Alternative } \\
\text { Strategies }(8)\end{array}$ & O & O & O & O \\
\hline $\begin{array}{c}\text { Enduring } \\
\text { Understanding (9) }\end{array}$ & 0 & 0 & 0 & 0 \\
\hline $\begin{array}{c}\text { Essential Questions } \\
(10)\end{array}$ & O & 0 & O & 0 \\
\hline Accommodations (11) & 0 & 0 & O & 0 \\
\hline Differentiation (12) & 0 & 0 & 0 & 0 \\
\hline Score Study (13) & 0 & $\mathrm{O}$ & 0 & O \\
\hline $\begin{array}{c}\text { Rehearsal Techniques } \\
\text { (14) }\end{array}$ & 0 & 0 & 0 & 0 \\
\hline $\begin{array}{c}\text { Lesson } \\
\text { sequencing/procedures } \\
(15)\end{array}$ & O & 0 & 0 & 0 \\
\hline Pacing (16) & O & O & O & O \\
\hline $\begin{array}{l}\text { Anticipated Problems } \\
\text { (17) }\end{array}$ & O & 0 & 0 & 0 \\
\hline $\begin{array}{l}\text { Anticipated Solutions } \\
\text { (18) }\end{array}$ & 0 & 0 & O & O \\
\hline National Standards (19) & O & O & O & O \\
\hline State Standards (20) & O & O & O & O \\
\hline
\end{tabular}

5. In these courses, were you asked to write using a specific style/template?

$\square$ No

口 Yes

If No Is Selected, Then Skip to "Which rehearsal strategies were you t... 
5.1. To what extent were you asked to write in the following specific style/template?

\begin{tabular}{|c|c|c|c|c|}
\hline $\begin{array}{c}\text { Detailed Lesson } \\
\text { Plans (1) }\end{array}$ & Not At All & Very Little & Somewhat & A Lot \\
$\begin{array}{c}\text { Semi-Detailed } \\
\text { Lesson Plans (2) }\end{array}$ & 0 & 0 & 0 & 0 \\
$\begin{array}{c}\text { Procedural (3) } \\
\text { Activity Based } \\
\text { (4) }\end{array}$ & 0 & 0 & 0 & 0 \\
$\begin{array}{c}\text { Bloom's } \\
\text { Taxonomy (5) }\end{array}$ & 0 & 0 & 0 & 0 \\
$\begin{array}{c}\text { Understanding } \\
\text { by Design Unit } \\
\text { Plan-Backwards } \\
\text { Design Process } \\
\text { (6) }\end{array}$ & 0 & 0 & 0 & 0 \\
$\begin{array}{c}\text { State Specific } \\
\text { Lesson Plan (7) } \\
\text { Course Specific }\end{array}$ & 0 & 0 & 0 & 0 \\
Lesson Plan (8) \\
$\begin{array}{c}\text { No specific } \\
\text { template was } \\
\text { used (9) }\end{array}$
\end{tabular}


6. To what extent were you taught the following rehearsal strategies in your education courses?

\begin{tabular}{|c|c|c|c|c|}
\hline & Not At All & Very Little & Somewhat & A Lot \\
\hline $\begin{array}{l}\text { Organization and } \\
\text { efficiency (1) }\end{array}$ & $\mathrm{O}$ & $\bigcirc$ & $\mathrm{O}$ & $\mathrm{O}$ \\
\hline $\begin{array}{c}\text { Use of } \\
\text { technology (2) }\end{array}$ & $\mathrm{O}$ & $\mathrm{O}$ & $\mathrm{O}$ & $\mathrm{O}$ \\
\hline $\begin{array}{l}\text { Use of effective } \\
\text { reinforcement } \\
\text { techniques (3) }\end{array}$ & $\mathrm{O}$ & $\mathrm{O}$ & 0 & O \\
\hline $\begin{array}{l}\text { Use of effective } \\
\text { questioning (4) }\end{array}$ & $\mathrm{O}$ & O & 0 & O \\
\hline $\begin{array}{l}\text { Relating content } \\
\text { to prior and } \\
\text { future learning } \\
\text { (5) }\end{array}$ & $\mathrm{O}$ & $\mathrm{O}$ & $\mathrm{O}$ & O \\
\hline $\begin{array}{c}\text { Provides for } \\
\text { individual rates } \\
\text { of learning (6) }\end{array}$ & $\mathrm{O}$ & $\mathrm{O}$ & $\mathrm{O}$ & O \\
\hline $\begin{array}{l}\text { Reducing teacher } \\
\text { talk (7) }\end{array}$ & O & $\mathrm{O}$ & $\mathrm{O}$ & 0 \\
\hline $\begin{array}{c}\text { Improving } \\
\text { ensemble } \\
\text { performance time } \\
\text { (8) }\end{array}$ & $\mathrm{O}$ & $\mathrm{O}$ & $\mathrm{O}$ & $\mathrm{O}$ \\
\hline $\begin{array}{l}\text { Appropriate } \\
\text { feedback (9) }\end{array}$ & $\mathrm{O}$ & $\mathrm{O}$ & $\mathrm{O}$ & O \\
\hline $\begin{array}{c}\text { Individual } \\
\text { practice } \\
\text { strategies (10) }\end{array}$ & $\mathrm{O}$ & $\mathrm{O}$ & 0 & 0 \\
\hline Modeling (11) & O & O & 0 & O \\
\hline $\begin{array}{c}\text { Contextualizing } \\
\text { performances } \\
\text { (12) }\end{array}$ & $\mathrm{O}$ & $\mathrm{O}$ & $\mathrm{O}$ & O \\
\hline $\begin{array}{c}\text { Breathing } \\
\text { exercise (13) }\end{array}$ & O & $\mathrm{O}$ & $\mathrm{O}$ & $\mathrm{O}$ \\
\hline Scaffolding (14) & O & O & O & O \\
\hline $\begin{array}{c}\text { No rehearsal } \\
\text { strategies given } \\
(15)\end{array}$ & $\mathrm{O}$ & $\mathrm{O}$ & $\mathrm{O}$ & O \\
\hline $\begin{array}{l}\text { Other, please } \\
\text { specify (16) }\end{array}$ & O & $\mathrm{O}$ & O & O \\
\hline
\end{tabular}




\section{Section 3: BELIEFS ABOUT THE IMPORTANCE OF LESSON/REHEARSAL PLANNING}

1. Please rank the following reasons to use lesson/rehearsal plans from most important to least important. (Drag and place in order.)

Prepare for ensemble rehearsal Document mental planning process Making teaching more purposeful Anticipate problems Develop transitional flow Organize necessary resources Develop instructional pacing Are used during teaching or rehearsal (as a paper copy)

2. When creating lesson/rehearsal plans, how many verbal statements do you believe should be written out?
O All
Most
O Some
A few
None

3. When creating lesson/rehearsal plans, how many procedural steps do you believe should be written out?
O All
O Most
O Some
O A Few
None

4. On average, how many hours per week should you spend working on lesson plans?

\section{SECTION 4: HOW PREPARED DO YOU FEEL USING LESSON/REHEARSAL PLANS?}

1. I am prepared to use lesson/rehearsal plans when I teach public/private school.

O Strongly Agree

O Agree

O Disagree

Strongly Disagree

2. The use of lesson/rehearsal plans is important for secondary courses.

O Strongly Agree

O Agree

O Disagree

Strongly Disagree 
3. The use of lesson/rehearsal plans is important for elementary courses.

Strongly Agree

O Agree

Disagree

Strongly Disagree

4. How often do you believe secondary music teachers should create lesson/rehearsal plans for rehearsal/lessons?

O Daily

Weekly

O By Unit

Do not plan

5. How often do you believe elementary teachers should create lesson/rehearsal plans?

Daily

O Weekly

O By Unit

Do not plan

6. Which of the following is the most important aspect of rehearsal preparation for middle school/high school music teachers?

S Score study

Lesson planning

O Combination of both

7. Do you plan on using written lesson/rehearsal plans during your student teaching semester?

$\mathrm{O}$ Yes

O No

8. Do you plan on using written lesson/rehearsal plans during your first year of teaching?

$\mathrm{O}$ Yes

O No

9. Is there anything further you would like to say about lesson/rehearsal planning? 


\section{Appendix E}

\section{Institutional Review Board (]) University of Missouri-Columbia}

190 Galena Hall; Dc074.00

Columbia, MO 65212

573-882-3181

irb@missouri.edu

December 24, 2015

Principal Investigator: Aaron Timothy Wacker Department: School of Music

Your Exempt Application to project entitled Effects of Content Knowledge and Pedagogy Content Knowledge on Perceptions of Novices' Rehearsal Effectiveness was reviewed and approved by the MU Institutional Review Board according to terms and conditions described below:

$\begin{array}{ll}\text { IRB Project Number } & 2004500 \\ \text { IRB Review Number } & 211243\end{array}$

Initial Application Approval Date December 24, 2015

IRB Expiration Date December 24, 2016

Level of Review Exempt

Project Status Active - Open to Enrollment

Exempt Categories 45 CFR 46.101b(2)

Risk Level Minimal Risk

Internal Funding Personal funds

The principal investigator (PI) is responsible for all aspects and conduct of this study. The PI must comply with the following conditions of the approval:

1. No subjects may be involved in any study procedure prior to the IRB approval date or after the expiration date.

2. All unanticipated problems, adverse events, and deviations must be reported to the IRB within 5 days.

3. All changes must be IRB approved prior to implementation unless they are intended to reduce immediate risk.

4. All recruitment materials and methods must be approved by the IRB prior to being used.

5. The Annual Exempt Form must be submitted to the IRB for review and approval at least 30 days prior to the project expiration date. If the study is complete, the Completion/Withdrawal Form may be submitted in lieu of the Annual Exempt Form

6. Maintain all research records for a period of seven years from the project completion date.

7. Utilize all approved research documents located within the attached files section of eCompliance. These documents are highlighted green.

If you have any questions, please contact the IRB at 573-882-3181 or irb@missouri.edu. 


\section{Appendix F}

\section{Conductor Recruitment Script}

Hello, my name is Aaron Wacker. I am a graduate student at MU in the Learning Teaching and Curriculum Department. I am conducting research on Content Knowledge and Pedagogy Content Knowledge in music education, and I am inviting you to participate in the study as a conductor.

To be eligible, you need to be a freshman or sophomore music major enrolled at the University of Missouri, that has not completed basic conducting.

Participation in this research includes taking in a 2-hour rehearsal instructional class. One week after this class, you will conduct a 5-minute rehearsal for an instrumental ensemble. After your rehearsal, you will be asked to fill out a short evaluation of your rehearsal. The class will take place on February $20^{\text {th }}$ and the rehearsal will be on February $28^{\text {th }}$.

On both February $20^{\text {th }}$ and $28^{\text {th }}$ you will be provided lunch.

If you are willing to participate please read and fill out the attached consent form. Please respond to this email is you have any questions. 


\section{Appendix G}

\section{Consent Form for Conductors}

Researcher's Name: Aaron T. Wacker

Project Number: 2004500

Project Title: Effects of Knowledge Type on Perceptions of Novices' Rehearsal Effectiveness: An Exploratory Study

\section{INTRODUCTION}

This consent may contain words that you do not understand. Please ask the investigator to explain any words or information that you do not clearly understand.

You are being asked to participate in a research study. This research is being conducted about content knowledge and teacher pedagogy knowledge in music. When you are invited to participate in research, you have the right to be informed about the study procedures so that you can decide whether you want to consent to participation. This form may contain words that you do not know. Please ask the researcher to explain any words or information that you do not understand.

You have the right to know what you will be asked to do so that you can decide whether or not to be in the study. Your participation is voluntary. You do not have to be in the study if you do not want to. You may refuse to be in the study and nothing will happen. If you do not want to continue to be in the study, you may stop at any time without penalty or loss of benefits to which you are otherwise entitled.

\section{WHY IS THIS STUDY BEING DONE?}

The purpose of this study is to investigate the effects of conducting knowledge and Pedagogy Content Knowledge on perceptions of novices' rehearsal effectiveness. I will explore whether novices' rehearsals would be judged differently based upon two different methods of preparation. How will novices who focused their rehearsal preparation using typical score study methodologies (conducting knowledge) differ from those whose preparation also included specific rehearsal strategies Pedagogy Content Knowledge.

\section{HOW MANY PEOPLE WILL BE IN THE STUDY?}

About 60 people will take part in this study at the University of Missouri.

\section{WHAT AM I BEING ASKED TO DO?}

You will be asked to participate in a 2-hour rehearsal instructional class. One week after this class, you will conduct a 5-minute rehearsal for an instrumental ensemble. After your rehearsal, you will be asked to fill out a short evaluation of your rehearsal. 


\section{HOW LONG WILL I BE IN THE STUDY?}

This study will take place over one week and will take approximately three total hours to complete. You can stop participating at any time without penalty.

\section{WHAT ARE THE RISKS OF BEING IN THE STUDY?}

This study poses minimal risk to participants. The study will benefit an increased understanding of music teachers' content knowledge and teach pedagogy knowledge. Understanding gained will be used to inform the professional field of practice.

\section{CONFIDENTIALITY}

Information produced by this study will be stored in the investigator's file and identified by a code number only. The code key connecting your name to specific information about you will be kept in a separate, secure location. Information contained in your records may not be given to anyone unaffiliated with the study in a form that could identify you without your written consent, except as required by law.

\section{WILL I BE COMPENSATED FOR PARTICIPATING IN THE STUDY?}

You will receive no payment for taking part in this study.

\section{WHAT ARE MY RIGHTS AS A PARTICIPANT?}

Participation in this study is voluntary. You do not have to participate in this study.

You will also be informed of any new information discovered during the course of this study that might influence your health, welfare, or willingness to be in this study.

\section{WHO DO I CONTACT IF I HAVE QUESTIONS, CONCERNS, OR COMPLAINTS?}

Please contact Aaron T. Wacker at xxxxxxx@xxxxxxx.edu if you have questions about the research. Additionally, you may ask questions, voice concerns, or complaints to the research team.

\section{WHOM DO I CALL IF I HAVE QUESTIONS OR PROBLEMS?}

If you have any questions regarding your rights as a participant in this research and/or concerns about the study, or if you feel under any pressure to enroll or to continue to participate in this study, you may contact the University of Missouri Campus Institutional Review Board (which is a group of people who review the research studies to protect participants' rights) at (xxx) xxx-xxxx or xxxxxxx@xxxxxxx.edu.

You may ask more questions about the study at any time. 
A copy of this Informed Consent form will be given to you before you participate in the research.

\section{SIGNATURE}

I have read this consent form and my questions have been answered. My signature below means that I do want to be in the study. I know that I can remove myself from the study at any time without any problems.

Subject

Date 


\title{
Appendix $\mathbf{H}$
}

\section{Consent Form for Ensemble Participation}

\author{
Researcher's Name: Aaron T. Wacker \\ Project Number: 2004500
}

Project Title: Effects of Knowledge Type on Perceptions of Novices' Rehearsal Effectiveness: An Exploratory Study

\section{INTRODUCTION}

This consent may contain words that you do not understand. Please ask the investigator to explain any words or information that you do not clearly understand.

You are being asked to participate in a research study. This research is being conducted about content knowledge and teacher pedagogy knowledge in music. When you are invited to participate in research, you have the right to be informed about the study procedures so that you can decide whether you want to consent to participation. This form may contain words that you do not know. Please ask the researcher to explain any words or information that you do not understand.

You have the right to know what you will be asked to do so that you can decide whether or not to be in the study. Your participation is voluntary. You do not have to be in the study if you do not want to. You may refuse to be in the study and nothing will happen. If you do not want to continue to be in the study, you may stop at any time without penalty or loss of benefits to which you are otherwise entitled.

\section{WHY IS THIS STUDY BEING DONE?}

The purpose of this study is to investigate the effects of conducting knowledge and Pedagogy Content Knowledge on perceptions of novices' rehearsal effectiveness. I will explore whether novices' rehearsals would be judged differently based upon two different methods of preparation. How will novices who focused their rehearsal preparation using typical score study methodologies (conducting knowledge) differ from those whose preparation also included specific rehearsal strategies Pedagogy Content Knowledge

\section{HOW MANY PEOPLE WILL BE IN THE STUDY?}

About 60 people will take part in this study at the University of Missouri.

\section{WHAT AM I BEING ASKED TO DO?}

You will be asked to participate in an instrumental ensemble that will play grade 2 (of 6) music, typical for an average middle school ensemble, rehearsed by 20 novice conductors. After each 5-minute rehearsal, you will be asked to fill out a short questionnaire about each conductor. 


\section{HOW LONG WILL I BE IN THE STUDY?}

This study will take approximately two and half hours to complete. You can stop participating at any time without penalty.

\section{WHAT ARE THE RISKS OF BEING IN THE STUDY?}

This study poses minimal risk to participants. The study will benefit an increased understanding of music teachers' content knowledge and teach pedagogy knowledge. Understanding gained will be used to inform the professional field of practice.

\section{CONFIDENTIALITY}

Information produced by this study will be stored in the investigator's file and identified by a code number only. The code key connecting your name to specific information about you will be kept in a separate, secure location. Information contained in your records may not be given to anyone unaffiliated with the study in a form that could identify you without your written consent, except as required by law.

\section{WILL I BE COMPENSATED FOR PARTICIPATING IN THE STUDY?}

You will receive no payment for taking part in this study.

\section{WHAT ARE MY RIGHTS AS A PARTICIPANT?}

Participation in this study is voluntary. You do not have to participate in this study.

You will also be informed of any new information discovered during the course of this study that might influence your health, welfare, or willingness to be in this study.

\section{WHO DO I CONTACT IF I HAVE QUESTIONS, CONCERNS, OR COMPLAINTS?}

Please contact Aaron T. Wacker at xxxxxxx@xxxxxxx.edu if you have questions about the research. Additionally, you may ask questions, voice concerns, or complaints to the research team.

\section{WHOM DO I CALL IF I HAVE QUESTIONS OR PROBLEMS?}

If you have any questions regarding your rights as a participant in this research and/or concerns about the study, or if you feel under any pressure to enroll or to continue to participate in this study, you may contact the University of Missouri Campus Institutional Review Board (which is a group of people who review the research studies to protect participants' rights) at (xxx) xxx-xxxx or xxxxxxx@xxxxxxx.edu. 
You may ask more questions about the study at any time.

A copy of this Informed Consent form will be given to you before you participate in the research.

\section{SIGNATURE}

I have read this consent form and my questions have been answered. My signature below means that I do want to be in the study. I know that I can remove myself from the study at any time without any problems.

Subject

Date 


\section{Appendix I}

\section{Ensemble Recruitment Script}

Hello, my name is Aaron Wacker. I am a graduate student at MU in the Learning Teaching and Curriculum Department. I am conducting research on Content Knowledge and Pedagogy Content Knowledge in music education, and I am inviting you to participate in the study as an ensemble member playing

You will be asked to participate in an instrumental ensemble that will play grade 2 (of 6) music rehearsed by 20 novice conductors. After each 5-mimute rehearsal, you will be asked to fill out a short questionnaire about each conductor. This rehearsal will take place on February $28^{\text {th }}$ at 9am, in Loeb Hall. Before the rehearsal coffee and doughnuts will be provided and after participants will be provided with lunch.

If you agree to participate please let me know by Friday, February $12^{\mathrm{Th}}$. attached is a letter of consent, please read over the letter and return it to me before the $28^{\text {th }}$.

If you have any questions or would like to participate in the research, I can be reached at xxxxxxx@xxxxxxx.edu or (xxx) xxx-xxxx. 


\title{
Appendix J
}

Consent Form for Experts Conductors to Participate in a Research Study

\author{
Researcher's Name: Aaron T. Wacker \\ Project Number: 2004500
}

Project Title: Effects of Knowledge Type on Perceptions of Novices' Rehearsal Effectiveness: An Exploratory Study

\section{INTRODUCTION}

This consent may contain words that you do not understand. Please ask the investigator or the study staff to explain any words or information that you do not clearly understand.

You are being asked to participate in a research study. This research is being conducted about content knowledge and teacher pedagogy knowledge. When you are invited to participate in research, you have the right to be informed about the study procedures so that you can decide whether you want to consent to participation. This form may contain words that you do not know. Please ask the researcher to explain any words or information that you do not understand.

You have the right to know what you will be asked to do so that you can decide whether or not to be in the study. Your participation is voluntary. You do not have to be in the study if you do not want to. You may refuse to be in the study and nothing will happen. If you do not want to continue to be in the study, you may stop at any time without penalty or loss of benefits to which you are otherwise entitled.

\section{WHY IS THIS STUDY BEING DONE?}

The purpose of this study is to investigate the effects of conducting knowledge and Pedagogy Content Knowledge on perceptions of novices' rehearsal effectiveness. I will explore whether novices' rehearsals would be judged differently based upon two different methods of preparation. How will novices who focused their rehearsal preparation using typical score study methodologies (conducting knowledge) differ from those whose preparation also included specific rehearsal strategies Pedagogy Content Knowledge

\section{HOW MANY PEOPLE WILL BE IN THE STUDY?}

About 60 people will take part in this study at the University of Missouri.

\section{WHAT AM I BEING ASKED TO DO?}

In this study, you will watch 20 5-minute conductor rehearsals. You will rate the conductor on score knowledge and rehearsal effectiveness by circling a number from 110 on an evaluation form. 


\section{HOW LONG WILL I BE IN THE STUDY?}

This study will take you approximately 100 minutes to complete. You can stop participating at any time without penalty.

\section{WHAT ARE THE RISKS OF BEING IN THE STUDY?}

This study poses minimal risk to participants. The study will benefit an increased understanding of music teachers' content knowledge and teach pedagogy knowledge. Understanding gained will be used to inform the professional field of practice.

\section{CONFIDENTIALITY}

Information produced by this study will be stored in the investigator's file and identified by a code number only. The code key connecting your name to specific information about you will be kept in a separate, secure location. Information contained in your records may not be given to anyone unaffiliated with the study in a form that could identify you without your written consent, except as required by law.

\section{WILL I BE COMPENSATED FOR PARTICIPATING IN THE STUDY?}

You will receive no payment for taking part in this study.

\section{WHAT ARE MY RIGHTS AS A PARTICIPANT?}

Participation in this study is voluntary. You do not have to participate in this study.

You will also be informed of any new information discovered during the course of this study that might influence your health, welfare, or willingness to be in this study.

\section{WHO DO I CONTACT IF I HAVE QUESTIONS, CONCERNS, OR COMPLAINTS?}

Please contact Aaron T. Wacker at xxxxxxx@xxxxxxx.edu if you have questions about the research. Additionally, you may ask questions, voice concerns, or complaints to the research team.

\section{WHOM DO I CALL IF I HAVE QUESTIONS OR PROBLEMS?}

If you have any questions regarding your rights as a participant in this research and/or concerns about the study, or if you feel under any pressure to enroll or to continue to participate in this study, you may contact the University of Missouri Campus Institutional Review Board (which is a group of people who review the research studies to protect participants' rights) at (xxx) xxx-xxxx or xxxxxxx@xxxxxxx.edu. 
You may ask more questions about the study at any time.

A copy of this Informed Consent form will be given to you before you participate in the research.

\section{SIGNATURE}

I have read this consent form and my questions have been answered. My signature below means that I do want to be in the study. I know that I can remove myself from the study at any time without any problems.

Subject

Date 


\section{Appendix K}

Songs and Measure Numbers for Rehearsals

As Torrents in Summer arranged by Albert O. Davis

Pickup m. 12 (0:35) Through m. 32 (1:40)

Flourish for Wind Band by Ralph Vaughn Williams

Rehearsal A (0:15) through 8 after rehearsal C (1:08)

Down a Country Lane by Aaron Copland

Rehearsal C (1:34) through one after E (2:35)

Llwyn Onn by Brian Hogg

m. 61 (3:05) through m. $86(4: 10)$

Mini-suite, Movement I by Morton Gould

Pickup to m. 13 (0:15) downbeat m. 42 (1:09)

Polly Oliver by Thomas Root

m. 109 (3:25) through End (3:73)

Rite of Tamburo by Robert W. Smith

m. $100(3: 05)$ to End (3:58)

Sonatina For Band, Movement III by Frank Erickson Beginning (3:06) through m. 24 (3:56)

They Led My Lord Away arranged by Fred J. Allen Pickup m.23 (1:19) through m. 36 (2:11)

When the Stars Begin to Fall arranged by Fred J. Allen Pickup to m. 21 (1:36) through beat 3 m. 36 (2:37) 


\section{Appendix L}

\section{Both Groups}

$1^{\text {st }}$ hour

\section{Basic Conducting:}

0:00: Introduction and rationale for the study

0:05: basic conducting technique

(for example, pattern, plane, left hand, basic gestures)

Score Study:

0:30: Score orientation

(for example, reading a score, melody, harmony, dynamics)

0:40: Score marking discussion

(Pass out scores I have marked and have a brief discussion of what they notice)

0:55: Pass out Score Marking Checklist (adapted from Battisti \& Garofalo, 1993) and musical

score (The North Face by Jay Bocook) to be used for discussion and practice.

\section{Content Knowledge Group}

$2^{\text {nd }}$ hour

\section{Detailed Score Study:}

1:00: Discuss identifying important musical lines, what are the melody, harmony, rhythmic parts (using the checklist as a guide)

1:10 Make score on melody, harmony, and rhythmic lines with a partner (mark with pens, pencils, or highlighters)

1:20: Large group discussion on melody, harmony, and rhythmic lines

1:25: Listen to a provided professional recording with score

1:30: Discussion on how the listening to the model effected what their score study

1:35: Sing individual lines of the score

1:45: Silent Score Study

2:00: Give participants their preparation checklist and musical score.

\section{Pedagogy Content Knowledge}

$2^{\text {nd }}$ hour

\section{Rehearsal Techniques:}

1:00: Discussion about rehearsal techniques: Modeling

1:05: Sing individual melodic lines in the manner they want them to sound

(for example, syllables, dynamics, pitch accuracy; using different melody lines with form The North Face to demonstrate modeling on primary instrument or singing with correct timbre, articulation, and dynamics).

1:15: Lecture about rehearsal techniques: Sequencing instruction with specific examples (for example, large group rehearsal, small group rehearsal, pacing)

1:20: Individual practice writing down a brief sequence place

1:25: Lecture about rehearsal techniques: Specific feedback 
1:30: Partner up and practice giving specific feedback each other.

1:35: Discussion about rehearsal techniques: Contextualizing the performance 1:45: Silent score study and rehearsal technique study time.

2:00: Give participants their preparation checklist 


\section{Appendix M \\ Evaluation Form, Conductor \\ Instructions}

Please circle a number from 1-10 that best represents your own score knowledge (from "no knowledge" to "very knowledgeable") and rehearsal effectiveness (from "not effective" to "very effective").

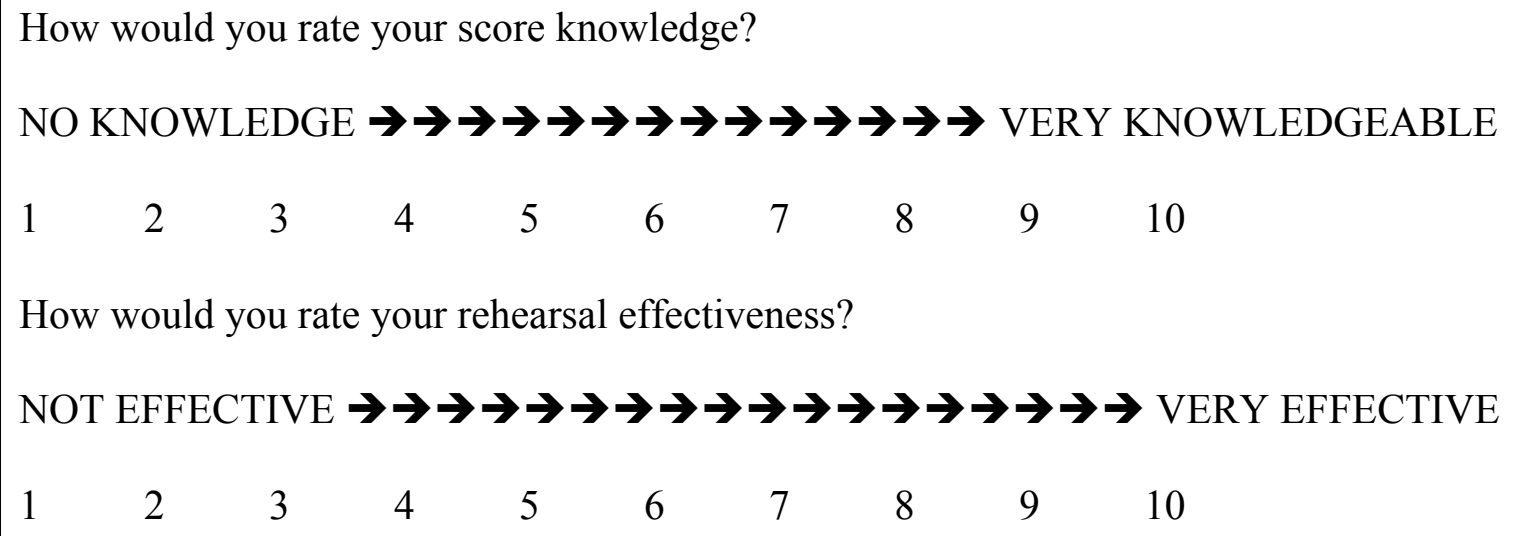

Please circle (or write) the appropriate response.

1. What is your gender?

Male Female

2. How old are you?

3. What is your school classification?

Freshman Sophomore

4. What is your major?

Music Performance Music Education Composition Bachelor of Arts

5. How many years of experience do you have playing in an instrumental ensemble?

6. How prepared did you feel to lead the rehearsal? Why? 
7. What were the strongest aspects of your rehearsal? Why?

8. What were the weakest aspects of your rehearsal? Why?

9. Any additional comments? 


\section{Evaluation Form, Ensemble}

Instructions

After each rehearsal, please circle a number from 1-10 that best represents each conductor's score knowledge (from "no knowledge" to "very knowledgeable") and rehearsal effectiveness (from "not effective" to "very effective").

\section{Conductor 1}

How would you rate the conductor's score knowledge?

NO KNOWLEDGE $\rightarrow \rightarrow \rightarrow \rightarrow \rightarrow \rightarrow \rightarrow \rightarrow \rightarrow \rightarrow \rightarrow \rightarrow \rightarrow \rightarrow \rightarrow$ VERY KNOWLEDGEABLE

$\begin{array}{llllllllll}1 & 2 & 3 & 4 & 5 & 6 & 7 & 8 & 9 & 10\end{array}$

How would you rate the conductor's rehearsal effectiveness?

NOT EFFECTIVE $\rightarrow \rightarrow \rightarrow \rightarrow \rightarrow \rightarrow \rightarrow \rightarrow \rightarrow \rightarrow \rightarrow \rightarrow \rightarrow \rightarrow \rightarrow \rightarrow \rightarrow$ VERY EFFECTIVE

$\begin{array}{llllllllll}1 & 2 & 3 & 4 & 5 & 6 & 7 & 8 & 9 & 10\end{array}$

\section{Conductor 2}

How would you rate the conductor's score knowledge?

NO KNOWLEDGE $\rightarrow \rightarrow \rightarrow \rightarrow \rightarrow \rightarrow \rightarrow \rightarrow \rightarrow \rightarrow \rightarrow \rightarrow \rightarrow \rightarrow$ VERY KNOWLEDGEABLE

$\begin{array}{llllllllll}1 & 2 & 3 & 4 & 5 & 6 & 7 & 8 & 9 & 10\end{array}$

How would you rate the conductor's rehearsal effectiveness?

NOT EFFECTIVE $\rightarrow \rightarrow \rightarrow \rightarrow \rightarrow \rightarrow \rightarrow \rightarrow \rightarrow \rightarrow \rightarrow \rightarrow \rightarrow \rightarrow \rightarrow \rightarrow$ VERY EFFECTIVE

$\begin{array}{llllllllll}1 & 2 & 3 & 4 & 5 & 6 & 7 & 8 & 9 & 10\end{array}$




\section{Conductor 3}

How would you rate the conductor's score knowledge?

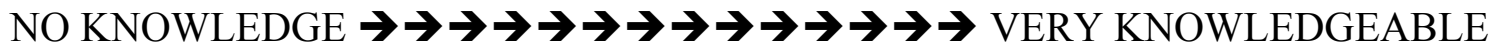

$\begin{array}{llllllllll}1 & 2 & 3 & 4 & 5 & 6 & 7 & 8 & 9 & 10\end{array}$

How would you rate the conductor's rehearsal effectiveness?

NOT EFFECTIVE $\boldsymbol{\rightarrow} \rightarrow \boldsymbol{\rightarrow} \rightarrow \boldsymbol{\rightarrow} \rightarrow \boldsymbol{\rightarrow} \rightarrow \boldsymbol{\rightarrow} \rightarrow \boldsymbol{\rightarrow} \rightarrow \boldsymbol{\rightarrow} \rightarrow \boldsymbol{\rightarrow} \rightarrow \boldsymbol{\rightarrow} \rightarrow$ VERY EFFECTIVE

$\begin{array}{llllllllll}1 & 2 & 3 & 4 & 5 & 6 & 7 & 8 & 9 & 10\end{array}$

\section{Conductor 4}

How would you rate the conductor's score knowledge?

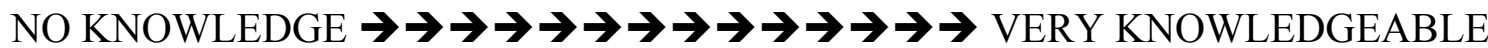

$\begin{array}{llllllllll}1 & 2 & 3 & 4 & 5 & 6 & 7 & 8 & 9 & 10\end{array}$

How would you rate the conductor's rehearsal effectiveness?

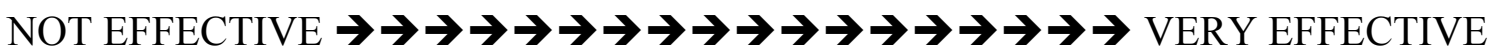

$\begin{array}{llllllllll}1 & 2 & 3 & 4 & 5 & 6 & 7 & 8 & 9 & 10\end{array}$

\section{Conductor 5}

How would you rate the conductor's score knowledge?

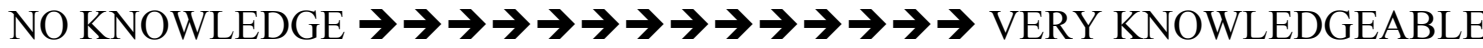

$\begin{array}{llllllllll}1 & 2 & 3 & 4 & 5 & 6 & 7 & 8 & 9 & 10\end{array}$

How would you rate the conductor's rehearsal effectiveness?

NOT EFFECTIVE $\boldsymbol{\rightarrow} \rightarrow \boldsymbol{\rightarrow \rightarrow \rightarrow \rightarrow \rightarrow \rightarrow \rightarrow \rightarrow \rightarrow \rightarrow \rightarrow \rightarrow \rightarrow \rightarrow ~ V E R Y ~ E F F E C T I V E ~}$

$\begin{array}{llllllllll}1 & 2 & 3 & 4 & 5 & 6 & 7 & 8 & 9 & 10\end{array}$ 
Conductor 6

How would you rate the conductor's score knowledge?

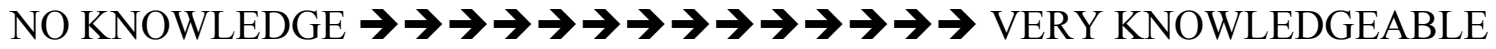

$\begin{array}{llllllllll}1 & 2 & 3 & 4 & 5 & 6 & 7 & 8 & 9 & 10\end{array}$

How would you rate the conductor's rehearsal effectiveness?

NOT EFFECTIVE $\boldsymbol{\rightarrow} \rightarrow \boldsymbol{\rightarrow} \rightarrow \boldsymbol{\rightarrow} \rightarrow \boldsymbol{\rightarrow} \rightarrow \boldsymbol{\rightarrow} \rightarrow \boldsymbol{\rightarrow} \rightarrow \boldsymbol{\rightarrow} \rightarrow \boldsymbol{\rightarrow} \rightarrow \boldsymbol{\rightarrow} \rightarrow$ VERY EFFECTIVE

$\begin{array}{llllllllll}1 & 2 & 3 & 4 & 5 & 6 & 7 & 8 & 9 & 10\end{array}$

\section{Conductor 7}

How would you rate the conductor's score knowledge?

NO KNOWLEDGE $\rightarrow \rightarrow \rightarrow \rightarrow \rightarrow \rightarrow \rightarrow \rightarrow \rightarrow \rightarrow \rightarrow \rightarrow \rightarrow$ VERY KNOWLEDGEABLE

$\begin{array}{llllllllll}1 & 2 & 3 & 4 & 5 & 6 & 7 & 8 & 9 & 10\end{array}$

How would you rate the conductor's rehearsal effectiveness?

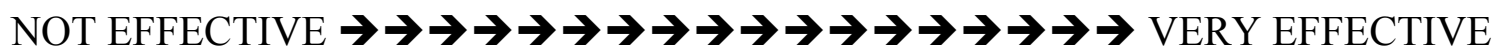

$\begin{array}{llllllllll}1 & 2 & 3 & 4 & 5 & 6 & 7 & 8 & 9 & 10\end{array}$

\section{Conductor 8}

How would you rate the conductor's score knowledge?

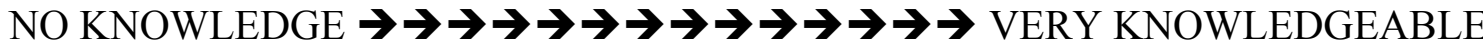

$\begin{array}{llllllllll}1 & 2 & 3 & 4 & 5 & 6 & 7 & 8 & 9 & 10\end{array}$

How would you rate the conductor's rehearsal effectiveness?

NOT EFFECTIVE $\boldsymbol{\rightarrow} \rightarrow \boldsymbol{\rightarrow \rightarrow \rightarrow \rightarrow \rightarrow \rightarrow \rightarrow \rightarrow \rightarrow \rightarrow \rightarrow \rightarrow \rightarrow \rightarrow ~ V E R Y ~ E F F E C T I V E ~}$

$\begin{array}{llllllllll}1 & 2 & 3 & 4 & 5 & 6 & 7 & 8 & 9 & 10\end{array}$ 
Conductor 9

How would you rate the conductor's score knowledge?

NO KNOWLEDGE $\boldsymbol{\rightarrow} \rightarrow \boldsymbol{\rightarrow} \rightarrow \boldsymbol{\rightarrow} \rightarrow \boldsymbol{\rightarrow} \rightarrow \boldsymbol{\rightarrow} \rightarrow \boldsymbol{\rightarrow} \rightarrow \boldsymbol{\rightarrow} \rightarrow$ VERY KNOWLEDGEABLE

$\begin{array}{llllllllll}1 & 2 & 3 & 4 & 5 & 6 & 7 & 8 & 9 & 10\end{array}$

How would you rate the conductor's rehearsal effectiveness?

NOT EFFECTIVE $\boldsymbol{\rightarrow} \rightarrow \boldsymbol{\rightarrow} \rightarrow \boldsymbol{\rightarrow} \rightarrow \boldsymbol{\rightarrow} \rightarrow \boldsymbol{\rightarrow} \rightarrow \boldsymbol{\rightarrow} \rightarrow \boldsymbol{\rightarrow} \rightarrow \boldsymbol{\rightarrow} \rightarrow \boldsymbol{\rightarrow} \rightarrow$ VERY EFFECTIVE

$\begin{array}{llllllllll}1 & 2 & 3 & 4 & 5 & 6 & 7 & 8 & 9 & 10\end{array}$

\section{Conductor 10}

How would you rate the conductor's score knowledge?

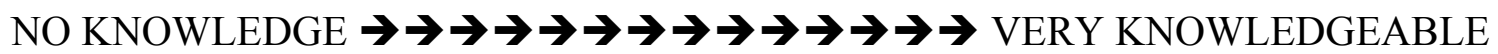

$\begin{array}{llllllllll}1 & 2 & 3 & 4 & 5 & 6 & 7 & 8 & 9 & 10\end{array}$

How would you rate the conductor's rehearsal effectiveness?

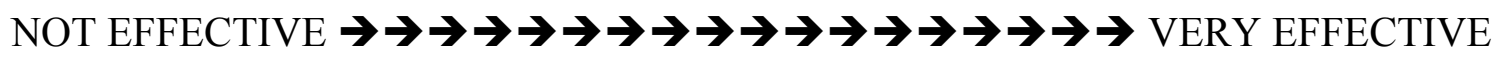

$\begin{array}{llllllllll}1 & 2 & 3 & 4 & 5 & 6 & 7 & 8 & 9 & 10\end{array}$

Conductor 11

How would you rate the conductor's score knowledge?

NO KNOWLEDGE $\boldsymbol{\rightarrow} \rightarrow \boldsymbol{\rightarrow} \rightarrow \boldsymbol{\rightarrow} \rightarrow \boldsymbol{\rightarrow} \rightarrow \boldsymbol{\rightarrow} \rightarrow \boldsymbol{\rightarrow} \rightarrow \boldsymbol{\rightarrow} \rightarrow$ VERY KNOWLEDGEABLE

$\begin{array}{llllllllll}1 & 2 & 3 & 4 & 5 & 6 & 7 & 8 & 9 & 10\end{array}$

How would you rate the conductor's rehearsal effectiveness?

NOT EFFECTIVE $\boldsymbol{\rightarrow} \rightarrow \boldsymbol{\rightarrow} \rightarrow \boldsymbol{\rightarrow} \rightarrow \boldsymbol{\rightarrow} \rightarrow \boldsymbol{\rightarrow} \rightarrow \boldsymbol{\rightarrow} \rightarrow \boldsymbol{\rightarrow} \rightarrow \boldsymbol{\rightarrow} \rightarrow \boldsymbol{\rightarrow}$ VERY EFFECTIVE

$\begin{array}{llllllllll}1 & 2 & 3 & 4 & 5 & 6 & 7 & 8 & 9 & 10\end{array}$ 


\section{Conductor 12}

How would you rate the conductor's score knowledge?

NO KNOWLEDGE $\boldsymbol{\rightarrow} \rightarrow \boldsymbol{\rightarrow} \rightarrow \boldsymbol{\rightarrow} \rightarrow \boldsymbol{\rightarrow} \rightarrow \boldsymbol{\rightarrow} \rightarrow \boldsymbol{\rightarrow} \rightarrow \boldsymbol{\rightarrow} \rightarrow$ VERY KNOWLEDGEABLE

$\begin{array}{llllllllll}1 & 2 & 3 & 4 & 5 & 6 & 7 & 8 & 9 & 10\end{array}$

How would you rate the conductor's rehearsal effectiveness?

NOT EFFECTIVE $\boldsymbol{\rightarrow} \rightarrow \boldsymbol{\rightarrow} \rightarrow \boldsymbol{\rightarrow} \rightarrow \boldsymbol{\rightarrow} \rightarrow \boldsymbol{\rightarrow} \rightarrow \boldsymbol{\rightarrow} \rightarrow \boldsymbol{\rightarrow} \rightarrow \boldsymbol{\rightarrow} \rightarrow \boldsymbol{\rightarrow} \rightarrow$ VERY EFFECTIVE

$\begin{array}{llllllllll}1 & 2 & 3 & 4 & 5 & 6 & 7 & 8 & 9 & 10\end{array}$

\section{Conductor 13}

How would you rate the conductor's score knowledge?

NO KNOWLEDGE $\rightarrow \rightarrow \rightarrow \rightarrow \rightarrow \rightarrow \rightarrow \rightarrow \rightarrow \rightarrow \rightarrow \rightarrow \rightarrow$ VERY KNOWLEDGEABLE

$\begin{array}{llllllllll}1 & 2 & 3 & 4 & 5 & 6 & 7 & 8 & 9 & 10\end{array}$

How would you rate the conductor's rehearsal effectiveness?

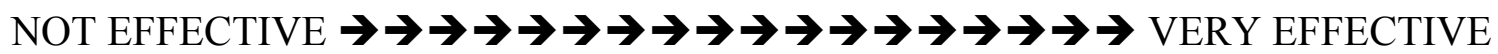

$\begin{array}{llllllllll}1 & 2 & 3 & 4 & 5 & 6 & 7 & 8 & 9 & 10\end{array}$

\section{Conductor 14}

How would you rate the conductor's score knowledge?

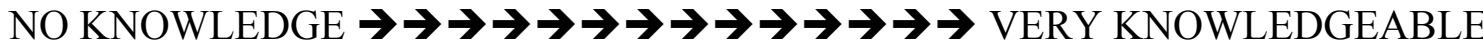

$\begin{array}{llllllllll}1 & 2 & 3 & 4 & 5 & 6 & 7 & 8 & 9 & 10\end{array}$

How would you rate the conductor's rehearsal effectiveness?

NOT EFFECTIVE $\boldsymbol{\rightarrow} \rightarrow \boldsymbol{\rightarrow \rightarrow \rightarrow \rightarrow \rightarrow \rightarrow \rightarrow \rightarrow \rightarrow \rightarrow \rightarrow \rightarrow \rightarrow \rightarrow ~ V E R Y ~ E F F E C T I V E ~}$

$\begin{array}{llllllllll}1 & 2 & 3 & 4 & 5 & 6 & 7 & 8 & 9 & 10\end{array}$ 
Conductor 15

How would you rate the conductor's score knowledge?

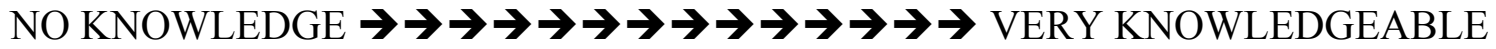

$\begin{array}{llllllllll}1 & 2 & 3 & 4 & 5 & 6 & 7 & 8 & 9 & 10\end{array}$

How would you rate the conductor's rehearsal effectiveness?

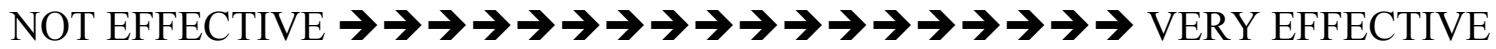

$\begin{array}{llllllllll}1 & 2 & 3 & 4 & 5 & 6 & 7 & 8 & 9 & 10\end{array}$

\section{Conductor 16}

How would you rate the conductor's score knowledge?

NO KNOWLEDGE $\rightarrow \rightarrow \rightarrow \rightarrow \rightarrow \rightarrow \rightarrow \rightarrow \rightarrow \rightarrow \rightarrow \rightarrow \rightarrow$ VERY KNOWLEDGEABLE

$\begin{array}{llllllllll}1 & 2 & 3 & 4 & 5 & 6 & 7 & 8 & 9 & 10\end{array}$

How would you rate the conductor's rehearsal effectiveness?

NOT EFFECTIVE $\rightarrow \rightarrow \rightarrow \rightarrow \rightarrow \rightarrow \rightarrow \rightarrow \rightarrow \rightarrow \rightarrow \rightarrow \rightarrow \rightarrow \rightarrow \rightarrow \rightarrow$ VERY EFFECTIVE

$\begin{array}{llllllllll}1 & 2 & 3 & 4 & 5 & 6 & 7 & 8 & 9 & 10\end{array}$

\section{Conductor 17}

How would you rate the conductor's score knowledge?

$\mathrm{NO} \mathrm{KNOWLEDGE} \rightarrow \rightarrow \rightarrow \rightarrow \rightarrow \rightarrow \rightarrow \rightarrow \rightarrow \rightarrow \rightarrow \rightarrow \rightarrow \rightarrow \rightarrow$ VERY KNOWLEDGEABLE

$\begin{array}{llllllllll}1 & 2 & 3 & 4 & 5 & 6 & 7 & 8 & 9 & 10\end{array}$

How would you rate the conductor's rehearsal effectiveness?

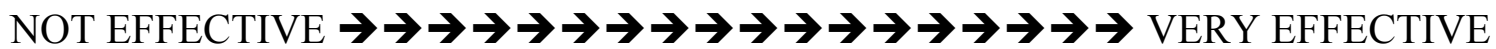

$\begin{array}{llllllllll}1 & 2 & 3 & 4 & 5 & 6 & 7 & 8 & 9 & 10\end{array}$ 
Conductor 18

How would you rate the conductor's score knowledge?

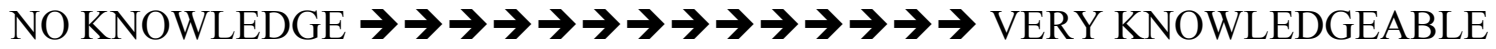

$\begin{array}{llllllllll}1 & 2 & 3 & 4 & 5 & 6 & 7 & 8 & 9 & 10\end{array}$

How would you rate the conductor's rehearsal effectiveness?

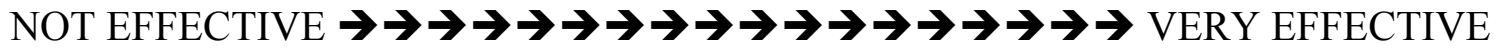

$\begin{array}{llllllllll}1 & 2 & 3 & 4 & 5 & 6 & 7 & 8 & 9 & 10\end{array}$

\section{Conductor 19}

How would you rate the conductor's score knowledge?

NO KNOWLEDGE $\rightarrow \rightarrow \rightarrow \rightarrow \rightarrow \rightarrow \rightarrow \rightarrow \rightarrow \rightarrow \rightarrow \rightarrow \rightarrow$ VERY KNOWLEDGEABLE

$\begin{array}{llllllllll}1 & 2 & 3 & 4 & 5 & 6 & 7 & 8 & 9 & 10\end{array}$

How would you rate the conductor's rehearsal effectiveness?

NOT EFFECTIVE $\rightarrow \rightarrow \rightarrow \rightarrow \rightarrow \rightarrow \rightarrow \rightarrow \rightarrow \rightarrow \rightarrow \rightarrow \rightarrow \rightarrow \rightarrow \rightarrow \rightarrow$ VERY EFFECTIVE

$\begin{array}{llllllllll}1 & 2 & 3 & 4 & 5 & 6 & 7 & 8 & 9 & 10\end{array}$

\section{Conductor 20}

How would you rate the conductor's score knowledge?

$\mathrm{NO} \mathrm{KNOWLEDGE} \rightarrow \rightarrow \rightarrow \rightarrow \rightarrow \rightarrow \rightarrow \rightarrow \rightarrow \rightarrow \rightarrow \rightarrow \rightarrow \rightarrow \rightarrow$ VERY KNOWLEDGEABLE

$\begin{array}{llllllllll}1 & 2 & 3 & 4 & 5 & 6 & 7 & 8 & 9 & 10\end{array}$

How would you rate the conductor's rehearsal effectiveness?



$\begin{array}{llllllllll}1 & 2 & 3 & 4 & 5 & 6 & 7 & 8 & 9 & 10\end{array}$ 


\section{Please circle (or write) the appropriate response.}

1. What is your gender?

Male Female

2. How old are you?

3. What is your school classification?

Undergraduate Graduate Student

4. What is your major?

Music Performance Music Education Bachelor of Arts Non-Music Major

5. How many years of experience do you have playing in an instrumental ensemble?

6. Have you ever taken (or are currently enrolled in) a basic conducting course?

Yes $\quad$ No




\section{Evaluation Form, Experts}

Instructions

After viewing each conductor, please circle a number from 1-10 that best represents each conductor's score knowledge (from "no knowledge" to "very knowledgeable") and rehearsal effectiveness (from "not effective" to "very effective").

\section{Conductor 1}

How would you rate the conductor's score knowledge?

$\mathrm{NO} \mathrm{KNOWLEDGE} \rightarrow \rightarrow \rightarrow \rightarrow \rightarrow \rightarrow \rightarrow \rightarrow \rightarrow \rightarrow \rightarrow \rightarrow \rightarrow \rightarrow$ VERY KNOWLEDGEABLE

$\begin{array}{llllllllll}1 & 2 & 3 & 4 & 5 & 6 & 7 & 8 & 9 & 10\end{array}$

How would you rate the conductor's rehearsal effectiveness?

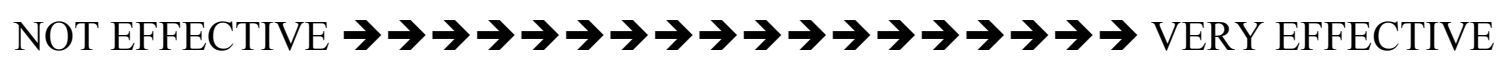

$\begin{array}{llllllllll}1 & 2 & 3 & 4 & 5 & 6 & 7 & 8 & 9 & 10\end{array}$

Conductor 2

How would you rate the conductor's score knowledge?

NO KNOWLEDGE $\rightarrow \rightarrow \rightarrow \rightarrow \rightarrow \rightarrow \rightarrow \rightarrow \rightarrow \rightarrow \rightarrow \rightarrow \rightarrow \rightarrow \rightarrow$ VERY KNOWLEDGEABLE

$\begin{array}{llllllllll}1 & 2 & 3 & 4 & 5 & 6 & 7 & 8 & 9 & 10\end{array}$

How would you rate the conductor's rehearsal effectiveness?

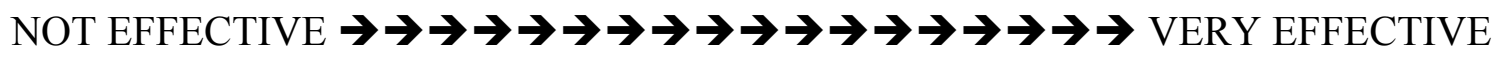

$\begin{array}{llllllllll}1 & 2 & 3 & 4 & 5 & 6 & 7 & 8 & 9 & 10\end{array}$




\section{Conductor 3}

How would you rate the conductor's score knowledge?

NO KNOWLEDGE $\boldsymbol{\rightarrow} \rightarrow \boldsymbol{\rightarrow} \rightarrow \boldsymbol{\rightarrow} \rightarrow \boldsymbol{\rightarrow} \rightarrow \boldsymbol{\rightarrow} \rightarrow \boldsymbol{\rightarrow} \rightarrow \boldsymbol{\rightarrow} \rightarrow$ VERY KNOWLEDGEABLE

$\begin{array}{llllllllll}1 & 2 & 3 & 4 & 5 & 6 & 7 & 8 & 9 & 10\end{array}$

How would you rate the conductor's rehearsal effectiveness?

NOT EFFECTIVE $\boldsymbol{\rightarrow} \rightarrow \boldsymbol{\rightarrow} \rightarrow \boldsymbol{\rightarrow} \rightarrow \boldsymbol{\rightarrow} \rightarrow \boldsymbol{\rightarrow} \rightarrow \boldsymbol{\rightarrow} \rightarrow \boldsymbol{\rightarrow} \rightarrow \boldsymbol{\rightarrow} \rightarrow \boldsymbol{\rightarrow} \rightarrow$ VERY EFFECTIVE

$\begin{array}{llllllllll}1 & 2 & 3 & 4 & 5 & 6 & 7 & 8 & 9 & 10\end{array}$

\section{Conductor 4}

How would you rate the conductor's score knowledge?

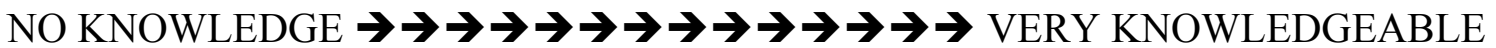

$\begin{array}{llllllllll}1 & 2 & 3 & 4 & 5 & 6 & 7 & 8 & 9 & 10\end{array}$

How would you rate the conductor's rehearsal effectiveness?

NOT EFFECTIVE $\boldsymbol{\rightarrow} \rightarrow \boldsymbol{\rightarrow \rightarrow \rightarrow \rightarrow \rightarrow \rightarrow \rightarrow \rightarrow \rightarrow \rightarrow \rightarrow \rightarrow \rightarrow \rightarrow ~ V E R Y ~ E F F E C T I V E ~}$

$\begin{array}{llllllllll}1 & 2 & 3 & 4 & 5 & 6 & 7 & 8 & 9 & 10\end{array}$

\section{Conductor 5}

How would you rate the conductor's score knowledge?

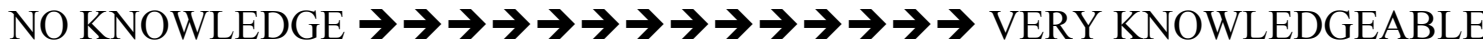

$\begin{array}{llllllllll}1 & 2 & 3 & 4 & 5 & 6 & 7 & 8 & 9 & 10\end{array}$

How would you rate the conductor's rehearsal effectiveness?

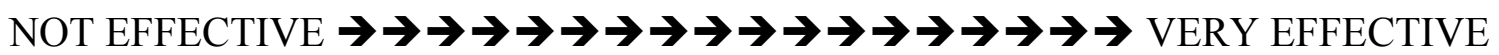

$\begin{array}{llllllllll}1 & 2 & 3 & 4 & 5 & 6 & 7 & 8 & 9 & 10\end{array}$ 
Conductor 6

How would you rate the conductor's score knowledge?

NO KNOWLEDGE $\boldsymbol{\rightarrow} \rightarrow \boldsymbol{\rightarrow} \rightarrow \boldsymbol{\rightarrow} \rightarrow \boldsymbol{\rightarrow} \rightarrow \boldsymbol{\rightarrow} \rightarrow \boldsymbol{\rightarrow} \rightarrow \boldsymbol{\rightarrow} \rightarrow$ VERY KNOWLEDGEABLE

$\begin{array}{llllllllll}1 & 2 & 3 & 4 & 5 & 6 & 7 & 8 & 9 & 10\end{array}$

How would you rate the conductor's rehearsal effectiveness?

NOT EFFECTIVE $\boldsymbol{\rightarrow} \rightarrow \boldsymbol{\rightarrow} \rightarrow \boldsymbol{\rightarrow} \rightarrow \boldsymbol{\rightarrow} \rightarrow \boldsymbol{\rightarrow} \rightarrow \boldsymbol{\rightarrow} \rightarrow \boldsymbol{\rightarrow} \rightarrow \boldsymbol{\rightarrow} \rightarrow \boldsymbol{\rightarrow} \rightarrow$ VERY EFFECTIVE

$\begin{array}{llllllllll}1 & 2 & 3 & 4 & 5 & 6 & 7 & 8 & 9 & 10\end{array}$

\section{Conductor 7}

How would you rate the conductor's score knowledge?

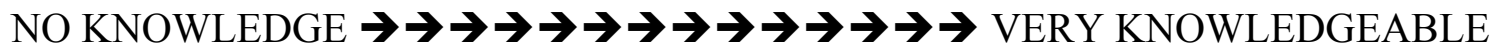

$\begin{array}{llllllllll}1 & 2 & 3 & 4 & 5 & 6 & 7 & 8 & 9 & 10\end{array}$

How would you rate the conductor's rehearsal effectiveness?

NOT EFFECTIVE $\boldsymbol{\rightarrow} \rightarrow \boldsymbol{\rightarrow \rightarrow \rightarrow \rightarrow \rightarrow \rightarrow \rightarrow \rightarrow \rightarrow \rightarrow \rightarrow \rightarrow \rightarrow \rightarrow ~ V E R Y ~ E F F E C T I V E ~}$

$\begin{array}{llllllllll}1 & 2 & 3 & 4 & 5 & 6 & 7 & 8 & 9 & 10\end{array}$

\section{Conductor 8}

How would you rate the conductor's score knowledge?

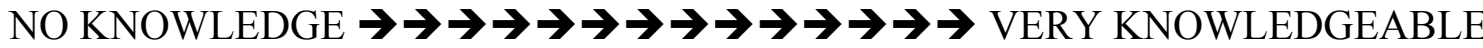

$\begin{array}{llllllllll}1 & 2 & 3 & 4 & 5 & 6 & 7 & 8 & 9 & 10\end{array}$

How would you rate the conductor's rehearsal effectiveness?

NOT EFFECTIVE $\boldsymbol{\rightarrow} \rightarrow \boldsymbol{\rightarrow \rightarrow \rightarrow \rightarrow \rightarrow \rightarrow \rightarrow \rightarrow \rightarrow \rightarrow \rightarrow \rightarrow \rightarrow \rightarrow ~ V E R Y ~ E F F E C T I V E ~}$

$\begin{array}{llllllllll}1 & 2 & 3 & 4 & 5 & 6 & 7 & 8 & 9 & 10\end{array}$ 
Conductor 9

How would you rate the conductor's score knowledge?

NO KNOWLEDGE $\boldsymbol{\rightarrow} \rightarrow \boldsymbol{\rightarrow} \rightarrow \boldsymbol{\rightarrow} \rightarrow \boldsymbol{\rightarrow} \rightarrow \boldsymbol{\rightarrow} \rightarrow \boldsymbol{\rightarrow} \rightarrow \boldsymbol{\rightarrow} \rightarrow$ VERY KNOWLEDGEABLE

$\begin{array}{llllllllll}1 & 2 & 3 & 4 & 5 & 6 & 7 & 8 & 9 & 10\end{array}$

How would you rate the conductor's rehearsal effectiveness?

NOT EFFECTIVE $\boldsymbol{\rightarrow} \rightarrow \boldsymbol{\rightarrow} \rightarrow \boldsymbol{\rightarrow} \rightarrow \boldsymbol{\rightarrow} \rightarrow \boldsymbol{\rightarrow} \rightarrow \boldsymbol{\rightarrow} \rightarrow \boldsymbol{\rightarrow} \rightarrow \boldsymbol{\rightarrow} \rightarrow \boldsymbol{\rightarrow} \rightarrow$ VERY EFFECTIVE

$\begin{array}{llllllllll}1 & 2 & 3 & 4 & 5 & 6 & 7 & 8 & 9 & 10\end{array}$

Conductor 10

How would you rate the conductor's score knowledge?

NO KNOWLEDGE $\rightarrow \rightarrow \rightarrow \rightarrow \rightarrow \rightarrow \rightarrow \rightarrow \rightarrow \rightarrow \rightarrow \rightarrow \rightarrow$ VERY KNOWLEDGEABLE

$\begin{array}{llllllllll}1 & 2 & 3 & 4 & 5 & 6 & 7 & 8 & 9 & 10\end{array}$

How would you rate the conductor's rehearsal effectiveness?

NOT EFFECTIVE $\boldsymbol{\rightarrow} \rightarrow \boldsymbol{\rightarrow \rightarrow \rightarrow \rightarrow \rightarrow \rightarrow \rightarrow \rightarrow \rightarrow \rightarrow \rightarrow \rightarrow \rightarrow \rightarrow ~ V E R Y ~ E F F E C T I V E ~}$

$\begin{array}{llllllllll}1 & 2 & 3 & 4 & 5 & 6 & 7 & 8 & 9 & 10\end{array}$

\section{Conductor 11}

How would you rate the conductor's score knowledge?

NO KNOWLEDGE $\boldsymbol{\rightarrow} \rightarrow \boldsymbol{\rightarrow} \rightarrow \boldsymbol{\rightarrow} \rightarrow \boldsymbol{\rightarrow} \rightarrow \boldsymbol{\rightarrow} \rightarrow \boldsymbol{\rightarrow} \rightarrow \boldsymbol{\rightarrow} \rightarrow$ VERY KNOWLEDGEABLE

$\begin{array}{llllllllll}1 & 2 & 3 & 4 & 5 & 6 & 7 & 8 & 9 & 10\end{array}$

How would you rate the conductor's rehearsal effectiveness?

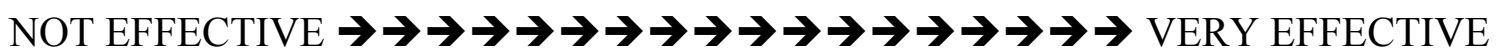

$\begin{array}{llllllllll}1 & 2 & 3 & 4 & 5 & 6 & 7 & 8 & 9 & 10\end{array}$ 


\section{Conductor 12}

How would you rate the conductor's score knowledge?

NO KNOWLEDGE $\boldsymbol{\rightarrow} \rightarrow \boldsymbol{\rightarrow} \rightarrow \boldsymbol{\rightarrow} \rightarrow \boldsymbol{\rightarrow} \rightarrow \boldsymbol{\rightarrow} \rightarrow \boldsymbol{\rightarrow} \rightarrow \boldsymbol{\rightarrow} \rightarrow$ VERY KNOWLEDGEABLE

$\begin{array}{llllllllll}1 & 2 & 3 & 4 & 5 & 6 & 7 & 8 & 9 & 10\end{array}$

How would you rate the conductor's rehearsal effectiveness?

NOT EFFECTIVE $\boldsymbol{\rightarrow} \rightarrow \boldsymbol{\rightarrow} \rightarrow \boldsymbol{\rightarrow} \rightarrow \boldsymbol{\rightarrow} \rightarrow \boldsymbol{\rightarrow} \rightarrow \boldsymbol{\rightarrow} \rightarrow \boldsymbol{\rightarrow} \rightarrow \boldsymbol{\rightarrow} \rightarrow \boldsymbol{\rightarrow} \rightarrow$ VERY EFFECTIVE

$\begin{array}{llllllllll}1 & 2 & 3 & 4 & 5 & 6 & 7 & 8 & 9 & 10\end{array}$

\section{Conductor 13}

How would you rate the conductor's score knowledge?

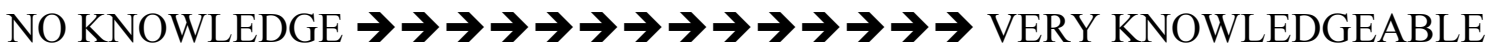

$\begin{array}{llllllllll}1 & 2 & 3 & 4 & 5 & 6 & 7 & 8 & 9 & 10\end{array}$

How would you rate the conductor's rehearsal effectiveness?

NOT EFFECTIVE $\boldsymbol{\rightarrow} \rightarrow \boldsymbol{\rightarrow \rightarrow \rightarrow \rightarrow \rightarrow \rightarrow \rightarrow \rightarrow \rightarrow \rightarrow \rightarrow \rightarrow \rightarrow \rightarrow ~ V E R Y ~ E F F E C T I V E ~}$

$\begin{array}{llllllllll}1 & 2 & 3 & 4 & 5 & 6 & 7 & 8 & 9 & 10\end{array}$

\section{Conductor 14}

How would you rate the conductor's score knowledge?

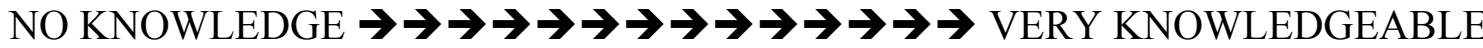

$\begin{array}{llllllllll}1 & 2 & 3 & 4 & 5 & 6 & 7 & 8 & 9 & 10\end{array}$

How would you rate the conductor's rehearsal effectiveness?

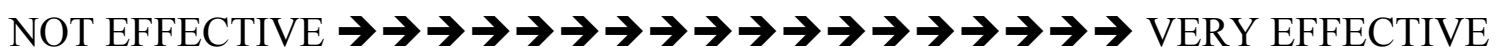

$\begin{array}{llllllllll}1 & 2 & 3 & 4 & 5 & 6 & 7 & 8 & 9 & 10\end{array}$ 
Conductor 15

How would you rate the conductor's score knowledge?

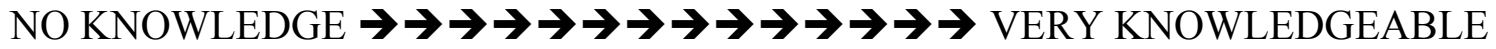

$\begin{array}{llllllllll}1 & 2 & 3 & 4 & 5 & 6 & 7 & 8 & 9 & 10\end{array}$

How would you rate the conductor's rehearsal effectiveness?

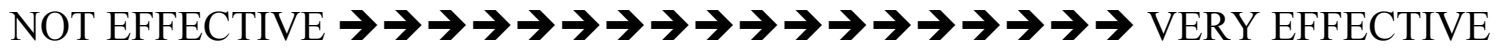

$\begin{array}{llllllllll}1 & 2 & 3 & 4 & 5 & 6 & 7 & 8 & 9 & 10\end{array}$

\section{Conductor 16}

How would you rate the conductor's score knowledge?

NO KNOWLEDGE $\rightarrow \rightarrow \rightarrow \rightarrow \rightarrow \rightarrow \rightarrow \rightarrow \rightarrow \rightarrow \rightarrow \rightarrow \rightarrow$ VERY KNOWLEDGEABLE

$\begin{array}{llllllllll}1 & 2 & 3 & 4 & 5 & 6 & 7 & 8 & 9 & 10\end{array}$

How would you rate the conductor's rehearsal effectiveness?

NOT EFFECTIVE $\rightarrow \rightarrow \rightarrow \rightarrow \rightarrow \rightarrow \rightarrow \rightarrow \rightarrow \rightarrow \rightarrow \rightarrow \rightarrow \rightarrow \rightarrow \rightarrow \rightarrow$ VERY EFFECTIVE

$\begin{array}{llllllllll}1 & 2 & 3 & 4 & 5 & 6 & 7 & 8 & 9 & 10\end{array}$

\section{Conductor 17}

How would you rate the conductor's score knowledge?

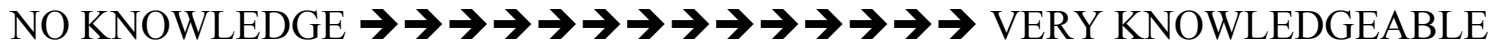

$\begin{array}{llllllllll}1 & 2 & 3 & 4 & 5 & 6 & 7 & 8 & 9 & 10\end{array}$

How would you rate the conductor's rehearsal effectiveness?

NOT EFFECTIVE $\rightarrow \rightarrow \rightarrow \rightarrow \rightarrow \rightarrow \rightarrow \rightarrow \rightarrow \rightarrow \rightarrow \rightarrow \rightarrow \rightarrow \rightarrow \rightarrow \rightarrow$ VERY EFFECTIVE

$\begin{array}{llllllllll}1 & 2 & 3 & 4 & 5 & 6 & 7 & 8 & 9 & 10\end{array}$ 
Conductor 18

How would you rate the conductor's score knowledge?

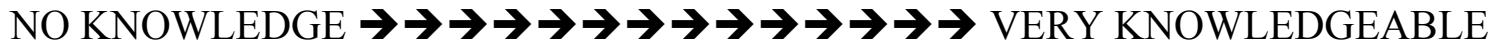

$\begin{array}{llllllllll}1 & 2 & 3 & 4 & 5 & 6 & 7 & 8 & 9 & 10\end{array}$

How would you rate the conductor's rehearsal effectiveness?

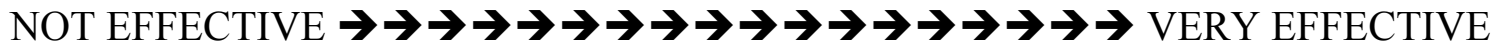

$\begin{array}{llllllllll}1 & 2 & 3 & 4 & 5 & 6 & 7 & 8 & 9 & 10\end{array}$

\section{Conductor 19}

How would you rate the conductor's score knowledge?

NO KNOWLEDGE $\rightarrow \rightarrow \rightarrow \rightarrow \rightarrow \rightarrow \rightarrow \rightarrow \rightarrow \rightarrow \rightarrow \rightarrow \rightarrow$ VERY KNOWLEDGEABLE

$\begin{array}{llllllllll}1 & 2 & 3 & 4 & 5 & 6 & 7 & 8 & 9 & 10\end{array}$

How would you rate the conductor's rehearsal effectiveness?

NOT EFFECTIVE $\rightarrow \rightarrow \rightarrow \rightarrow \rightarrow \rightarrow \rightarrow \rightarrow \rightarrow \rightarrow \rightarrow \rightarrow \rightarrow \rightarrow \rightarrow \rightarrow \rightarrow$ VERY EFFECTIVE

$\begin{array}{llllllllll}1 & 2 & 3 & 4 & 5 & 6 & 7 & 8 & 9 & 10\end{array}$

\section{Conductor 20}

How would you rate the conductor's score knowledge?

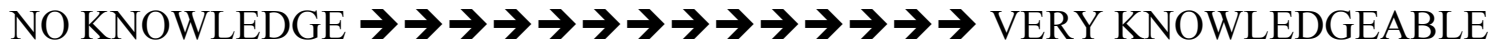

$\begin{array}{llllllllll}1 & 2 & 3 & 4 & 5 & 6 & 7 & 8 & 9 & 10\end{array}$

How would you rate the conductor's rehearsal effectiveness?

NOT EFFECTIVE $\rightarrow \rightarrow \rightarrow \rightarrow \rightarrow \rightarrow \rightarrow \rightarrow \rightarrow \rightarrow \rightarrow \rightarrow \rightarrow \rightarrow \rightarrow \rightarrow \rightarrow$ VERY EFFECTIVE

$\begin{array}{llllllllll}1 & 2 & 3 & 4 & 5 & 6 & 7 & 8 & 9 & 10\end{array}$ 


\section{Please circle (or write) the appropriate response.}

1. What is your gender?

Male Female

2. How old are you?

3. What is your school classification?

Master's Student Ph.D. Student

4. What is your emphasis?

Music Performance Music Education Conducting

5. How many years of experience do you have playing in an instrumental ensemble?

6. How many years of experience do you have teaching instrumental music? 


\section{Appendix N \\ Conductors Written Comments}

\section{Conductor 1}

\section{Group 1}

How prepared did you feel to lead the rehearsal? Why?

I felt relatively prepared for the rehearsal, and then you walk in and see 40 eyes looking back at you, and it all goes down the drain, but I still thought it went well

What were your strongest aspects of my rehearsal? Why?

I feel like I was doing sequencing okay, separating the melody from the bass line and checking that balance

What were your weakest aspect of my rehearsal? Why?

I got so nervous when modeling. I just want it to be over so I sped through it, so that was definitely weak.

Any additional comments?

N/A

\section{Conductor 2}

\section{Group 2}

How prepared did you feel to lead the rehearsal? Why?

I felt really comfortable with actually conducting buy not very comfortable with rehearsing because I had no idea what I should talk about when rehearsing a band.

What were your strongest aspects of my rehearsal? Why?

I had prepared what I was going to work on ahead of time so I didn't have to think of anything right on the spot.

What were your weakest aspect of my rehearsal? Why? 
I think I looked at my score a lot and didn't seem super confident in front of the

group.

Any additional comments?

N/A

Conductor 3

Group 2

\section{How prepared did you feel to lead the rehearsal? Why?}

Generally, I felt underprepared. While I know a lot about the score and had

listened to the piece, I was unsure of how to lead a rehearsal. I wasn't sure what to focus on, how to speak, etc.

What were your strongest aspects of my rehearsal? Why?

I think I was good at having one main clear goal: dynamics and really focusing in on that. This was because of the time frame, but also so there was a clear goal for the ensemble.

What were your weakest aspect of my rehearsal? Why?

I think my conducting was the weakest aspect. I messed up the meter several times, I couldn't cue, and everything I had prepared went out the window because of nerves.

Any additional comments?

It was easy when I was nervous to latch onto my main rehearsal goal when I was nervous, but everything else flew out of my mind.

\section{Conductor 4}

\section{Group 1}

\section{How prepared did you feel to lead the rehearsal? Why?}


Fairly, I'm always scared of what to happen, and I find it hard to predict the layout of the instruments.

What were your strongest aspects of my rehearsal? Why?

I felt confident on the comment of the cornets. I feel that I spoke clearly enough, hopefully.

What were your weakest aspect of my rehearsal? Why?

Talking. I get scared shaking with fear.

Any additional comments?

The sound and quality felt very good.

\section{Conductor 5}

Group 1

How prepared did you feel to lead the rehearsal? Why?

I don't know really. It's been a long time since I conducted. I did a lot of score studying and listened to it a lot. I was as prepared as I could be.

What were your strongest aspects of my rehearsal? Why?

I was pretty specific on what I wanted. I keep the rehearsal going so we get more done.

What were your weakest aspect of my rehearsal? Why?

I don’t look up sometimes. I don’t know what to work on.

Any additional comments?

I wish I could have been a little better. I was very nervous. I hope it was okay!

\section{Conductor 6}

\section{Group 1}

How prepared did you feel to lead the rehearsal? Why? 
I felt pretty prepared. I practiced a lot with the recording before the rehearsal. I have not done a lot with rehearsing an ensemble before, so it was a new experience for me.

\section{What were your strongest aspects of my rehearsal? Why?}

Probably my conducting. I feel like I give pretty good cues and keep tempo well.

\section{What were your weakest aspect of my rehearsal? Why?}

I get nervous occasionally, sometimes I get a little mixed up with what I want to rehearse first. I need to work on my organizing.

\section{Any additional comments?}

I struggled a bit with time management. I had a long list of what I wanted to do and I didn't get a lot done. It's hard to figure out what all can be accomplished in 5 minutes. I liked the challenge though and I enjoyed the experience!

\section{Conductor 7}

\section{Group 1}

\section{How prepared did you feel to lead the rehearsal? Why?}

I felt very prepared because this was a piece I had played many times beforehand, and that gave me good score study knowledge. That in turn helped me what I wanted to get out of the ensemble

\section{What were your strongest aspects of my rehearsal? Why?}

I thought of what I wanted out of the ensemble, translated to the ensemble.

\section{What were your weakest aspect of my rehearsal? Why?}

My conducting... I felt like my conducting improving would without a doubt help me to get more out of the ensemble.

\section{Any additional comments?}


I was really glad to have this opportunity.

\section{Conductor 8}

Group 2

How prepared did you feel to lead the rehearsal? Why?

I felt prepared because I read through the score a lot and listened to different bands play it.

What were your strongest aspects of my rehearsal? Why?

Dynamics because there are many parts in the piece where it drops to $m p$ then builds to Forte.

What were your weakest aspect of my rehearsal? Why?

Remembering everything that I wanted to say about bringing certain instruments out.

Any additional comments?

I got nervous and wish I could have done more.

\section{Conductor 9}

\section{Group 1}

How prepared did you feel to lead the rehearsal? Why?

Pretty prepared, I did a bit of score study.

What were your strongest aspects of my rehearsal? Why?

The strongest aspect was sequencing because it allowed me to work from the bottom up.

What were your weakest aspect of my rehearsal? Why?

Specific feedback, I feel I didn’t give a lot

Any additional comments? 
I don't think you counted for the band not site reading the second time they

played it with another conductor.

\section{Conductor 10}

Group 2

How prepared did you feel to lead the rehearsal? Why?

Like a 6 or so. I felt like I used good key ideas to point out, but didn't effectively communicate.

What were your strongest aspects of my rehearsal? Why?

Made an idea or what I wanted to do. I had given it much thought before What were your weakest aspect of my rehearsal? Why?

I looked down at my score the entire time, No Eyes to them, tongue tied.

Any additional comments?

Was nervous. Very nervous.

\section{Conductor 11}

Group 2

How prepared did you feel to lead the rehearsal? Why?

So-So. I didn't quite know what to say.

What were your strongest aspects of my rehearsal? Why?

I didn't try to be pedantic.

What were your weakest aspect of my rehearsal? Why?

I did not address all of the balance issues.

Any additional comments?

N/A

Conductor 12

Group 2

How prepared did you feel to lead the rehearsal? Why? 
I felt prepared score wise. I knew the score, \& I felt comfortable in my patterns.

However, once I got on the podium I was very nervous \& I felt like I didn't know how to convey what I wanted from the band

What were your strongest aspects of my rehearsal? Why?

I think strongest is my pattern, and my eye contact.

\section{What were your weakest aspect of my rehearsal? Why?}

Probably being able to convey what I wanted from the band. My verves kind of screwed me up.

\section{Any additional comments?}

I felt like these wasn't much to my score, but it was very constant which was good. I found myself not looking at my score a lot, which gave me more opportunity to give eye contact to the trumpets. More time would have been good, also the set-up of the room was very disconjointed.

\section{Conductor 13}

\section{Group 2}

\section{How prepared did you feel to lead the rehearsal? Why?}

I felt very prepared, but I think I need to work on my effectiveness. It was a learning experience! I wish I had a second chance.

\section{What were your strongest aspects of my rehearsal? Why?}

My conducting and cuing. Being in band so long has helped with my musicality. I had good expression and could lead the music effectively.

\section{What were your weakest aspect of my rehearsal? Why?}

I need to work on not being awkward when addressing the ensemble. I need to work on my rehearsal etiquette. 
Any additional comments?

I had a great time participating! Thank you, I learned a lot!

\section{Conductor 14}

\section{Group 1}

How prepared did you feel to lead the rehearsal? Why?

I felt very prepared because I listened to the piece a lot before and I had a set plan going into it $\mathrm{w} /$ good score prep.

What were your strongest aspects of my rehearsal? Why?

I think I was able to model well \& have them play exactly what I wanted.

What were your weakest aspect of my rehearsal? Why?

I didn't involve percussion and I think I just didn't have time. I had planned to involve them but I didn't execute.

Any additional comments?

N/A

Conductor 15

\section{Group 1}

How prepared did you feel to lead the rehearsal? Why?

I felt I was mostly prepared because I knew the score pretty well. However, I felt my actual conducting was not prepared. I did not spend much time

What were your strongest aspects of my rehearsal? Why?

I think I modelled well and received greater contrast in shaping and dynamics from the ensemble.

What were your weakest aspect of my rehearsal? Why?

I think I was unclear about the articulation I wanted.

Any additional comments? 


\section{N/A}

Conductor 16

Group 1

How prepared did you feel to lead the rehearsal? Why?

I felt prepared, but once I stepped in front of the ensemble I felt very nervous and out of my comfort zone.

What were your strongest aspects of my rehearsal? Why?

Preparatory, telling the band what to listen for.

What were your weakest aspect of my rehearsal? Why?

Modelling, identifying problems.

Any additional comments?

N/A

Conductor 17

Group 2

How prepared did you feel to lead the rehearsal? Why?

I didn't feel very prepared because I knew how to find the key components of the score, but I wasn't sure how to get the point across.

What were your strongest aspects of my rehearsal? Why?

I think my strongest aspect was knowing what I wanted to improve because I

knew the song well.

What were your weakest aspect of my rehearsal? Why?

Being able to actually get my point across was difficult because I wasn't very well prepared to lead a rehearsal.

Any additional comments?

$\mathrm{N} / \mathrm{A}$ 


\section{Conductor 18}

\section{Group 1}

How prepared did you feel to lead the rehearsal? Why?

I didn't feel prepared at all. I've never conducted before and I was just super

nervous.

What were your strongest aspects of my rehearsal? Why?

I talked about dynamics, so I guess that was good.

What were your weakest aspect of my rehearsal? Why?

I suck at conducting, mostly because I've never really done it before.

Any additional comments?

$\mathrm{N} / \mathrm{A}$

Conductor 19

Group 2

How prepared did you feel to lead the rehearsal? Why?

$100 \%$ I had tons of fun and appreciated the work ethic of the students. I never felt uncomfortable.

What were your strongest aspects of my rehearsal? Why?

Keeping the focus. I know they were instructed to pay attention but I still felt a good connection.

What were your weakest aspect of my rehearsal? Why?

I would say general jitteriness. A little to antsy and caused some mess ups for me.

Any additional comments?

Your study reminded me how much I want to be a music educator. Thank you for letting me be a part of it.

Conductor 20

Group 2 


\section{How prepared did you feel to lead the rehearsal? Why?}

I was very prepared, because I was at the point musically where I could feel the music go by, and not just watch it.

What were your strongest aspects of my rehearsal? Why?

My communication of the theory behind the piece I studied.

\section{What were your weakest aspect of my rehearsal? Why?}

My conducting. I've never done it before, so I felt I was kind've shaky.

Any additional comments?

N/A 


\section{VITA}

Aaron T. Wacker attended the University of Northern Colorado in Greeley, Colorado, earning a Bachelor of Music Education degree in 2008. After nearly 4 years of teaching secondary instrumental, choral, and general music in the Vail Valley of Colorado, he received a Master's of Music in Music Education from the University of Northern Colorado in 2013. Mr. Wacker will complete a Doctor of Philosophy in Learning, Teaching, and Curriculum, with an emphasis in Music Education in 2017, from the University of Missouri in Columbia, Missouri, where he taught courses including instrumental rehearsal technique, basic conducting, music student teaching seminar, elementary folk guitar, basic music skills, applied tuba lessons, and conducted the MU tuba and euphonium ensemble. He assisted with the band and music education programs at the University of Northern Colorado and University of Missouri, frequently serving as a guest conductor for many ensembles. Mr. Wacker's manuscripts have been accepted for publication in the Journal of Band Research, International Journal of Music Education, The Colorado Music Educator, and School Band and Orchestra Magazine. He has also had investigations accepted for poster presentation and both state and national conferences. As a clinician for school band programs, he plans to continue his involvement in public and private school music education, focusing his research on preservice teacher preparation, conducting, and teacher effectiveness in the music classroom. In addition to his teaching at the University, Mr. Wacker has also taught general and instrumental music education in the public and private schools in Columbia, Missouri. 